\title{
Understanding the Ecological Consequences of Stress in Wild Fish Using Exogenous Cortisol Implants
}

\author{
By \\ Sarah Helen McConnachie \\ Honours B.Sc. Cornell University, 2007
}

A thesis submitted to the Faculty of Graduate and Postdoctoral Affairs in partial fulfillment of the requirements for the degree of

Master of Science

in

Biology

Carleton University

Ottawa, Ontario

(c) 2010, Sarah Helen McConnachie 
Library and Archives

Canada

Published Heritage

Branch

395 Wellington Street

Ottawa ON K1A ON4

Canada
Bibliothèque et

Archives Canada

Direction du

Patrimoine de l'édition

395, rue Wellington

Ottawa ON K1A ON4

Canada
Your file Votre référence

ISBN: 978-0-494-71592-5

Our file Notre référence

ISBN: 978-0-494-71592-5
NOTICE:

The author has granted a nonexclusive license allowing Library and Archives Canada to reproduce, publish, archive, preserve, conserve, communicate to the public by telecommunication or on the Internet, loan, distribute and sell theses worldwide, for commercial or noncommercial purposes, in microform, paper, electronic and/or any other formats.

The author retains copyright ownership and moral rights in this thesis. Neither the thesis nor substantial extracts from it may be printed or otherwise reproduced without the author's permission.
AVIS:

L'auteur a accordé une licence non exclusive permettant à la Bibliothèque et Archives Canada de reproduire, publier, archiver, sauvegarder, conserver, transmettre au public par télécommunication ou par l'Internet, prêter, distribuer et vendre des thèses partout dans le monde, à des fins commerciales ou autres, sur support microforme, papier, électronique et/ou autres formats.

L'auteur conserve la propriété du droit d'auteur et des droits moraux qui protège cette thèse. $\mathrm{Ni}$ la thèse ni des extraits substantiels de celle-ci ne doivent être imprimés ou autrement reproduits sans son autorisation.
In compliance with the Canadian Privacy Act some supporting forms may have been removed from this thesis.

While these forms may be included in the document page count, their removal does not represent any loss of content from the thesis.
Conformément à la loi canadienne sur la protection de la vie privée, quelques formulaires secondaires ont été enlevés de cette thèse.

Bien que ces formulaires aient inclus dans la pagination, il n'y aura aucun contenu manquant.

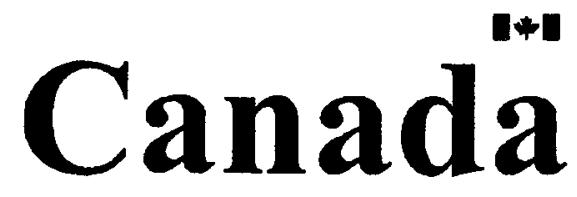




\section{Dedication}

I dedicate my motivation to undertake this endeavour to my parents, Martha and Daniel, whose endless, unwavering love and support allowed me to get me where I am today. They have pushed me to excel and never accept less than I deserve and work towards. They are also the source of my interests, and have been supporting my intellectual and physical strengths since childhood (all those mini-science projects have not gone wasted; we can now laugh at how big of a mess I always made).

To my sister Grace and my brother-in-law Jun for always being there when graduate student life became lonely. Also to my extended family members for being proud of me and believing in me. Special mention to my grandfather, the late Thomas McLaren, whose drive and determination inspires me to this day.

Special thanks to my life-long friends and to all the members of the Cooke lab. Each and every one of you has been a role model to me and I look forward to seeing what you all accomplish in the future. Especially you Sean Landsman - I can't thank you enough for the support and patience you have shown me.

Lastly, I would like to express my utmost appreciation for my advisor, Steve. I cannot thank him enough for providing me with the opportunities that I have experienced during my time in his lab. 


\begin{abstract}
This thesis proposed to elucidate the relationship between stress and long-term behaviour and survival in fish. The first study investigated whether "carryover" effects of stress influence a fish's ability to tolerate future stressors. Bluegill (Lepomis macrochirus) were exposed to chronic cortisol elevations and exposed to stressors in the short- and longterm. Fish were unable to tolerate secondary stressors in the long-term even after physiologically recovering from the cortisol elevation. Next, the consequences of stress on spawning grounds were investigated using a semelparous species, the pink salmon (Oncorhynchus gorbuscha). Pink salmon did not alter reproductive behaviour, physiology or success after exposure to acute stress. Chronically elevating cortisol levels caused a decrease in longevity and reproductive success and affected behaviour. The findings from both studies suggest that chronic elevations of cortisol can influence fitness. The experimental approach used is novel since few field studies have manipulated cortisol titres in the wild.
\end{abstract}




\section{Acknowledgments}

Although this thesis is my own, it would not have been possible to complete it without the assistance and support of many individuals and organizations. I would like to acknowledge my funding support: the Canada Research Chairs program, NSERC Discovery Grants, Carleton University and the Ottawa-Carleton Institute of Biology.

I would like to thank my co-authors on the manuscripts developed from chapters two and three of my thesis: Steven Cooke, Connie O'Connor, Katrina Cook, Katie Gilmour, George Iwama, Scott Hinch, David Patterson and Tony Farrell. I would also like to thank Mark Forbes.

Special thanks to my lovely field assistant for the spring 2009 field season: Laura Chomyshyn. Also thanks for help in the lab and the field in Ontario: Katrina Cook, Graham Raby, Alison Colotelo, Connie O’Connor, Marie-Ange Gravel, Sam Wilson, Cody Dey, Liane Nowell, Tom Binder, Keegan McGrath and Alex Wilson. Thanks for help in the field, lab and for intellectual support in B.C.: Katrina Cook, Graham Raby, Mike Donaldson, Alison Colotelo, Connie O’Connor, Lisa Thompson, Kim Hruska, Tim Clark, Charlotte Whitney, Matt Drenner Andrew Lotto, Jayme Hills, D’Arcy McKay.

I would also like to acknowledge Frank Phelan and Floyd Connor and the rest of the staff at the Queen's University Biological Field Station for use of their facilities and logistical support. To that end I also thank Rick Stitt and the rest of the crew at the Weaver Creek Spawning Channel for their much appreciated assistance and support. 
Thanks to Sean Landsman, Amanda O'Toole, Caleb Hasler, Marie-Ange Gravel and Katrina Cook for editing assistance on earlier versions of this thesis. 


\section{Co-Authorship}

\section{Chapter 2: Short-and Long-Term Consequences of Supraphysiological Cortisol}

Elevation in a Wild Fish. S.H. McConnachie, C.M. O'Connor, K.M. Gilmour, G.K. Iwama, and S.J. Cooke

While this study is my own, the research was undertaken as part of a collaborative effort, and each co-author played a valuable role in its completion. All co-authors provided comments and feedback on the manuscript. This manuscript is in preparation for submission to a suitable journal. The project was conceived by Cooke and McConnachie, inspired by previous work done by O'Connor and with support from Gilmour and Iwama. Field work was completed by McConnachie, Cooke and O'Connor. All analysis was conducted by McConnachie.

Chapter 3: Understanding the consequences of varying levels of stress on the fitness and behaviour of spawning pink salmon. S.H. McConnachie, K.V. Cook, D.A. Patterson, K.M. Gilmour, S.G. Hinch, A.P. Farrell and S.J. Cooke.

While this study is my own, the research was undertaken as part of a collaborative effort and each co-author played a valuable role in its completion. The project was conceived by McConnachie and Cooke. Field work was conducted by McConnachie, Cook and Cooke. All writing and analysis was conducted by McConnachie. All coauthors provided comments and feedback throughout the planning and interpretation process. This manuscript is being prepared for submission to a peer-reviewed journal. 


\section{Table of Contents}

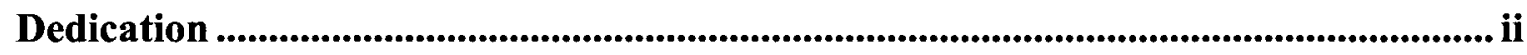

Abstract......................................................................................................................................................... iii

Acknowledgments ................................................................................................................................... iv

Co-Authorship ................................................................................................................................ vi

Table of Contents .................................................................................................................... vii

List of Tables .......................................................................................................................................... ix

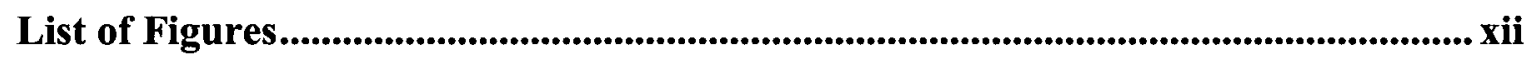

Acronyms ........................................................................................................................... xiii

Chapter 1: General Introduction .................................................................................... 1

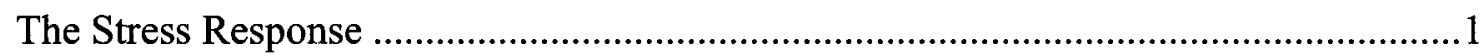

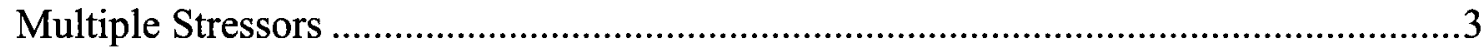

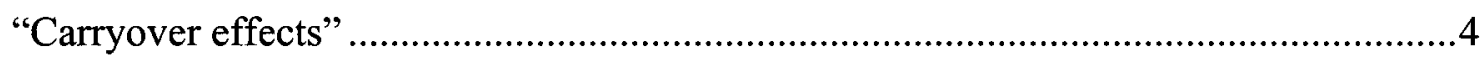

Stress and Life History Characteristics.........................................................................5

Using Hormone Implants to Manipulate Cortisol Titres ................................................

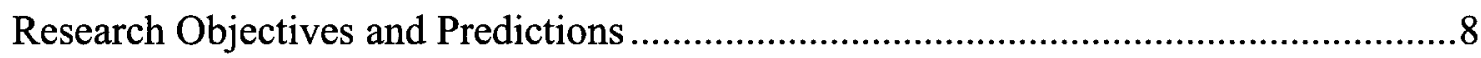

Rationale and Predictions for Chapter 2 …………............................................... 8

Model Species for Chapter 2-Bluegill sunfish (L. macrochirus) ............................ 10

Rationale and Predictions for Chapter 3 ............................................................ 10

Model Species for Chapter 3-Pink salmon (O. gorbuscha) .................................... 13

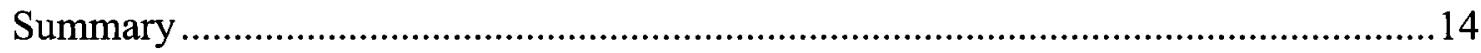

Chapter 2: Supraphysiological cortisol elevation alters the response of wild bluegill to subsequent ecologically-relevant stressors ....................................................................... 16

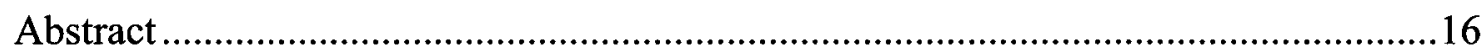

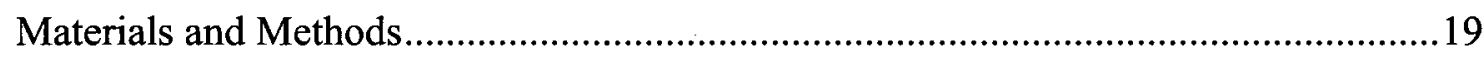

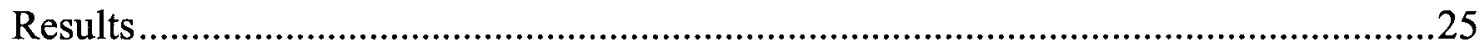

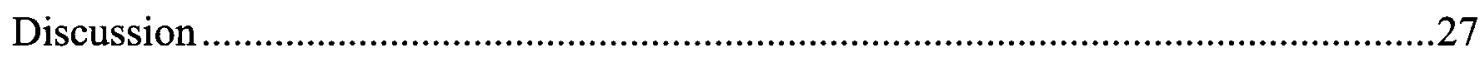

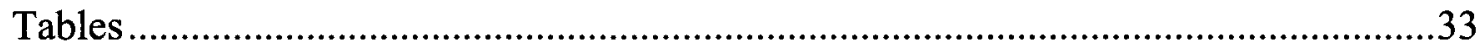

Chapter 3: Understanding the Consequences of Stress and Cortisol Elevation on the Behaviour and Fitness of Spawning Pink Salmon (Oncorhynchus gorbuscha).......... 46 


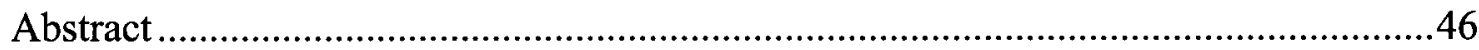

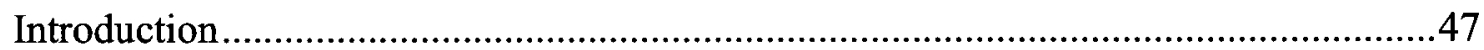

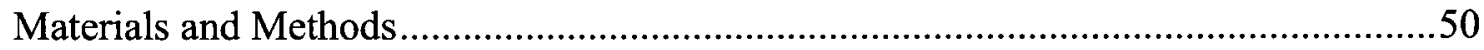

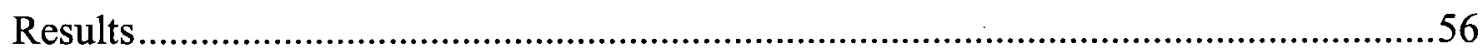

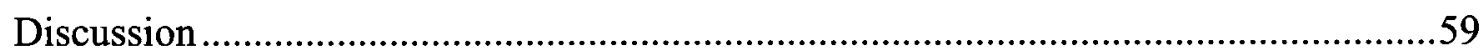

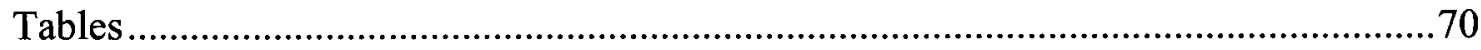

Chapter 4: General Discussion .............................................................................. 84

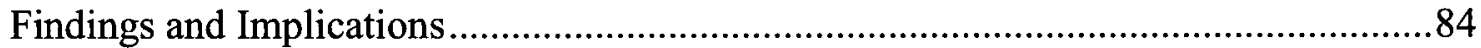

Summary and Future Research Directions ..................................................... 86

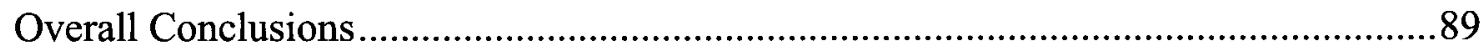

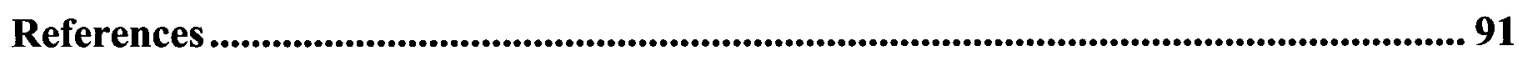




\section{List of Tables}

Table 2 - 1. L. macrochirus cortisol, glucose and hematocrit values for short- and longterm heat challenges. Sample sizes are as follows: short-term cortisol (control=11, sham $=12$, cortisol=15), glucose and hematocrit $(\mathrm{N}=25$ control, cortisol, sham=23); longterm cortisol (control $=18$, sham $=19$, cortisol $=8)$, glucose $(\mathrm{N}=22$ control, sham, cortisol $=10$ ), hematocrit ( control $=22$, sham $=21$, cortisol $=9$ ). Variables denoted with '*, were analyzed using Wilcoxon Rank-Sum tests . ' $\dagger$ ' indicates variables where data were log-transformed. ' $\dagger \dagger$ ' refers to treatments whose data was Square root transformed. Bonferroni corrected $\alpha=0.017$. All parameters indicated as percentages were analyzed as (ArcSin(Square Root(value)). Dissimilar letters denote significant differences among treatment groups (Tukey-Kramer HSD test, $\mathrm{p}<0.017$ ).

Table 2 - 2. Summary of $L$. macrochirus condition variables for the short-term fasting challenge. Analyses were separated by fish that succumbed to the challenge during the 50 $\mathrm{d}$ fasting period and by fish that remained in the experiment for the full $50 \mathrm{~d}$ period. Sample sizes are as follows: fish removed during (control=17, sham $=17$, cortisol $=22$ ); fish removed afterwards (control=5, sham $=4$, cortisol=3). ' $\dagger$ ' refers to treatments whose data was log-transformed. All comparisons were analyzed using 1-way ANOVAs. Bonferroni corrected $\alpha=0.01$ for fish removed during fasting period and $\alpha=0.013$ for fish removed following $50 \mathrm{~d}$ fasting period. Dissimilar letters denote significant differences among treatment groups (Tukey-Kramer HSD test, $\mathrm{p}<0.01 \& \mathrm{p}<0.013$ ).

Table 2 - 3. Summary of $L$. macrochirus condition variables for the long-term fasting challenge. Analyses were separated by fish that were removed during the $30 \mathrm{~d}$ holding period, removed during the $50 \mathrm{~d}$ fasting period and those that completed the $50 \mathrm{~d}$ fasting period. Sample sizes are as follows: fish removed before (control=3, sham $=4$, cortisol=14); fish removed during $(\mathrm{N}=5$, all groups); fish removed after (control=16, sham $=9$, cortisol $=5$ ). ' $\dagger$ ' refers to treatments whose data was log-transformed. All comparisons were analyzed using 1-way ANOVAs. Bonferroni corrected $\alpha=0.01$ for fish removed before and during fasting period and $\alpha=0.013$ for fish removed following $50 \mathrm{~d}$ fasting period. Dissimilar letters denote significant differences among treatment groups (Tukey-Kramer HSD test, $\mathrm{p}<0.01 \& \mathrm{p}<0.013$ ).

Table 2 - 4. Blood and condition parameters for $L$. macrochirus after $24 \mathrm{~h}, 4 \mathrm{~d}, 10 \mathrm{~d}$ or $30 \mathrm{~d}$ of treatment with a cortisol-impregnated intraperitoneal implant (cortisol), vehicle alone (sham) or no treatment (control). Sample sizes were as follows: $24 \mathrm{~h}$ (control=12, sham $=10$, cortisol $=13), 4 \mathrm{~d}$ (control $=11$, sham $=11$, cortisol $=8), 10 \mathrm{~d}$ (control $=12$, sham $=12$, cortisol $=11,30 \mathrm{~d}$ (control $=12$, sham $=11$, cortisol $=13$ ). Significant differences (Bonferroni corrected $\alpha=0.006$ ) are noted by dissimilar letters. Variables denoted with '*' 
were analyzed using Wilcoxon Rank-Sum tests. ' $\dagger$ ' indicates variables where data were log-transformed. All parameters indicated as percentages were analyzed as (ArcSin(Square Root(value))

Table 3 - 1. Starting blood physiology and hormone values of all $O$. gorbuscha removed from the Weaver creek raceway in October, 2009, presented as mean ( $\pm \mathrm{SE}$ ). $N=52$ for ripe fish and $N=60$ for ripe fish. All data was analyzed using the Wilcoxon Rank-Sum Test, except for cortisol $\left({ }^{*}\right)$ which was analyzed using log-transformed data in a one-way ANOVA.

Table 3 - 2. Summary of $O$. gorbuscha physiology and hormone results from the unripe and ripe recovery box profiles before and after $24 \mathrm{~h}$ stated as mean $( \pm \mathrm{SE}) . N=6$ for each treatment for unripe fish; $N=6$ for control and sham groups for ripe fish and $N=12$ for cortisol and metyrapone-treated fish. All data were analyzed using repeated-measures MANOVAs.

Table 3 - 3. $O$. gorbuscha blood physiology and hormone values before experimentation and $4 \mathrm{~d}$ after for unripe fish, stated as mean ( $\pm \mathrm{SE}$ ). All data was analyzed using repeatedmeasures MANOVAs. Sample sizes are as follows: Before; cortisol = 10, control, chase and metyrapone $=9$, chase +1 and sham $=8$. After; cortisol $=10$, chase and control $=9$, chase +1 , sham and metyrapone $=8$.

Table 3-4. O. gorbuscha behaviour profiles for unripe fish during $4 \mathrm{~d}$ trials stated as mean $( \pm \mathrm{SE})$. All data were analyzed using Wilcoxon Rank-Sum tests and Tukey's HSD test used to determine where differences were when a significant value was obtained (noted by letter scores). All data expressed as a "\%" was transformed into ArcSine(Square root) values before being analyzed. Data for all variables except the aggression score were averaged over days that fish were on established territories. Aggression scores were added for all days spent on territories and divided by number of observational min. Each fish had a similar score for aggressive attacks against, and this score, divided by number of observational min was subtracted from the previous value to obtain the overall aggression score. Sample sizes are as follows; chase $=9$, control and sham $=7$, chase +1 and cortisol $=6$, metyrapone $=5$.

Table 3 - 5. $O$. gorbuscha blood physiology and hormone values before experimentation and $4 \mathrm{~d}$ after for ripe fish, stated as mean $( \pm \mathrm{SE})$. All data was analyzed using repeatedmeasures MANOVAs. $N=10$ for all groups except for the 'after' chase group where $N=$ 9. 76

Table 3 - 6. $O$. gorbuscha behaviour profiles for ripe fish during $4 \mathrm{~d}$ trials stated as mean $( \pm \mathrm{SE})$. All data were analyzed using Wilcoxon Rank-Sum tests and Tukey's HSD test 
used to determine where differences were when a significant value was obtained (noted by letter scores). All data expressed as a "\%" was transformed into ArcSine(Square root) values before being analyzed. Data for all variables except the aggression score were averaged over days that fish were on established territories. Aggression scores were added for all days spent on territories and divided by number of observational min. Each fish had a similar score for aggressive attacks against, and this score, divided by number of observational min was subtracted from the previous value to obtain the overall aggression score. Sample sizes are as follows; metyrapone $=10$, sham, cortisol, control and chase $+1=9$ and chase $=7$. 


\section{List of Figures}

Figure 1-1. Overview of what occurs when stressors elicit the stress response in fish. Figure adapted from Barton, 2002.

Figure 2-1 A\&B. Log-rank survival analyses to $50 \%$ mortality for $L$. macrochirus during the short- (A) and long-term (B) heat challenges.Sample sizes are as follows: Short-term; control $=25$, sham $=24$, cortisol $=25$. Long-term; control and sham $=23$, cortisol $=11$.

Figure 2-2A \& B. Log-rank survival analyses to $50 \%$ mortality for L. macrochirus during the short- (A) and long-term (B) fasting challenges. Sample sizes are as follows: Short-term; control $=18$, sham $=19$, cortisol $=24$. Long-term; control and cortisol=6, sham $=8$.

Figure 2 - 3. Mean $( \pm \mathrm{SE})$ plasma cortisol concentration among treatment groups for each of the time intervals during the time course study. For sample sizes, see Table 2 - 4

Figure 2 - 4. Mean ( $\pm \mathrm{SE}$ ) whole blood glucose concentration among treatment groups for each of the time intervals during the time course study. For sample sizes, see Table 2 $-4$

Figure 3 - 1. Mean $( \pm \mathrm{SE})$ cortisol values for control $(\mathrm{CON})$ and metyrapone-treated $O$. mykiss. (MET) $24 \mathrm{~h}$ after treatment and $5 \mathrm{~d}$ after treatment. Sample sizes are as follows: $24 \mathrm{~h}$; control $=2$, metyrapone $=5.5 \mathrm{~d}$; control $=4$, metyrapone $=4$. The effects tests for the two-way ANOVA are as follows (using log transformed cortisol data): treatment, $\mathrm{df}=1, \mathrm{~F}$ ratio $=3.07, \mathrm{p}=0.103 ;$ day, $\mathrm{df}=1, \mathrm{~F}$ ratio $=7.82, \mathrm{p}=0.0151$; interaction, $\mathrm{df}=3$, $\mathrm{F}=4.70, \mathrm{p}=0.0240$. Metyrapone-treated fish at $24 \mathrm{~h}$ had the lowest cortisol levels, when compared to controls and both groups at $5 \mathrm{~d}$.

Figure 3 - 2. Log-rank survival analysis to $50 \%$ mortality in each treatment group, comparing longevity among $O$. gorbuscha in the Weaver Creek spawning channel. Sample sizes are as follows; chase and control $=20$, cortisol $=18$, chase +1 and metyrapone $=17$ and sham $=14$.

Figure 3-3. A comparison of percent (\%) eggs dropped by $O$. gorbuscha in the Weaver Creek spawning channel during experiment 1 . All data were transformed into ArcSine(Square root) values before being analyzed. Sample sizes are as follows; chase and control $=20$, cortisol $=18$, chase +1 and metyrapone $=17$ and sham $=14$. Dissimilar 
letters denote significant differences among treatment groups (Tukey-Kramer HSD test, $\mathrm{p}<0.05$ )

Figure 3 - 4A \&B. Figure A represents the percentage of $O$. gorbuscha that became ripe during the unripe behaviour trials and thus being able to spawn for experiment 2 . Figure $\mathrm{B}$ represents the amount of eggs (\%) that were dropped during the $4 \mathrm{~d}$ trials by ripe fish, by treatment group. Sample sizes are as follows; chase $=1 / 9$, chase $+1=2 / 8$, control $=3 / 9$, cortisol $=3 / 10$, metyrapone $=2 / 9$, sham $=4 / 8$. All data were transformed into ArcSine(Square root) values before being analyzed. Dissimilar letters denote significant differences among treatment groups (Tukey-Kramer HSD test, $\mathrm{p}<0.05$ )....................... 82

Figure 3-5. A comparison of the amount of eggs (\%) that were dropped by $O$. gorbuscha during the ripe net-pen behaviour trials during experiment 2. $N=10$ for all groups. Number values (in \%) are stated on top of each column. All data were transformed into ArcSine(Square root) values before being analyzed. 


\section{Acronyms}

ANOVA: Analysis of variance

ELISA: Enzyme-linked immunosorbent assay

FL: Fork length

HAI: Health assessment index

HPI axis: Hypothalamic-pituitary-interrenal axis

HSI: Hepato-somatic index

$\mathrm{K}$ : Condition factor

MANOVA: Multivariate analysis of variance

QUBS: Queen's University Biological Field Station

RIA: Radioimmunoassay

SE: Standard error

SL: Standard length

SSI: Splenic-index

TL: Total length

UBC: University of British Columbia 


\section{Chapter 1: General Introduction}

\section{The Stress Response}

Fish are exposed to a broad scope of natural and anthropogenic stressors that cover a range of temporal scales. For example, avoiding a predator may take only seconds, but exposure to pollution may cause challenges for an extended period of time (i.e., months). Anthropogenic stressors are becoming more prevalent as the human population increases (Dietz et al. 2007). As a result, there is an explicit need for elucidating the relationship between physiological stress and long-term behaviour and survival. Specifically, there is a need to identify levels and thresholds of physiological stress that can lead to direct or indirect fish mortality in wild fish (Cooke and O'Connor, 2010).

The "stress response" has many varied meanings and interpretations. As such, for the purposes of this thesis I will adopt Barton and Iwama's (1991) definition of a stress response: the reaction by fish to a stimulus which may somehow alter the fish's homeostatic state. Thus, a stressor is a stimulus that initiates a stress response. The stress response in fish involves stimulation of sympathetic nerve fibres to release catecholamines (e.g., epinephrine) and stimulation of the hypothalamic-pituitaryinterrenal (HPI) axis, which culminates in the production and release of corticosteroid hormones (i.e., cortisol). Cortisol serves two major roles in fish in fish - the regulation of energy metabolism and hydromineral balance (Wendelarr Bonga, 1997). After release, corticosteroid hormones are associated with secondary system-level responses (e.g., changes in immune function, metabolism, etc.) and tertiary whole-animal responses (e.g., behaviour and survivorship) (Barton, 2002) (Figure 1-1). Following an acute stressor, 
plasma cortisol concentrations will increase quickly (i.e., to peak values within an hour) then will decrease slowly to baseline levels within $24 \mathrm{~h}$ (Mommsen et al. 1999). Initially, the stress response is adaptive; allowing fish to cope with the challenge, and increasing the ability to recover from the challenge (Barton, 2002). However, if the intensity of a stressor is severe or long-lasting, this same response can become maladaptive, compromising the animal's well-being (Barton, 2002). Furthermore, the adaptive phase of the stress response can inhibit other necessary functions (e.g., reproduction; Schreck $e t$ al. 2001).

Physiological Consequences of the Maladaptive Stress Response

As mentioned above, when a stressor becomes chronic, the responses that are necessary for overcoming a stressor become maladaptive. One example of a maladaptive response is an increase in ion and water flux (Barton \& Iwama, 1991). In addition, chronic stress can elicit changes in gill structure and increase gill necrosis - which is cell death caused by hypertrophy and hyperplasia of epithelial and chloride cells in gills (Mallat, 1985; Wendelaar Bonga, 1997). Another example of a maladaptive response is an increase in metabolic rates which is associated with an increase in plasma glucose levels, gluconeogenesis, ventilation rate, oxygen consumption and a decrease in liver carbohydrate reserves (Barton, 1988; De Oliveria Fernandes \& Volpato, 1993; Pickering \& Pottinger, 1995; review by Wendelaar Bonga, 1997; review by Mommsen et al. 1999). In addition, cortisol has been shown to inhibit growth (Pickering, 1990) and reduces appetite (Pickering et al. 1982; Rice, 1990). Hematocrit can increase as a result of stress through a decrease in extracellular fluid relative to blood cell volume or by proliferation 
of erythrocytes (Barton et al. 1987; Soldatov, 1996; review by Wendelaar Bonga, 1997). Lastly, a well-documented decrease in immunocompetence and resistance to disease can occur following chronic stress (see review by Barton \& Iwama, 1991).

The hallmark of the stress response is the reallocation of metabolic energy from growth and reproduction, towards the restoration of homeostasis (Wingfield \& Sapolsky, 2003). The metabolic changes caused by a chronic stress response start to elicit changes in growth and condition (Gregory \& Wood, 1999; O'Connor et al. 2009; O'Connor et al. in review). Chan \& Woo (1978) found hepatosomatic indices (HSI) to be lower in fish treated with cortisol, along with a reduction in liver glycogen which coincides with increased metabolic rate (see Mommsen et al. 1999). Energy is shifted away from growth and reproductive pathways causing changes in whole animal indices (tertiary responses) (Barton, 2002).

Maladaptive responses have the potential to cause change at the population or community level. From an ecological perspective, these maladaptive physiological responses have the most relevant implications, but are also the responses which have received the least amount of attention (Barton \& Iwama, 1991).

\section{Multiple Stressors}

Barton et al. (1986) noted that the accumulation of physiological stressors is additive. Fish exhibit a cumulative cortisol response to repeated stressors and this is also demonstrated at the secondary response level with cumulative effects on plasma glucose (Maule et al. 1988; Barton et al. 1986). However, repeated exposure to mild stressors 
(e.g., fluctuating temperatures and salinity levels in tide pools; Todgham et al. 2005) can cause attenuation in the neuroendocrine and metabolic response to subsequent stressors, suggesting that fish can become habituated after repeated disturbances (Barton et al. 1987; Reid et al. 1998). Similarly, fish that reside in habitats that are chronically stressful (e.g., pollutants or poor water quality) have an impaired stress response when challenged with acute stressors (Hontela et al. 1997; Vijayan et al. 1997; Wilson et al. 1998; Basu et al. 2002). It seems that continual interrenal activity will down-regulate the HPI axis through negative feedback from cortisol so when an acute stressor occurs, the corticosteroid response is reduced (Hontela et al. 1997; Barton, 2002). Therefore, the stress response is impaired when fish experience an acute stressor when residing in poor habitats. However, there is still little information regarding how fish respond to multiple sequential stressors rather than simultaneous stressors. For example, it is unknown how an individual exposed to one stress event will respond to a secondary stressor, temporally separated from the initial stressor.

\section{"Carryover effects"}

In ecological literature, temporally separated effects of stress, as described above, on the responses to subsequent stressors are referred to as "carryover effects" (Norris \& Marra, 2007). To date, carryover effects have been primarily studied on migratory birds.

Research has revealed that diet quality during winter months or extreme changes in climatic conditions can "carry over" to influence reproductive success in the following summer (Norris et al. 2004; Sorensen et al. 2008). This concept has rarely been explored in fish, but it is likely that sub-lethal stressful events modulate how a fish can respond to 
subsequent stressors after physiological recovery from the initial, acute or chronic stressor.

Stress and Life History Characteristics

The term "allostasis" has recently been used to describe the ability of an animal to achieve stability through change to maintain homeostasis in the face of environmental perturbations (McEwen \& Wingfield, 2003). Therefore, allostatic state refers to the altered and sustained activity levels of the primary physiological mediators that integrate physiology and associated behaviours in response to changing environments (McEwen \& Wingfield, 2003). Allostatic load refers to the cumulative result of the allostatic state, and allostatic overload occurs when there is an imbalance (McEwen \& Wingfield, 2003). There are two types of allostatic overload; Type 1 is where energy demand exceeds energy supply which causes an adjustment of physiology and behaviour in response (McEwen \& Wingfield, 2003). This adjustment has been termed "the emergency lifehistory stage" (Wingfield et al. 1998). Type II overload occurs when allostatic load is too high for too long, causing prolonged activation of the physiological parameters that mediate allostasis, causing pathological problems (McEwen \& Wingfield, 2003; Romero et al. 2009).

The concept of the emergency life-history stage has been used to describe the response an organism has to unpredictable environmental events that interrupts its lifehistory cycle to direct behaviour and physiology towards survival (Wingfield et al. 1998; Wingfield, 2003). Such and responses (physiological and behavioural) are interconnected to allow an organism to elicit the most appropriate response to the stressor, including; 
proactive/reactive coping styles, fight -or-flight responses, facultative behaviour and physiological responses and sickness behaviour (see Figure 2. Wingfield, 2003;

Wingfield, 2005). Glucocorticoids are tightly connected to each of the above responses and are linked with the outcome of chronic stress as described in previous sections (i.e., suppression of reproduction and immune function). One main feature of the emergency life-history stage is the suppression and ultimate inhibition of reproductive behaviour and function. This response is the outcome of Type 1 allostatic load where the energy demand from the stressor exceeds energy supply of the organism (McEwen \& Wingfield, 2003; Wingfield, 2003). In this case, the emergency life-history stage is adaptive as it allows recovery from the perturbation and enhances lifetime reproductive success by allowing the organism to be in good condition to reproduce in future breeding seasons (Wingfield et al. 1998).

It is theorized that semelparous animals, which only have one opportunity to breed, should resist entering the emergency life-history stage in favour of allotting energy to current reproductive opportunities (Sapolsky et al. 2000; Wingfield \& Sapolsky, 2003. (Sapolsky et al. 2000; Wingfield \& Sapolsky, 2003. Research on non-semelparous species such as birds has shown that older birds and those with fewer reproductive opportunities will attenuate their stress response during reproduction when compared to younger birds, or those with more opportunity to spawn (Angelier et al. 2007; Silverin, 1997). Additionally, in animals where one sex provides parental care, the parent who does not provide care retains HPI axis sensitivity to stress, where the parent who provides parental care shows a reduced response to stress during reproduction (O'Reilly \& Wingfield, 2003; O'Connor et al. 2009). 


\section{Using Hormone Implants to Manipulate Cortisol Titres}

Cortisol responds rapidly and predictably following stressful external stimuli, making cortisol and the consequences of elevated cortisol a good indicator of the changes that occur following a stressor (Wendelaar Bonga, 1997). To understand how cortisol affects physiology and survivorship, many researchers have used intraperitoneal cortisol implants to manipulate plasma cortisol levels, most effectively done using cortisol mixed with cocoa butter to increase cortisol levels using a slow-release mechanism. Cocoa butter implants are useful as they have been shown to deliver steroids at a relatively stable rate rather than causing a transient increase with saline or oil injections. In addition, fish likely recover from the initial stress of the injection before the effects of the releasing hormones are lost (Gamperl et al, 1994). Previous studies using cortisol implants have revealed that experimental cortisol elevations elicit changes in the following ways: reduced feeding behaviour and impaired growth in juvenile rainbow trout (Oncorhynchus mykiss) (Gregory \& Wood, 1999); increase in standard metabolic rate in rainbow trout (Morgan \& Iwama, 1996); lowered plasma glucose and hepatic glycogen concentrations over time in brook charr (Salvelinus fontinalis)(Vijayan et al. 1991); depressed non-specific immunity and increased susceptibility to disease in grass carp (Ctenopharyngodon idellus) (Wang et al. 2005); and lastly an increased probability that cortisol-treated juvenile rainbow trout will be subordinate to control conspecifics, suggesting changes in behaviour and/or competitive ability (DiBattista et al. 2005). 
Although useful in determining how chronic cortisol elevations can influence physiology and behaviour, the majority of the above studies have been completed in a laboratory setting, neglecting to replicate the complexities of wild habitats. To fully understand how natural and anthropogenic stressors influence wild populations, it is necessary to investigate how wild animals respond to stressors in their own environment. In addition, studies involving stress during reproduction are few, especially involving semelparous animals. It is generally assumed that animals with a semelparous life strategy will mute their stress response during reproduction (Wingfield \& Sapolsky, 2003), but this has not been explicitly shown in wild salmon populations.

\section{Research Objectives and Predictions}

This thesis includes two distinct studies that will experimentally manipulate cortisol levels using hormone implants in the following settings: (a) wild fish in a flow through lake water tank system and (b) wild fish in their natural reproductive habitat. The overall objective of this thesis is to determine how stress influences physiology, behaviour and survival in wild fish populations, contributing to our understanding of the ecology of stress in wild animals.

\section{Rationale and Predictions for Chapter 2}

Fish respond to multiple stressors in a cumulative fashion (see Barton et al. 1987), and fish attenuate their stress response when exposed to an acute stressor while in a degraded habitat (which cause chronic stress) (see Hontela et al. 1997). However, the direct cause 
and effect relationships between chronic cortisol elevations and delayed mortality have not been identified and established conclusively, especially after fish have recovered physiologically (Barton \& Iwama, 1991). Chapter 2 set out to identify the sub-lethal aspects of stress that may affect disease resistance, growth, reproduction and general health and condition of fish populations, once fish have recovered from the initial stressor (i.e., carryover effects). It is also desirable to identify direct (i.e., individual effects) or indirect effects (i.e., at the population or community level) affects of stress in the shortand long-term. These facts represent the rationale behind Chapter 2; to identify how sublethal chronic cortisol elevations affect fish in the short- and long-term as well as quantify direct and indirect effects of chronic stress.

Chapter 2 will present a study investigating the consequences relating to overall condition, and physiology following a chronic cortisol elevation. Wild bluegill sunfish (Lepomis macrochirus) were used in an outdoor tank set up at the Queen's University Biological Field Station (QUBS) at Lake Opinicon in southeast Ontario, Canada. In general it is hypothesized that fish enduring a chronic cortisol elevation will experience maladaptive secondary and tertiary effects of the stressor over time and will be less able to endure additional stressors in the future. Even if a fish has recovered physiologically from a chronic cortisol elevation, it is desirable to determine if fish are experiencing carryover effects that reduce its ability to endure future stressors. The findings from this study are presented in chapter 2 . 
Model Species for Chapter 2 - Bluegill sunfish (L. macrochirus)

The model species for chapter 2 was adult bluegill, a sunfish species (Centrarchidae spp.). Bluegill were chosen in this setting since they are extremely abundant, yet still are a prized recreational fish. They are easily captured using non-invasive angling techniques and adapt quickly to holding and feeding. This makes them an ideal model to be used for studies involving wild fish.

Rationale and Predictions for Chapter 3

Chapter 3 will present a study that set out to determine how varying levels of stress can influence reproductive behaviour, success and physiology in semelparous salmon on their spawning grounds. This study also aims to elucidate the role of cortisol during the final maturation process through experimental cortisol manipulations.

Stressful migrations for semelparous salmon

Anadromous migration (from sea-water to freshwater) for the purpose of reproduction is an inherently physiologically demanding and often stressful process. For example, Pacific salmon enter the Fraser River in a catabolic state, depending on fixed energy reserves to transition from life in saltwater to freshwater, migrate up the river, develop gonads, and spawn, all in a short period of time. This process is energetically demanding thus salmon must be in peak physical condition to be successful (Brett 1995). All fish die after spawning. 
Reproductive development mainly occurs as fish are migrating upriver. In female pink salmon (Oncorhynchus gorbuscha), 17beta-estradiol and vitellogenein levels peak just before fish reach spawning grounds and fall to negligible levels once fish mature (Dye et al. 1986). At the beginning of pink salmon migrations (O. gorbuscha), testosterone remains high, but decreases steadily as fish approach spawning grounds and this trend continues during reproduction (Dye et al. 1986). During especially challenging portions of migration, the stress response becomes maladaptive, causing a reduction in sex hormone titres and likely hindering reproductive development (Hinch et al. 2006). In addition, high levels of stress during migration is associated with immune suppression and decreased resistance to disease (Maule et al. 2006); reduced sperm quality (Parenskiy \& Podlesnykh, 1995) and degeneration of the somatic and neural systems (Carruth et al. 2002). However, Carruth and others (2002) propose that the presence of cortisol during migration is actually adaptive and necessary for salmon to be able to return to their natal streams and therefore increases fitness.

"Baseline" cortisol levels are elevated on Pacific salmon spawning grounds to titres that represent the response to an acute stressor (McBride et al. 1986; Hinch et al, 2006). Specifically, McBride and others (1986) observed that there is marked increase in cortisol from the arrival (females averaged approx. $75 \mathrm{ng} \mathrm{ml}^{-1}$ ) at the spawning grounds to when the fish have reproduced (females averaged $252.8 \mathrm{ng} \mathrm{ml}^{-1}$ ). The role of corticosteroid functions in fish reproduction is mostly unknown, but there is some suggestion that it may play a role in the maturation of oocytes in females (Milla, 2009). Additionally, fish on the spawning grounds are also entering their senescent phase where many physiological processes, such as hormone regulation, are altered as a result 
(Morbey et al, 2005; Hruska et al, 2007). In particular, interrenal hypertrophy occurs which leads to cortisol hypersecretion, which eventually causes the fish's death (Robertson \& Wexlar, 1957; Fagerlund \& McBride, 1969; Dickhoff, 1989).

It is interesting that Pacific salmon respond to stress during their migration as they should be adapted to maintain reproductive development in the face of significant stressors since they only have one opportunity to spawn. Thus semelparous fish (e.g., Pacific salmon) should lack the reproductively inhibitory effects of stress to ensure fitness remains intact (Wingfield \& Sapolsky, 2003). Perhaps the stress response is muted once fish reach their spawning grounds, but this has not been investigated to date. Despite this unknown, it is evident that cortisol levels are high on Pacific salmon spawning grounds. Cortisol's role on salmon spawning grounds seems to be more complex than its role during migration and is likely a combination of the factors described in the above section. Reproductive hormones and behaviour are not affected by the increased cortisol levels so there must be some underlying mechanisms that enable fish to proceed reproductively even with elevated cortisol levels (Wingfield \& Sapolsky, 2003).

Pink salmon were used as a model representing a species of semelparous Pacific salmon. Given their unique life history model, it is hypothesized that acute stressors will result in a muted response allowing the fish to exhibit normal reproductive function (Wingfield \& Sapolsky, 2003). It is also hypothesized that a chronic elevation in cortisol negatively influences spawning behaviour, success and physiology given the fragility of a salmon's metabolic and physiological state at the end of their life cycle. The results of this experiment should clarify the role of cortisol during the final maturation stages; specifically we hope to determine how blocking cortisol synthesis will alter reproductive 
physiology, behaviour and success using metyrapone (which blocks cortisol synthesis).

Overall these experiments represent a novel approach to experimental cortisol manipulation on wild fish populations. It is acknowledged that each fish will exhibit inherent variability, but the results will more closely represent how wild fish populations will respond to cortisol elevations.

The experiments for chapter 3 were conducted at the Weaver Creek Spawning Channel within the Fraser River watershed in southwest British Columbia, Canada. The channel is man-made channel and provides ideal spawning habitat for pink salmon as well as sockeye (O. nerka) and chum (O. keta) salmon (Quinn, 1999).

\section{Model Species for Chapter 3 - Pink salmon (O. gorbuscha)}

Pink salmon are the smallest and most abundant species of semelparous Pacific salmon. They have a strict 2-year life cycle and show less spawning site fidelity than other Pacific salmon species (Heard, 1991). We used only female pink salmon in our study so we could determine reproductive success through the number of eggs released during spawning. Pink salmon exhibit typical spawning behaviours (see review, Heard, 1991). Briefly, females compete for ideal spawning sites to create their redds. Once a redd is chosen fish use a sweeping motion (referred to as a dig) to create redd and perhaps as a display to males advertising that they are ready to spawn. Females will actively defend their territories and will often display their aggression to conspecific females in competition for nesting sites. Aggression is displayed through chasing, biting and ramming actions. Once their spawning site is ready, males will show interest and spawning will occur. Following spawning, females will continue to "dig" around their 
redds to ensure that it is well protected. It is generally accepted that longevity on spawning grounds is beneficial to female salmon as it ensures that their red will be protected form later arriving females (Hendry et al. 2004; Hruska et al. 2010).

\section{Summary}

Collectively, this body of work will represent one of the first studies to examine the ecological consequences of stress in wild fish using an experimental approach. More specifically, this thesis will attempt to summarize and identify the role stress and cortisol has in the behaviour, overall condition and survival of wild fish populations. 


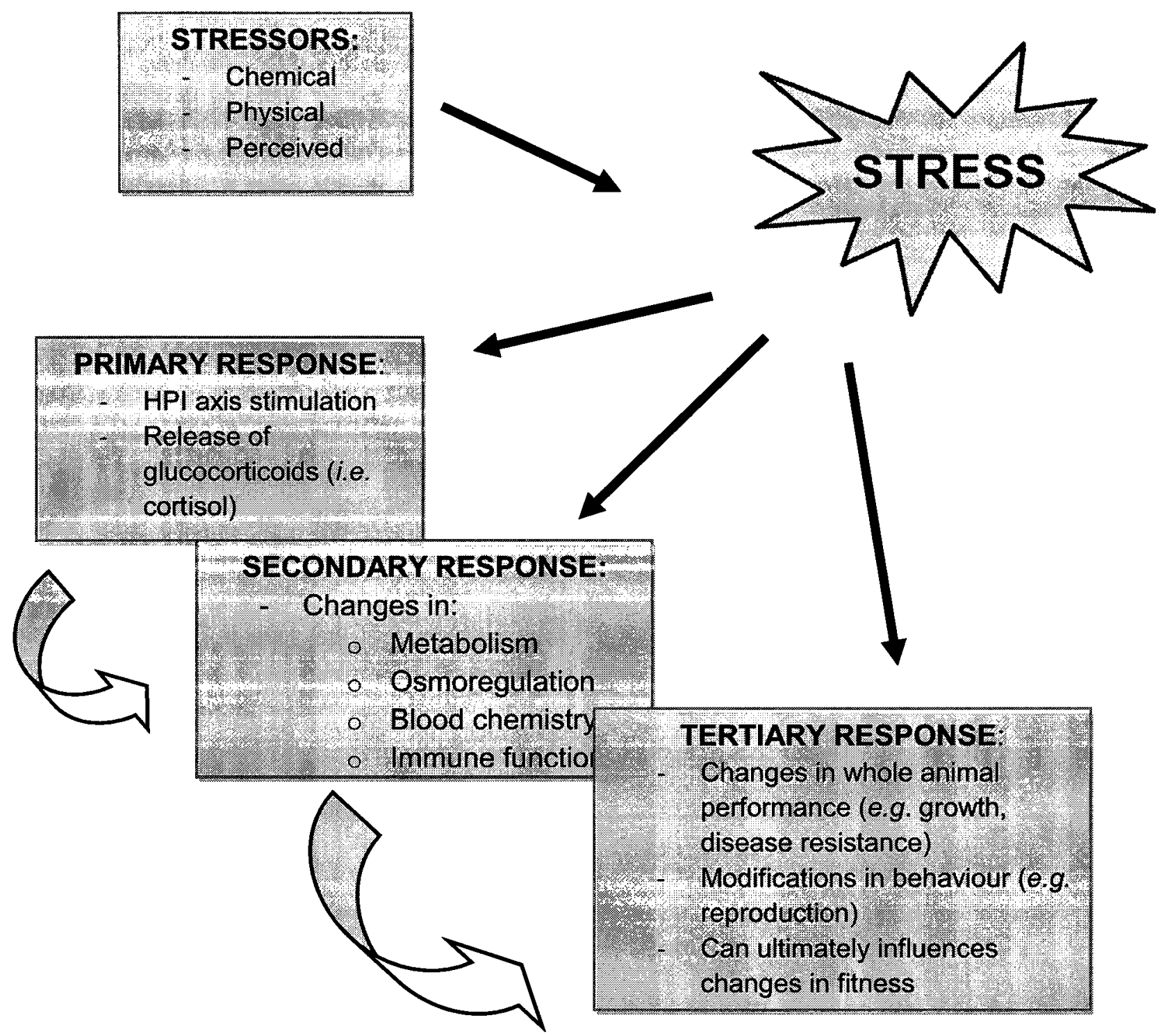

Figure 1-1. Overview of what occurs when stressors elicit the stress response in fish.

Figure adapted from Barton, 2002. 


\title{
Chapter 2: Supraphysiological cortisol elevation alters the response of wild bluegill to subsequent ecologically-relevant stressors
}

\begin{abstract}
Wild fish are frequently exposed to multiple stressors, but the influence of previous stress in dictating an animal's response to subsequent stressors is poorly understood. With wild bluegill sunfish (Lepomis macrochirus) as a model, we used hormone implants to experimentally raise circulating cortisol in a group of fish to supraphysiological levels for $\sim 10$ days. We also maintained sham-treated and control groups of fish. We then subjected animals to a second stressor in the form of either a heat or fasting challenge, both ecologically-relevant stressors for this species. We compared survival, body condition and plasma-borne indicators of physiological stress among cortisol-treated, sham-treated and control groups. In order to compare short- and long-term effects, we subjected the animals to the second stressor either 4 or 30 days following initial treatment. Cortisoltreated fish lost equilibrium sooner than sham-treated and control fish during the heat challenge conducted at 30 days, but not at 4 days. Cortisol-treated fish succumbed to the fasting challenge sooner than sham-treated and control fish at both 4 and 30 days. These results imply that wild fish experiencing a stress response are more vulnerable to mortality if exposed to an additional challenge during this period. Furthermore, these results indicate that the experience of a stress response can alter the long-term responses of wild fish to additional challenges, even after the cessation of the initial stress response. The results of this study emphasize the importance of considering multiple stressors and the long-term effects of stress in wild fish populations.
\end{abstract}




\section{Introduction}

Wild fish encounter many stressors throughout their lifetime that have the potential to influence survival. Some of these stressors are natural, such as scarcity of food resources (Dutil \& Lambert, 2000), disease exposure (Barton et al. 1986; Barton, 2002; Lepak \& Kraft, 2008), or predation attempts (Pfeiffer, 1962; Fraser \& Gilliam, 1992). Other stressors are anthropogenic, including urbanization (Wang et al. 2000), agricultural development (Stauffer et al. 2000), dams and turbines (Anderson et al. 2006; Murchie et al. 2008), or exposure to angling or commercial fishing practices (e.g., Davis, 2002; Cooke \& Suski, 2005; Arlinghaus et al. 2007). Given the pervasive nature of these challenges, there is an explicit need to elucidate the relationship between physiological stress and long-term survival. Because these challenges do not occur in isolation, it is especially necessary to identify the impact of multiple simultaneous or sequential stressors and how this might lead to decreases in organismal fitness.

For the purposes of this study we adopt Barton's and Iwama's (1991) definition of a stress response: the reaction by fish to a stimulus that may somehow alter the fish's homeostatic state. Thus, a stressor is a stimulus that initiates a stress response. The stress response in fish involves stimulation of sympathetic nerve fibres to release catecholamines and stimulation of the hypothalamic-pituitary-interrenal (HPI) axis, culminating in the production and release of corticosteroid hormones (cortisol being the main corticosteroid in teleosts) (Barton, 2002). These hormones are in turn associated with secondary system-level responses (e.g., changes in immune function, metabolism, etc.) and tertiary whole-animal responses (e.g., behaviour and survivorship) (Barton, 
2002). This stress response is initially adaptive, allowing a fish to cope with the challenge, and increasing the ability to recover from the challenge (Barton, 2002). However, if the intensity of a stressor is severe or long-lasting, the response can become maladaptive, compromising the animal's well-being (Barton, 2002). Furthermore, even the adaptive phase of the stress response can inhibit other necessary functions (i.e., reproduction; Schreck et al. 2001).

Barton et al. (1986) noted that physiological stressors accumulate in an additive fashion. However, distinct changes to the physiological condition of a fish exposed to multiple stressors are poorly understood. Fish residing in polluted water systems exhibit an impaired stress response when challenged with an acute stressor (Hontela et al. 1997; Vijayan et al. 1997). Basu and colleagues (2002) also found that fish exposed to chronic stressors displayed an impaired stress response at the cellular (i.e., heat shock proteins) and organismal (i.e., cortisol) level. Therefore, the stress response is impaired when fish residing in poor habitats experience an acute stressor. However, there is still little information regarding how fish respond to multiple sequential stressors rather than simultaneous stressors. For example, it is unknown how an individual exposed to one stress event will respond to a secondary stressor, temporally separated from the initial stressor. In the ecological literature, such temporally separated effects of stressors on responses to subsequent stressors are referred to as carryover effects (Norris \& Marra, 2007). This concept has rarely been explored in fish (see O'Connor et al. In Press), but it is likely that sub-lethal stressful events modulate how a fish can respond to subsequent stressors after physiological recovery from the initial, chronic stressor. 
Injections of cortisol are an established method of mimicking a physiological stress response in a fish in a controlled manner, and are associated with the same secondary and tertiary changes as a natural stressor (Gamperl et al. 1994). However, often these studies do not address recovery time in an ecologically-relevant context, where fish may be continuously subjected to environmental stressors during or after the period of recovery from cortisol elevation. Indeed, almost all studies involving experimental cortisol elevation have been conducted in the laboratory and on domesticated fish (Vijayan et al. 1991; Morgan \& Iwama, 1996; Gregory \& Wood, 1999; Wang et al. 2005). Few studies have evaluated the long-term consequences of chronic stress and multiple stressors in wild fish (but see O'Connor et al. in press). In the present study we used wild bluegill sunfish (Lepomis machrochirus), that had received an intraperitoneal injection of cortisol in cocoa butter, as a model to address several questions. First, we asked whether fish treated with cortisol show additive or cumulative effects of stress when subjected to secondary, ecologically-relevant stressors during the period of cortisol elevation (i.e., several days after experimental cortisol elevation)? Second, do fish treated with cortisol exhibit long-term carryover effects of "stress" (i.e., cortisol elevation, effect seen after recovery from elevation) when subjected to secondary, ecologically-relevant stressors 30-days following the initial cortisol treatment?

\section{Materials and Methods}

All fish were sampled under an Ontario Ministry of Natural Resources Scientific Collection Permit and handled in accordance with the guidelines of the Canadian Council 
on Animal Care (Carleton University, B09-11). Experimentation took place at Queen's University Biological Field Station (QUBS) in eastern Ontario, Canada $\left(44^{\circ} 31^{\prime} \mathrm{N}\right.$, $76^{\circ} 20^{\prime} \mathrm{W}$ ). Adult wild bluegill sunfish (total length $>150 \mathrm{~mm}$ ) were used as a model species because they are abundant and can easily be captured and held in captivity. In May and June, 2009, fish were captured from Lake Opinicon by angling and were then held in 1000L outdoor tanks supplied with flow-through lake water. Fish were randomly distributed into 3 groups: cortisol treatment, sham treatment, and control. Cortisol-treated fish received an intraperitoneal injection of $50 \mathrm{mg} \mathrm{kg}^{-1}$ cortisol (hydrocortisone 21hemisuccinate; Sigma H4881, Sigma-Aldrich) emulsified in pure cocoa butter $(0.005 \mathrm{ml}$ $\mathrm{g}^{-1}$ ). Sham-treated received only the cocoa butter vehicle, while control fish were not injected. All fish were identified by individual and treatment type using anchor tags. We conducted two distinct experiments, each using these initial cortisol treatments. Both experiments consisted of applying an ecologically-relevant stressor at either 4 days or 30 days following the initial treatment. All fish were fed twice-daily during the 4 or 30 day holding periods, and were monitored closely at regular intervals for loss of condition leading to mortality and/or abnormal behaviour (e.g., loss of equilibrium).

Experiment 1: Heat challenge (short- and long-term)

For the short-term heat challenge, 75 fish ( $\mathrm{n}=25$ per treatment) were placed together into a 1000L tank after being exposed to the above treatments. Four days after treatment, the tank was outfitted with a temperature logger and two electrical water heaters that increased water temperature by approximately $1^{\circ} \mathrm{C}$ per hour until all fish had lost equilibrium. Fish were monitored closely during the heat challenge and were removed 
from the tank immediately following loss of equilibrium. The time and temperature at removal were documented and the fish was sampled for $\sim 1 \mathrm{ml}$ of blood by caudal puncture, using lithium heparinised $1 \mathrm{ml}$ syringes and 25 -gauge, $38 \mathrm{~mm}$ needles. Blood samples were held in an ice-water slurry for no more than $1 \mathrm{~h}$ until they were processed. Glucose was measured on $10 \mu 1$ of whole blood with a hand-held glucose meter (ACCUCHEK glucose meter; Roche Diagnostics, Basel, Switzerland), a device previously validated for use on fish (Cooke et al. 2008). Hematocrit values were determined using microhematocrit tubes centrifuged for $5 \mathrm{~min}$ in a hematocrit centrifuge (CritSpin-MicroHematocrit Centrifuge). The remaining blood was centrifuged (Fisher Scientific MicroFuge) at $2000 \mathrm{~g}$ for $5 \mathrm{~min}$. Plasma samples were frozen immediately in liquid nitrogen and then transferred to an ultra-cold freezer and stored at $-80^{\circ} \mathrm{C}$ until cortisol and lysozyme analysis.

For the long-term challenge, 75 fish ( $\mathrm{n}=25$ per treatment) were placed together into a $1000 \mathrm{~L}$ tank after being exposed to one of the three treatments. Fish were fed twicedaily and monitored closely for a $30 \mathrm{~d}$ period. After $30 \mathrm{~d}$, the heat challenge protocol described above was carried out. Mortality rates were quantified during the $30 \mathrm{~d}$ holding period; any fish that exhibited endpoints characterized as loss of equilibrium and reflex responsiveness were netted and considered as "mortalities".

Experiment 2: Fasting challenge (short- and long-term)

For the short-term challenge, 75 fish ( $\mathrm{n}=25$ per treatment) were placed together into a $1000 \mathrm{~L}$ tank after being exposed to the above treatments. After $4 \mathrm{~d}$, fish were fasted for up 
to $50 \mathrm{~d}$. Fish were removed from the experiment if loss of equilibrium occurred (considered a humane and appropriate endpoint) and the day of removal was noted. Upon removal or at the end of the experiment, fish were euthanized using cerebral percussion and the following measures were collected: hepato-somatic index (HSI), splenic index (SSI), condition factor $(\mathrm{K})$, and several condition indices modified from the health assessment index (HAI) as described in Adams et al. (1993). HSI (HSI = (liver mass/body mass) $100 \%$ ) is expected to be correlated with the nutritional state of the fish (Busacker et al. 1990). The splenic index (SSI = (spleen mass/body mass) $100 \%)$ enabled us to evaluate splenic enlargement which is an indicator of disease (Adams et al. 1993). Condition factor $\left(\mathrm{K}=\right.$ mass $\cdot$ length $\left.^{-3}\right)$, was measured because it is useful in reflecting the nutritional state of fish (Busacker et al. 1990). The HAI is a rapid and inexpensive method used to evaluate the effects of stress on the health of fish populations. It is a quantitative index where necropsy observations are given numerical values so that statistical comparisons can be made among experimental groups. We modified the index to focus on three main variables expected to reveal differences in health and immune function among our treatments: total parasite load (each organ affected was given a score of $5=$ low, $10=$ moderate, $15=$ high), gill condition (level of gill fray $[10=$ low, $20=$ moderate, $30=$ high], necrotic gill tissue present [5=low, 10=moderate, 15=high], and parasite load [5=low, $10=$ moderate, $15=$ high $]$ ) and fungus covering the fish's skin (measured as percent [\%] cover).

For the long-term challenge, 75 fish ( $\mathrm{n}=25$ per treatment) were placed together into a 1000L tank after being exposed to one of the three treatments. Fish were fed twice daily and monitored closely for a $30 \mathrm{~d}$ period. After $30 \mathrm{~d}$, the fasting challenge protocol 
described above was carried out. Mortality rates were quantified during holding.

\section{Time course of cortisol effects}

To provide context for the elevation of cortisol used in experiments 1 and 2, we conducted a time course experiment in which cortisol, glucose, hematocrit and condition values were measured over a $30 \mathrm{~d}$ period. In the spring of 2010 , groups of 60 fish ( $n=20$ per treatment) were angled, randomly subjected to one of our three treatments, and placed in a 1000L outdoor tank. Fish were fed twice-daily and monitored closely for $24 \mathrm{~h}, 4 \mathrm{~d}$, $10 \mathrm{~d}$, or $30 \mathrm{~d}$. At the end of the monitoring period, a subset of fish ( $\mathrm{n}=10$ per treatment) was removed from the tank and placed into individual opaque experimental chambers $(\sim$ 2L) supplied with a constant flow of lake water for $24 \mathrm{~h}$. Fish were then removed from the chambers individually and blood sampled as described above. In addition, a separate group of fish was sampled immediately after angling from the lake ( $\mathrm{n}=20$ fish). Whole blood was analyzed for glucose concentration and hematocrit and plasma was stored for later cortisol and lysozyme analysis. Fish were euthanized by cerebral percussion and dissected, collecting information relevant to condition and health of the individual as described above

We also utilized a chasing protocol to compare our exogenous cortisol elevation to endogenous cortisol elevation caused by stress in bluegill sunfish. A group of fish $(n=10)$ was obtained from Lake Opinicon. Fish were chased to exhaustion (loss of equilibrium, $\sim 5 \mathrm{~min}$ ). Once equilibrium was lost, fish were held in isolation chambers for $\sim 40$ min to ensure fish were sampled as cortisol peaked (K. Cook, unpublished data) 
and blood samples were taken and processed as previously described.

\section{Cortisol analysis}

Plasma cortisol concentration was determined using a commercial radioimmunoassay kit (ImmunoChem Cortisol ${ }_{125}$ I RIA kit, MP Biomedicals, Orangeburg, NY) previously validated for teleost fish (Gamperl et al. 1994) and a Cobra Auto-Gamma (HewlettPackard, Palo Alto, CA). Intra-assay variability (\% CV) was $7.9 \%$.

\section{Statistical analyses}

For the $24 \mathrm{~h}, 4 \mathrm{~d}, 10 \mathrm{~d}$, and $30 \mathrm{~d}$ time course analysis, one-way ANOVAs were performed for all parameters to determine whether there were any treatment effects. Mortality for each experiment was expressed as a percentage (\%). Log-rank survival analyses were conducted separately for all of the short- and long-term portions of both experiments. Survival analyses for the heat challenge were performed in terms of temperature at loss of equilibrium. Survival analyses for the fasting challenge were performed in terms of date of removal from the experiment. A one-way ANOVA was carried out on the blood parameters (plasma cortisol concentration, whole blood glucose concentration and hematocrit) from the short- and long- term heat challenge separately to find differences among treatment groups. The assumptions of equality of variances and normal distribution were tested for all analyses and relevant transformations applied where assumptions could not be met. For those analyses not able to be transformed, nonparametric analyses were performed. Tukey-Kramer HSD tests were used for post hoc 
tests for the one-way ANOVAs when significant differences were found. All analyses were conducted using JMP 8.0.2 software (SAS institute, Cary, North Carolina). The significance level was set at $\alpha=0.05$, except when Bonferroni-corrected significance levels were used to address the problem of multiple comparisons.

\section{Results}

\section{Experiment 1: Heat challenge (short- and long-term)}

For the short-term heat challenge, no mortalities occurred in the $4 \mathrm{~d}$ prior to the challenge. There were no differences among treatment groups for rate of equilibrium loss when considering temperature (log-rank survival analysis to $50 \%$ mortality; $\lambda^{2}=1.96$, $d f=2, p=0.375$; Figure 2-1A). Cortisol-treated fish exhibited higher plasma cortisol levels than both control and sham-treated groups $(F=16.7, \mathrm{df}=2, \mathrm{p}<0.001)$. There were no differences in plasma glucose levels or hematocrit among the groups (see Table 2-1).

In the $30 \mathrm{~d}$ prior to the long-term heat challenge, $56 \%$ of cortisol treated fish were removed from the experiment, and $8 \%$ of both sham-treated and control fish were removed. Cortisol-treated fish lost equilibrium at lower temperatures (log-rank survival analysis to $50 \%$ having lost equilibrium; $\lambda^{2}=40.7, \mathrm{df}=2, \mathrm{p}<0.001$ ) (Figure 2-1B ). For the long-term heat challenge, cortisol treated fish displayed higher cortisol levels than controls and sham-treated fish $(\mathrm{F}=6.87, \mathrm{df}=2, \mathrm{p}=0.003)$ (Table 2-1). Cortisol treated fish also displayed significantly lower glucose values $\left(\mathrm{df}=2, \lambda^{2}=10.3, \mathrm{p}=0.006\right)$ and higher hematocrit values $(\mathrm{F}=3.92, \mathrm{df}=2 \mathrm{p}=0.026)$ than control and sham-treated fish (Table 2-1). 


\section{Experiment 2: Fasting challenge (short- and long-term)}

There were no mortalities during the $4 \mathrm{~d}$ prior to the short-term fasting challenge. During the fasting challenge itself, cortisol-treated fish were removed from the experiment at a higher rate than sham-treated and control fish (log-rank survival analysis to $50 \%$ mortality; $\left.\lambda^{2}=12.0, \mathrm{df}=2, \mathrm{p}=0.0024\right)$ (Figure $\left.2-2 \mathrm{~A}\right)$. Neither fish that were removed from the experiment before or after the $50 \mathrm{~d}$ period was completed differed among treatment groups in terms of any condition variable (see Table 2-2 ).

Prior to the long-term fasting challenge, $56 \%$ of cortisol-treated fish were removed from the experiment, $32 \%$ of sham-treated fish were removed and $12 \%$ of control fish were removed. There were no differences in the rate of removal from the experiment among the three treatment groups (log-rank survival analysis to $50 \%$ mortality; $\left(\lambda^{2}=1.64, \mathrm{df}=2, \mathrm{p}=0.440\right.$ ) (Figure 2-2B). Fish removed during the $30 \mathrm{~d}$ period before the $50 \mathrm{~d}$ fast did not differ among treatment groups for any condition parameters except HSI, where cortisol-treated fish had lower HSI values than sham-treated and control fish $(\mathrm{F}=4.10, \mathrm{df}=2, \mathrm{p}=0.037)$. No condition parameters differed among treatment groups for fish removed during or at the end of the $50 \mathrm{~d}$ fasting period (see Table 2-3).

\section{Time course of cortisol effects}

After $24 \mathrm{~h}$, bluegill injected with cortisol had cortisol levels that averaged $1804 \pm 118 \mathrm{ng}$ $\mathrm{ml}^{-1}$, which were significantly higher than both sham $\left(102 \pm 129 \mathrm{ng} \mathrm{ml}^{-1}\right)$ and control fish $\left(44 \pm 118 \mathrm{ng} \mathrm{ml}^{-1}\right)(\mathrm{F}=70.0, \mathrm{df}=2, \mathrm{p}<0.0001)$. At $4 \mathrm{~d}$, cortisol levels in cortisol treated fish $\left(662 \pm 112 \mathrm{ng} \mathrm{ml}^{-1}\right)$ still remained significantly higher than both shams $(21 \pm 89 \mathrm{ng}$ $\left.\mathrm{ml}^{-1}\right)$ and controls $\left(77 \pm 89 \mathrm{ng} \mathrm{ml}^{-1}\right)\left(\lambda^{2}=17.6, \mathrm{df}=2, \mathrm{p}<0.001\right)$. At $10 \mathrm{~d}$, cortisol values 
remained significantly elevated $\left(953 \pm 96 \mathrm{ng} \mathrm{ml}^{-1}\right)$ relative to shams $\left(119 \pm 92 \mathrm{ng} \mathrm{ml}^{-1}\right)$ and controls $\left(36 \pm 92 \mathrm{ng} \mathrm{ml}^{-1}\right)$ suggesting our cortisol injection was still active $\left(\lambda^{2}=14.4\right.$, $\mathrm{df}=2, \mathrm{p}=0.0008)$. At $30 \mathrm{~d}$ cortisol values for sham-treated, cortisol-treated and control fish did not differ significantly $\left(246 \pm 89,325 \pm 78 \mathrm{ng} \mathrm{ml}^{-1}\right.$ and $79 \pm 81 \mathrm{ng} \mathrm{ml}^{-1}$ respectively) $(\mathrm{F}=4.34, \mathrm{df}=2, \mathrm{p}=0.022)$ (see Table 2-4). Refer to Figures 2-3 and 2-4 for a graphical depiction of plasma cortisol and blood glucose respectively throughout the time course. Mortality prior to the $30 \mathrm{~d}$ sampling was as follows: $24 \%$ control fish, $36 \%$ shamtreated and $48 \%$ cortisol-treated fish.

Plasma cortisol values for bluegill captured from the lake and sampled within 2 $\min$ (representative of baseline values for wild fish) were on average $47.7 \pm 34 \mathrm{ng} \mathrm{ml}^{-1}$ $(\mathrm{N}=20)$ with a range of 0.3 to $552.9 \mathrm{ng} \mathrm{ml}^{-1}$. Values measured in bluegill that were chased to exhaustion and allowed to recover for $\sim 40$ min averaged $560 \pm 69 \mathrm{ng} \mathrm{ml}^{-1}$ $(\mathrm{N}=15)$ (range 248 to $1172 \mathrm{ng} \mathrm{ml}^{-1}$ ). These circulating cortisol levels were lower than those generated via cortisol implants at $24 \mathrm{~h}$ (i.e., $1804 \pm 118 \mathrm{ng} \mathrm{ml}^{-1}$; range of 675 to $2834 \mathrm{ng} \mathrm{ml}^{-1}$ ) although comparable to those observed in cortisol-treated fish at 4 or $10 \mathrm{~d}$.

\section{Discussion}

In this study, we found that chronically elevating cortisol values increases mortality when fish are faced with additional stressors in the long-term, even when fish have recovered physiologically. After $30 \mathrm{~d}$ and prior to a secondary stressor, glucose, cortisol and hematocrit values did not differ in cortisol-treated fish when compared to sham-treated or control fish. However, when cortisol-treated fish were exposed to a secondary stressor at $30 \mathrm{~d}$, they were less able to tolerate and recover from an ecologically relevant stressor 
when compared to control and sham-treated fish. This provides evidence of carryover effects where the physiological consequences of a chronic cortisol elevation manifest themselves after physiological recovery from that elevation.

\section{Experiment 1: Heat challenge (short- and long-term)}

Thirty days after administration of the cortisol implants, cortisol-treated fish were less able to tolerate a heat challenge than control or sham-treated fish even though the treatment groups did not differ significantly in physiological condition at $30 \mathrm{~d}$ prior to application of the secondary stressor; this effect was not apparent in the short-term (4 d after treatment). Cortisol-treated fish may be more susceptible to thermal stress, as it has been shown by Basu and colleagues (2001) that thermal stress and an increase in circulating cortisol values reduce hsp70 levels in liver and gill tissue in fish. In this context it may be useful to look at heat shock protein expression during thermal stress in cortisol-treated fish.

In the long-term experiment, glucose values were on average $15 \mathrm{mmol} \mathrm{L}^{-1}$ lower in cortisol-treated fish than in both sham-treated and control fish which suggests glycogen reserves were exhausted more quickly, since resting values did not differ at 30 $\mathrm{d}$ in the time course study. Cortisol has been shown to increase blood cell size, causing hematocrit to be inflated in cortisol-treated fish, which may explain the differences seen in the long-term (Barton \& Iwama, 1991). Both the depressed glucose levels and increased hematocrit are examples of secondary responses that occur when a stress response becomes maladaptive (Barton, 2002). Since there were no differences in physiological parameters at $30 \mathrm{~d}$ in the time course study, fish have recovered 
physiologically from the injections. However, since there were differences in blood physiology and rate of loss of equilibrium during the long-term heat challenge, cortisoltreated fish were less able to tolerate the heat challenge.

Experiment 2: Fasting challenge (short- and long-term)

In the short-term fasting challenge, cortisol-treated fish were removed from the experiment at a faster rate than both sham-treated and control fish. This trend also appears to be present for the long-term experiment, but it must be noted that $54 \%$ of cortisol-treated fish were removed from the experiment before that fasting challenge even took place, causing lower sample sizes by $30 \mathrm{~d}$ (12 instead of 25). Before the fasting began, cortisol-treated fish that were removed had lower HSI values compared to the other groups. The initial increase in gluconeogenesis following an elevation in cortisol can cause a decrease in liver glycogen levels and/or the hepatic capacity for glycogen synthesis (Mommson et al. 1999). Also, cortisol elevation is known to reduce feeding and body condition, leaving fish with low energy stores (Gregory \& Wood, 1999; Mommsen et al. 1999). Similarly, O'Connor et al. (2009) revealed that fish showed signs of “carryover" effects (i.e., sub-lethal mortality following a stressor after physiological recovery from a chronic cortisol elevation). In the O'Connor study (2009), cortisoltreated fish showed reduced growth rates when compared with controls and sham-treated fish which suggest a lack of stored energy.

It seems that cortisol treatment in some cases reduced energy reserved resulting in mortality. However, those fish that survived to $30 \mathrm{~d}$ showed no differences in HSI. 
Whether cortisol affects HSI may depend on the nutritional state of the fish prior to capture.

\section{Effectiveness of Cortisol Implants}

The cortisol implants effectively increased cortisol levels by $24 \mathrm{~h}$, and this effect was seen for up to $10 \mathrm{~d}$. At $30 \mathrm{~d}$, cortisol values did not differ among treatment groups suggesting that the implant was inactive after $30 \mathrm{~d}$. Resting glucose levels were significantly higher in cortisol-treated fish after $24 \mathrm{~h}\left(10 \mathrm{mmol} \mathrm{L}^{-1}\right.$ higher than shams and $13 \mathrm{mmol} \mathrm{L}^{-1}$ higher than controls). This effect was not seen at any other time, but is likely a direct effect of increased cortisol levels at $24 \mathrm{~h}$. The elevation of glucose at $24 \mathrm{~h}$ of cortisol treatment is consistent with the general pattern for cortisol to enhance the rate of gluconeogenesis (Mommson et al. 1999). In addition, resting glucose, hematocrit and all condition parameters did not differ among groups at $30 \mathrm{~d}$.

The exhaustive chasing protocol provided context for the level of circulating cortisol achieved with the cortisol implants, allowing endogenous cortisol elevation following a stressor to be compared with exogenous elevation by cortisol administration. Values from the chasing protocol were lower than those that we generated via the cortisol implants at $24 \mathrm{~h}$. Our cortisol dose was therefore pharmacological at $24 \mathrm{~h}$, and produced a cortisol response higher than the endogenous response of bluegill to a stressor. However, even though our dose was pharmacological at $24 \mathrm{~h}$, this probably is an inevitable consequence of elevating cortisol using a long-lasting implant. By $4 \mathrm{~d}$, levels were comparable to those seen in the chasing protocol, and this was maintained in fish by $10 \mathrm{~d}$ 
and by $30 \mathrm{~d}$, no significant differences among groups were detected. Cortisol dosage values were initially selected based on previous studies using cortisol implants in the confamilial smallmouth bass (Micropterus dolomieu) in a wild setting (Dey et al. In Press). Future studies conducted using ecologically-relevant dosages may be helpful and this can be achieved by completing a validation study prior to experimentation. Despite the high dosages, however, interesting observations were made during each experiment, and provide valuable context for future research investigating the long-term consequences of multiple stressors. In addition, the severe dose used in the present study likely maximised the likelihood of seeing an effect.

Fish condition decreased over $30 \mathrm{~d}$ in all treatment groups (Table 2-2). Also, considerable mortality was noted in groups of fish held for $30 \mathrm{~d}$. Temperature data collected throughout the time course and long-term experiments revealed that mortality began to occur around $16^{\circ} \mathrm{C}$. Elevated water temperatures are generally associated with stress and incidences of parasites and pathogens (Gilhousen, 1990; Harvell et al. 2002). However, we were still able to compare within experiments given that all fish in each experiment were exposed to similar conditions and we did see differences among our treatment groups that were consistent among experiments.

Overall synthesis

Our study can be viewed as an extreme experimental manipulation set out to determine how fish respond to multiple stressors following a chronic cortisol elevation. The results from this study show that chronic cortisol elevation carries immediate (i.e., glucose 
elevation) and long-term physiological (i.e., lowering of energy stores) costs that make fish less able to withstand multiple stressors. However, the effects of the cortisol treatment appear to have disappeared by $30 \mathrm{~d}$, but become apparent when fish are exposed to secondary stressors, providing evidence of carryover effects. As a whole, these results suggest that fish exposed to sub-lethal stressors that cause chronic cortisol elevation, will experience lower survival in the short and long-term, negatively impacting long-term fitness of populations as a whole. The results of our experiment support the concept that carryover effects can influence survival after recovery from a chronic cortisol elevation. These findings emphasize the importance of considering cumulative and long-term effects of stress in wild fish population. 


\section{Tables}

Table 2 - 1. L. macrochirus blood cortisol, glucose and hematocrit values for short- and long-term heat challenges. Sample sizes are as follows: short-term cortisol (control=11, sham $=12$, cortisol $=15)$, glucose and hematocrit $(N=25$ control, cortisol, sham=23); longterm cortisol (control $=18$, sham $=19$, cortisol $=8)$, glucose $(\mathrm{N}=22$ control, sham, cortisol $=10$ ), hematocrit (control=22, sham $=21$, cortisol=9). Variables denoted with '*” were analyzed using Wilcoxon Rank-Sum tests . ' $\dagger$ ' indicates variables where data were log-transformed. ' $\dagger$ ' refers to treatments whose data was Square root transformed. Bonferroni corrected $\alpha=0.017$. All parameters indicated as percentages were analyzed as (ArcSin(Square Root(value)). Dissimilar letters denote significant differences among treatment groups (Tukey-Kramer HSD test, $\mathrm{p}<0.017$ ).

\begin{tabular}{|c|c|c|c|c|c|}
\hline \multirow[b]{2}{*}{ VARIABLE } & \multicolumn{3}{|c|}{ TREATMENT } & \multirow[b]{2}{*}{ Statistic } & \multirow[b]{2}{*}{$\begin{array}{c}P \text { - } \\
\text { Value }\end{array}$} \\
\hline & $\begin{array}{c}\text { Control } \\
\text { (mean } \pm \\
\text { SE) }\end{array}$ & $\begin{array}{c}\text { Sham } \\
\text { (mean } \pm \\
\text { SE) }\end{array}$ & $\begin{array}{c}\text { Cortisol } \\
(\text { mean } \pm \text { SE })\end{array}$ & & \\
\hline \multicolumn{6}{|c|}{ Short-Term Heat Challenge } \\
\hline Cortisol (ng ml$\left.)^{-1}\right)^{\dagger}$ & $\begin{array}{l}350.6 \pm \\
268.3^{\mathrm{B}}\end{array}$ & $\begin{array}{c}412.3 \pm \\
256.8^{B}\end{array}$ & $\begin{array}{c}1974.4 \pm \\
229.7^{\mathrm{A}}\end{array}$ & 16.7 & $<0.0001$ \\
\hline$\underset{1}{\operatorname{Glucose}(\mathrm{mmol})^{\dagger}}$ & $11.4 \pm 1.1$ & $11.2 \pm 1.1$ & $13.0 \pm 1.1$ & 0.403 & 0.670 \\
\hline Hematocrit $(\%)$ & $40 \pm 1$ & $38 \pm 1$ & $39 \pm 1$ & 0.400 & 0.819 \\
\hline
\end{tabular}




\section{Long-Term Heat Challenge}

\begin{tabular}{|c|c|c|c|c|c|}
\hline Cortisol (ng ml $\left.{ }^{-1}\right)^{\dagger \dagger}$ & $\begin{array}{c}208.4 \pm \\
45.2^{\mathrm{B}}\end{array}$ & $\begin{array}{c}237.5 \pm \\
44.1^{\mathrm{B}}\end{array}$ & $544.1 \pm 67.7^{\mathrm{A}}$ & 6.87 & 0.003 \\
\hline Glucose $\left(\mathrm{mmol} \mathrm{L}^{-}\right.$ & $24.8 \pm 2.1^{\mathrm{A}}$ & $24.5 \pm 2.1^{\mathrm{A}}$ & $9.7 \pm 2.1^{\mathrm{B}}$ & 10.3 & 0.006 \\
\hline Hematocrit (\%) & $34 \pm 2$ & $32 \pm 2$ & $39 \pm 2$ & 3.92 & 0.026 \\
\hline
\end{tabular}


Table 2 - 2. Summary of $L$. macrochirus condition variables for the short-term fasting challenge. Analyses were separated by fish that succumbed to the challenge during the 50 $\mathrm{d}$ fasting period and by fish that remained in the experiment for the full $50 \mathrm{~d}$ period.

Sample sizes are as follows: fish removed during (control=17, sham=17, cortisol=22); fish removed afterwards (control=5, sham=4, cortisol=3). ' $\dagger$ ' refers to treatments whose data was log-transformed. All comparisons were analyzed using 1-way ANOVAs.

Bonferroni corrected $\alpha=0.01$ for fish removed during fasting period and $\alpha=0.013$ for fish removed following $50 \mathrm{~d}$ fasting period. Dissimilar letters denote significant differences among treatment groups (Tukey-Kramer HSD test, $\mathrm{p}<0.01 \& \mathrm{p}<0.013$ ).

\begin{tabular}{cccccc}
\hline & \multicolumn{3}{c}{ TREATMENT } & & \\
\cline { 2 - 3 } VARIABLE & $\begin{array}{c}\text { Control } \\
\text { (mean } \pm \\
\text { SE) }\end{array}$ & $\begin{array}{c}\text { Sham } \\
\text { (mean } \pm \\
\text { SE) }\end{array}$ & $\begin{array}{c}\text { Cortisol } \\
\text { (mean } \pm \\
\text { SE) }\end{array}$ & $\begin{array}{c}\text { Statisti } \\
\text { c }\end{array}$ & $\begin{array}{c}\text { P - } \\
\text { Value }\end{array}$ \\
\hline \multicolumn{2}{c}{ Fish Removed During 50d Fasting Period } \\
Fungal Cover (\%)
\end{tabular}


$\begin{array}{llllll}\text { HSI (\% Body Weight }) & 0.56 \pm 0.03 & 0.51 \pm 0.03 & 0.70 \pm 0.04 & 5.91 & 0.023\end{array}$

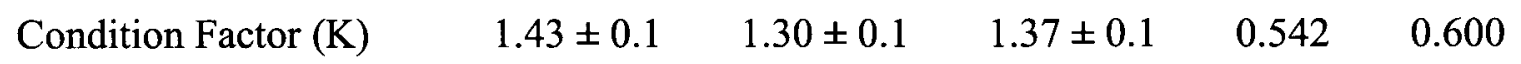




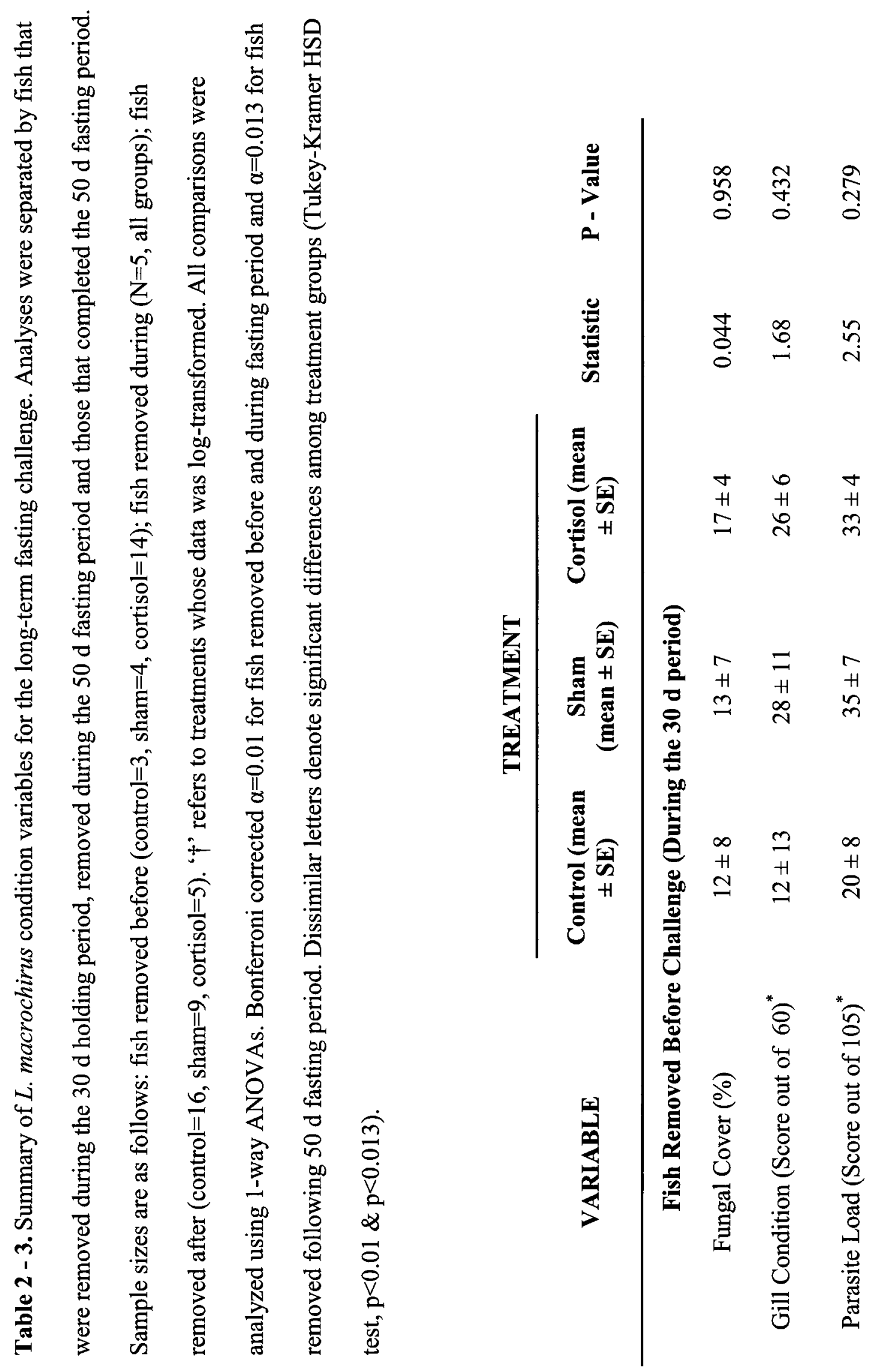




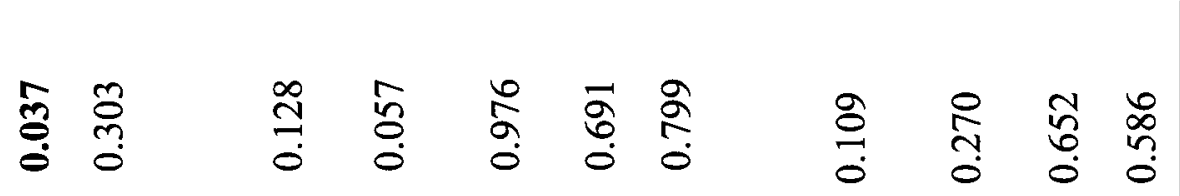

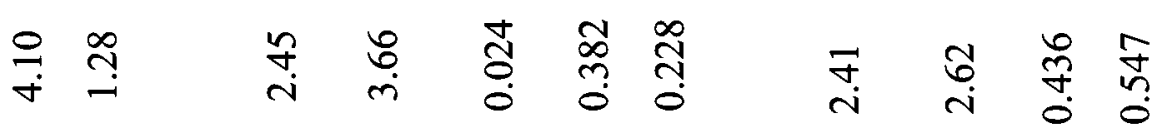

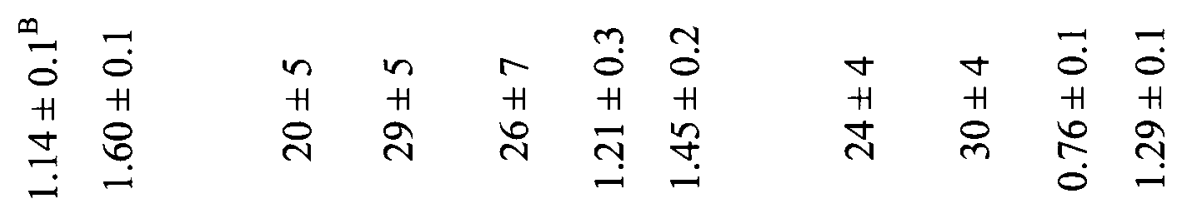

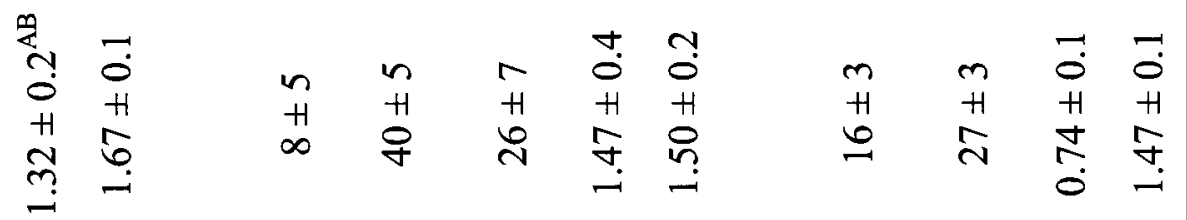

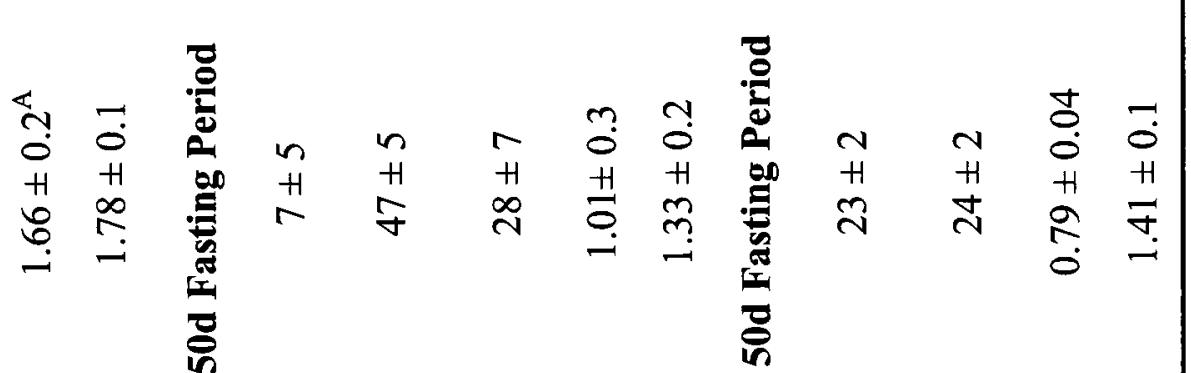

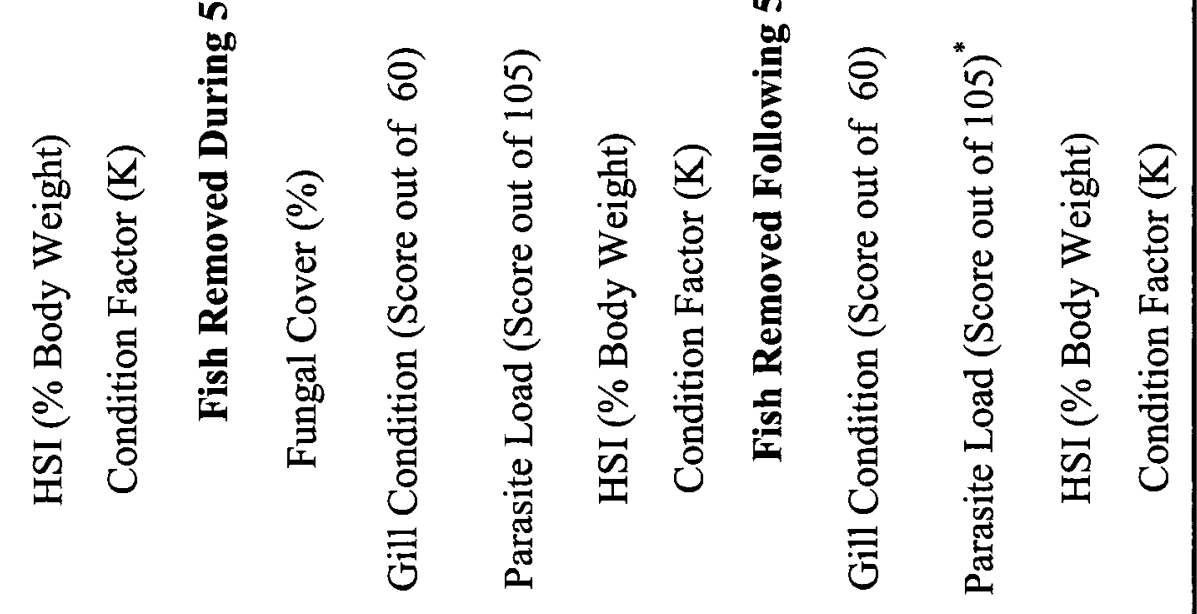



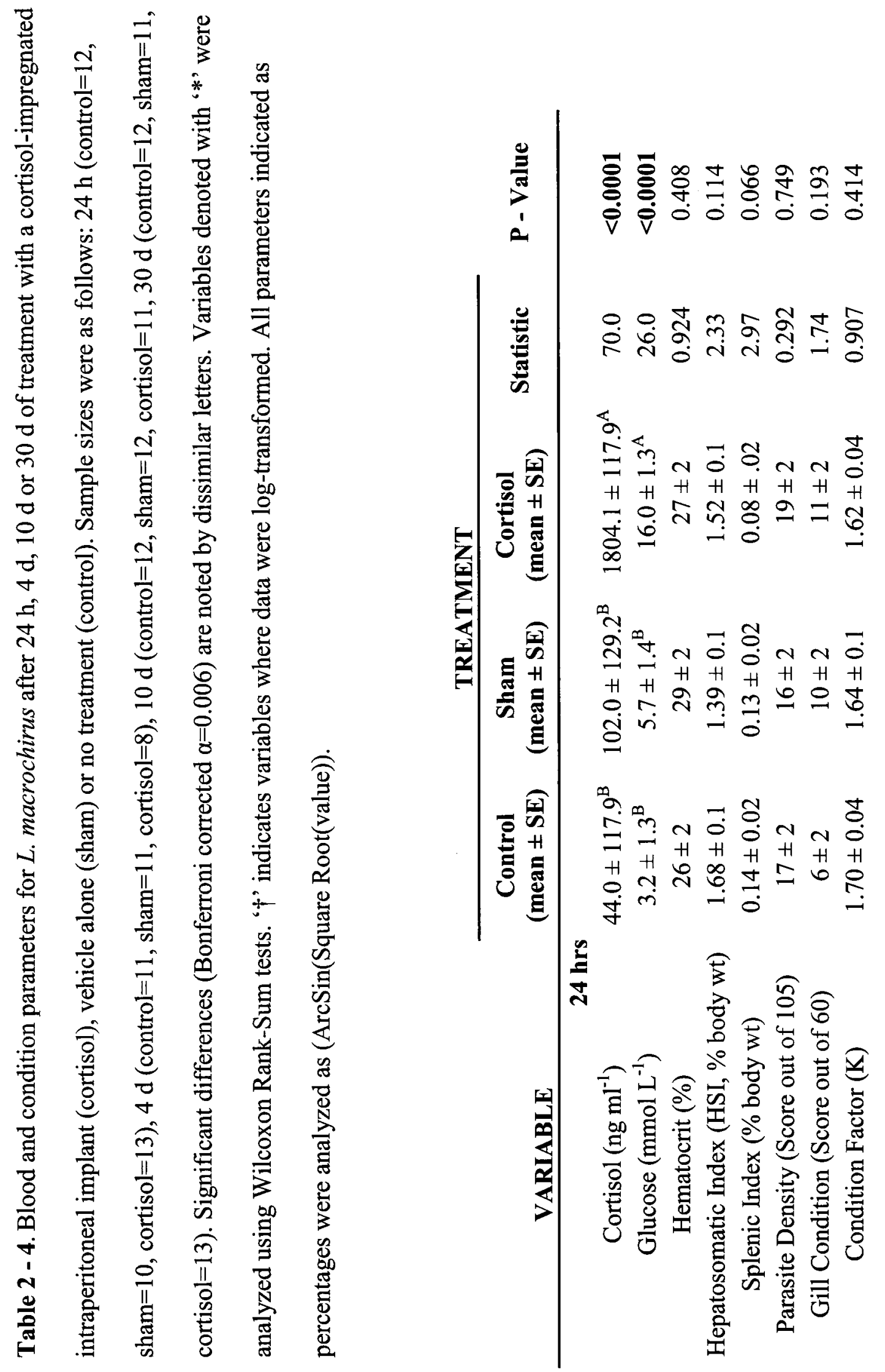


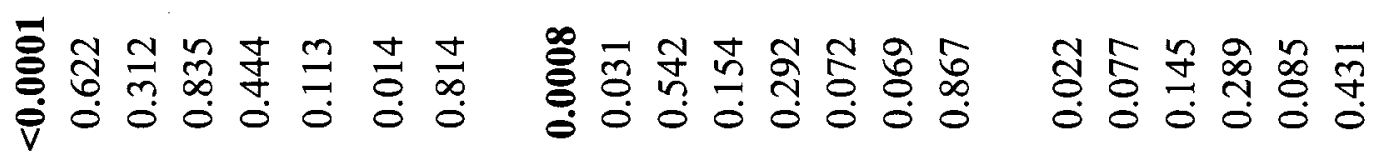

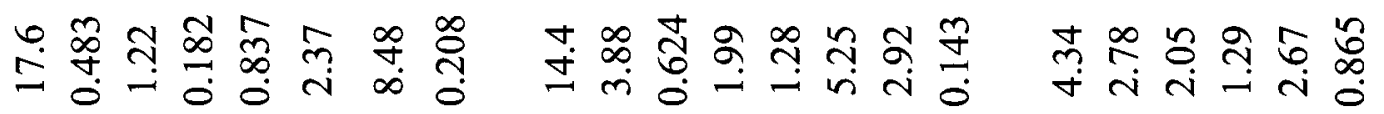

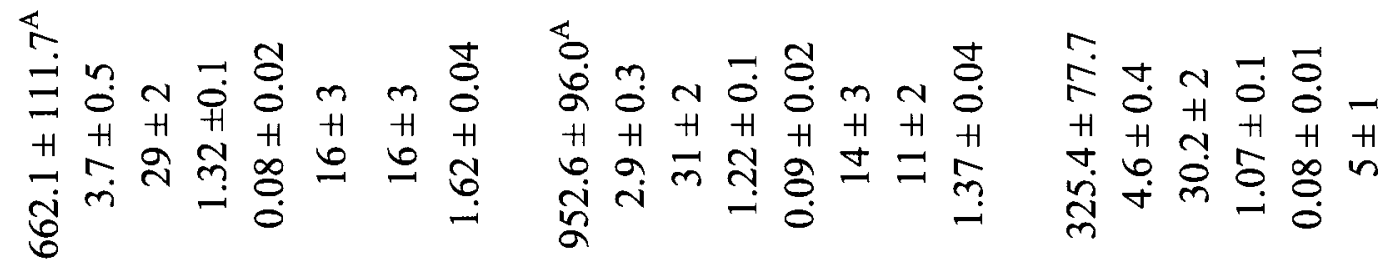

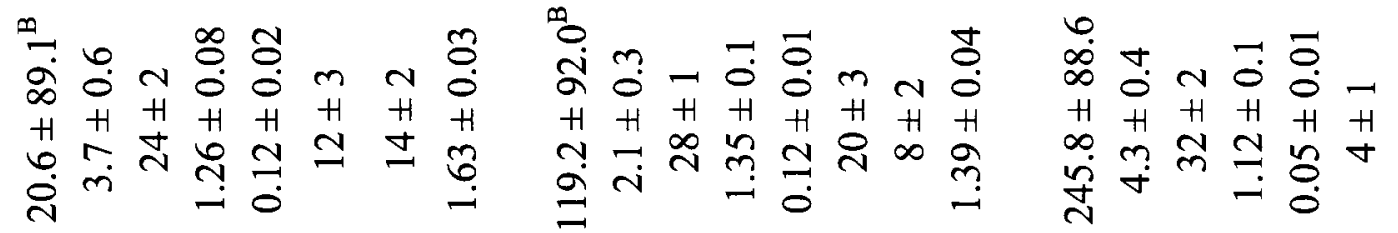

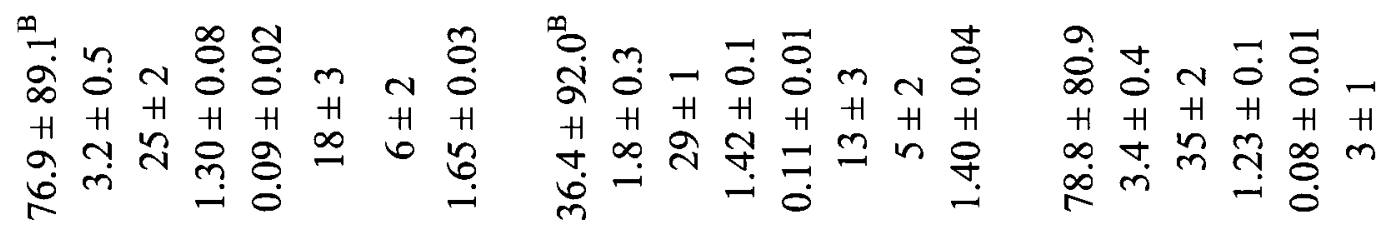

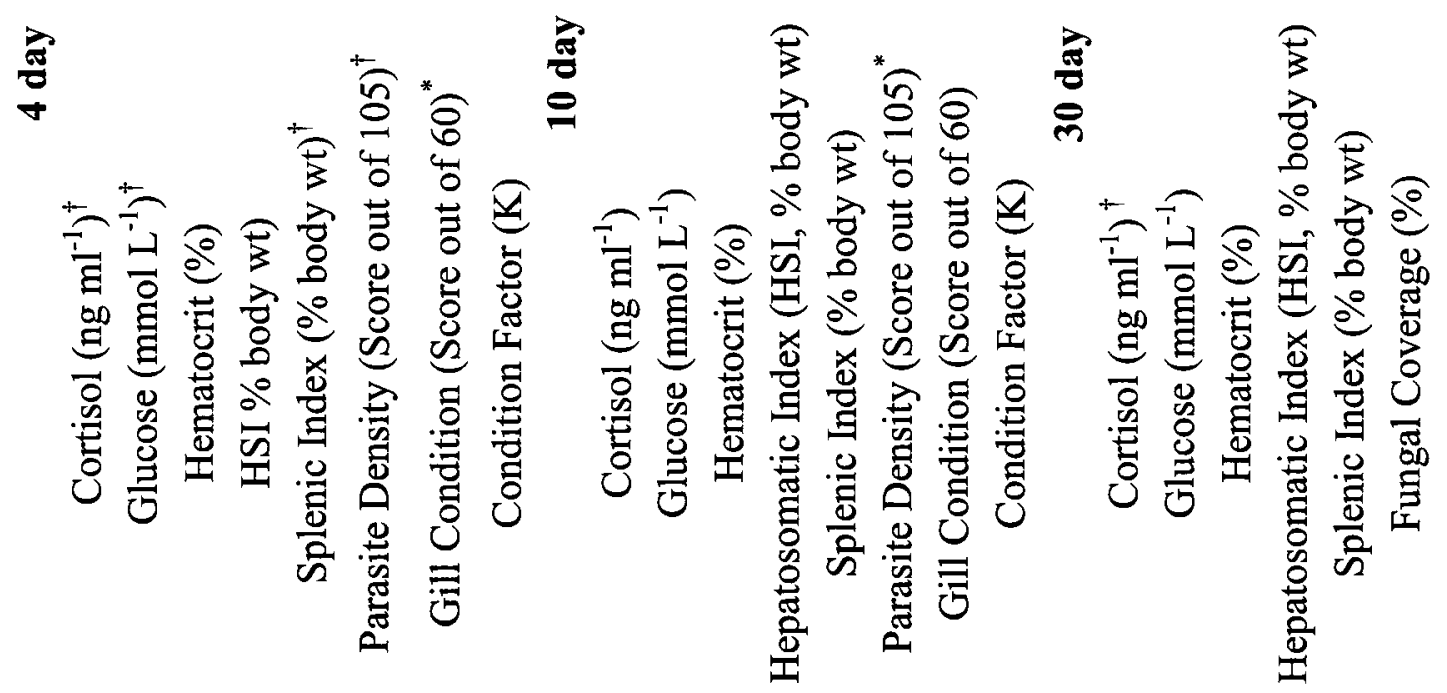




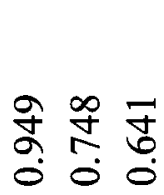

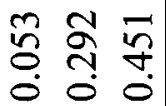

$m m \overrightarrow{0}$

$\mathrm{H} H \mathrm{H}$

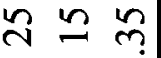

$\checkmark m 0$

$\mathrm{H}+\mathrm{H}$

귀ำ

$m$ m

ㅊ

초

ริ)

फ

当 䓂

苞

곻흐음

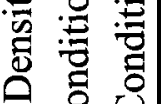

¿

营

त

$$
\text { . }
$$

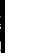



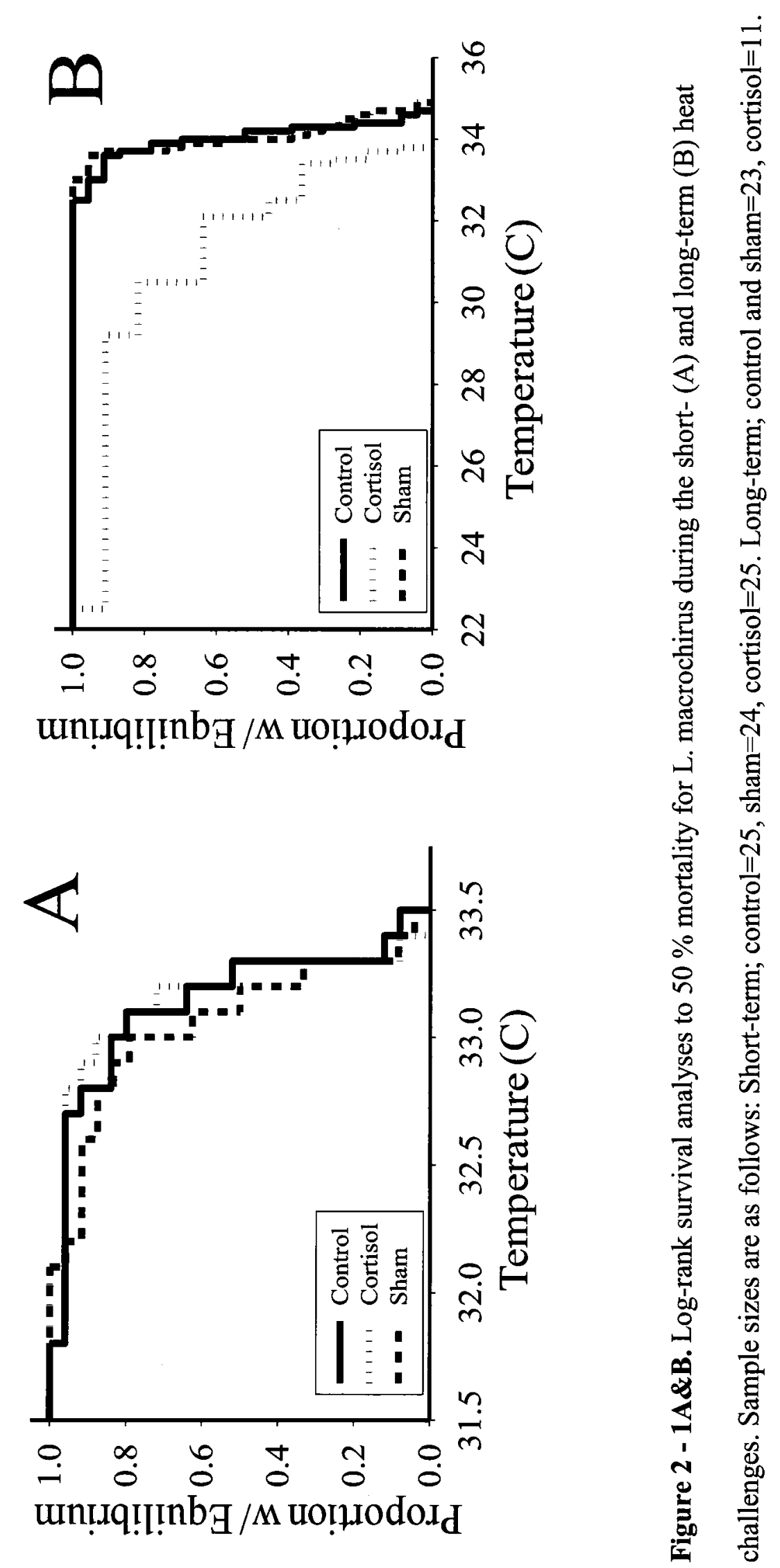


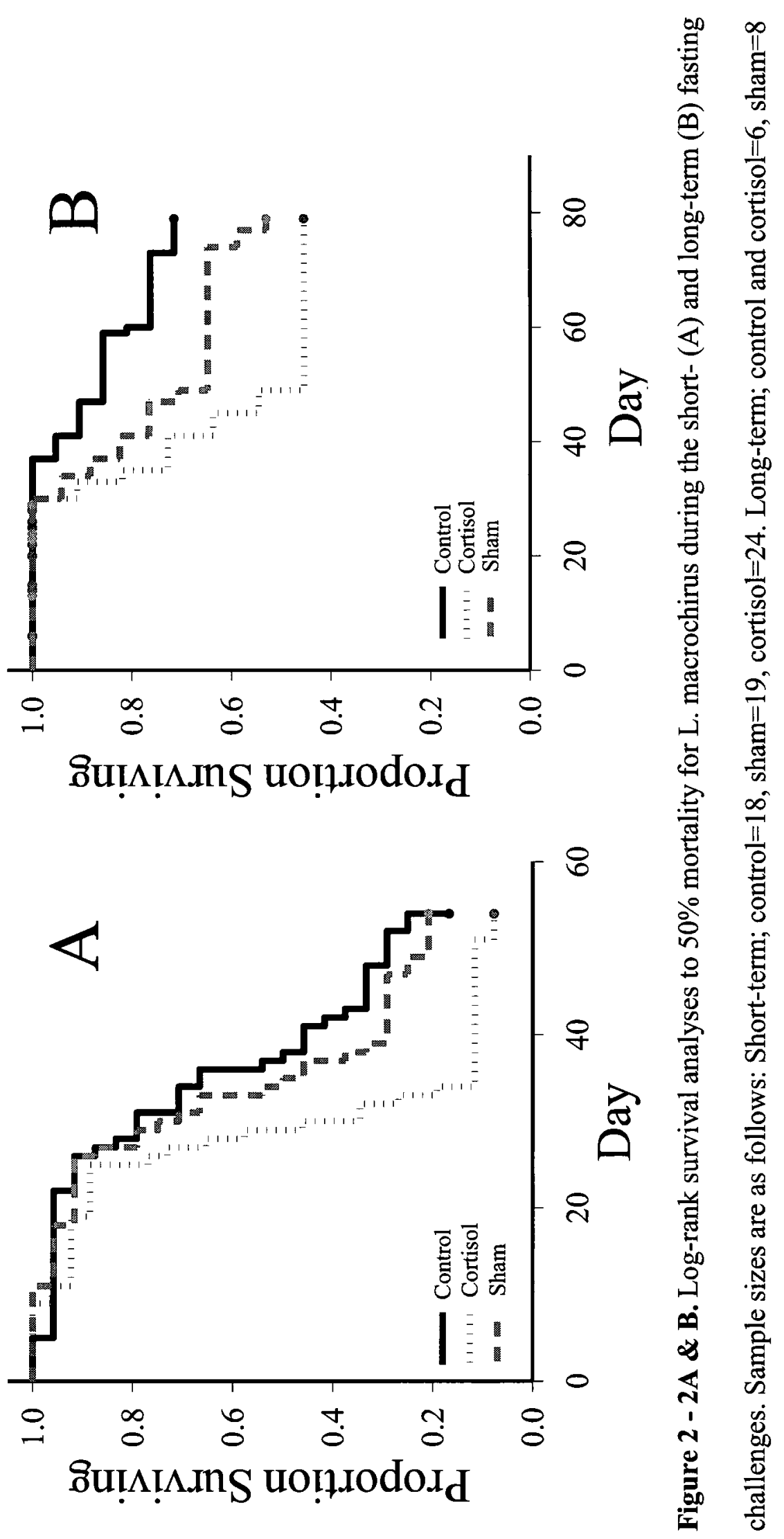




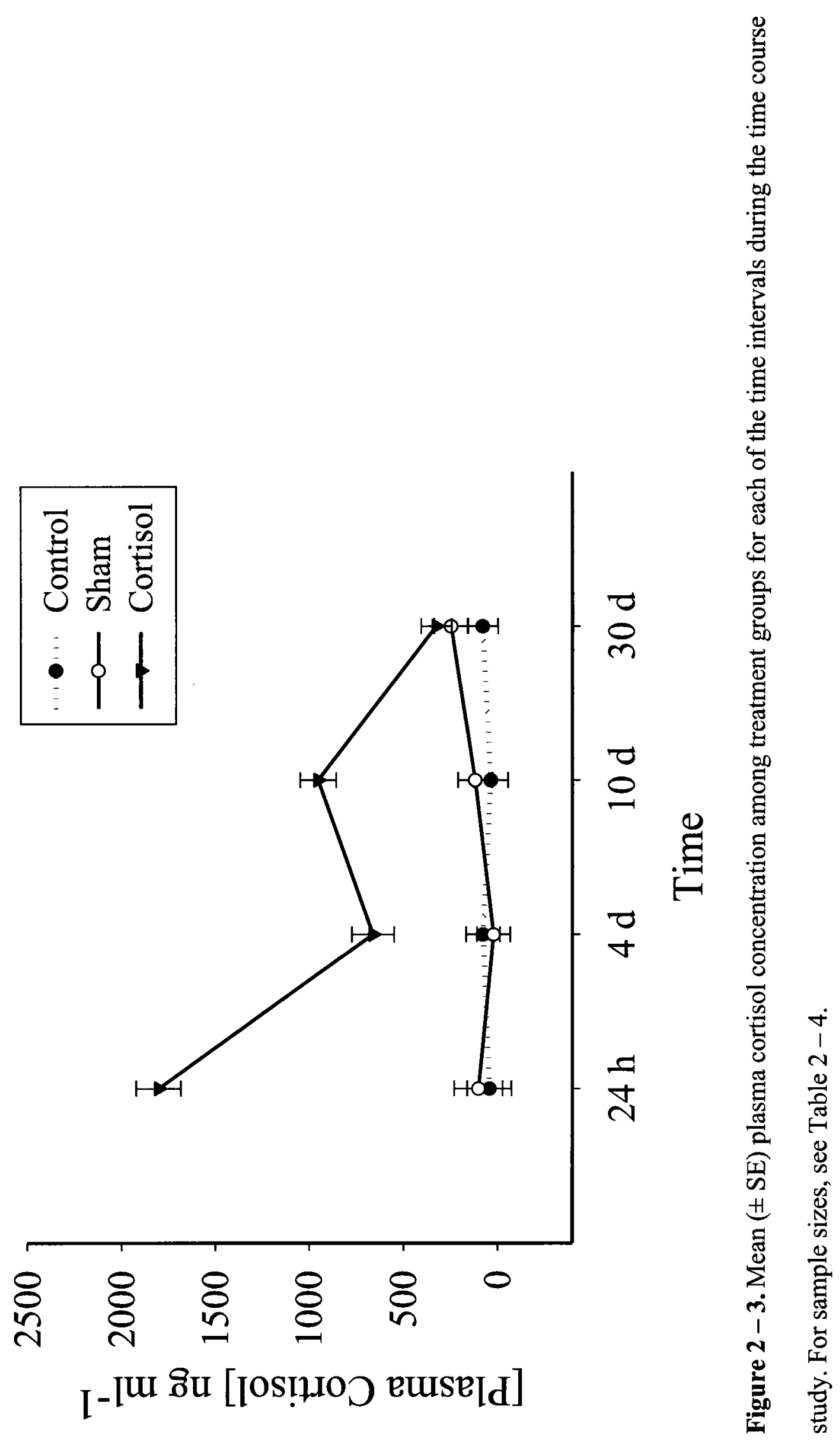




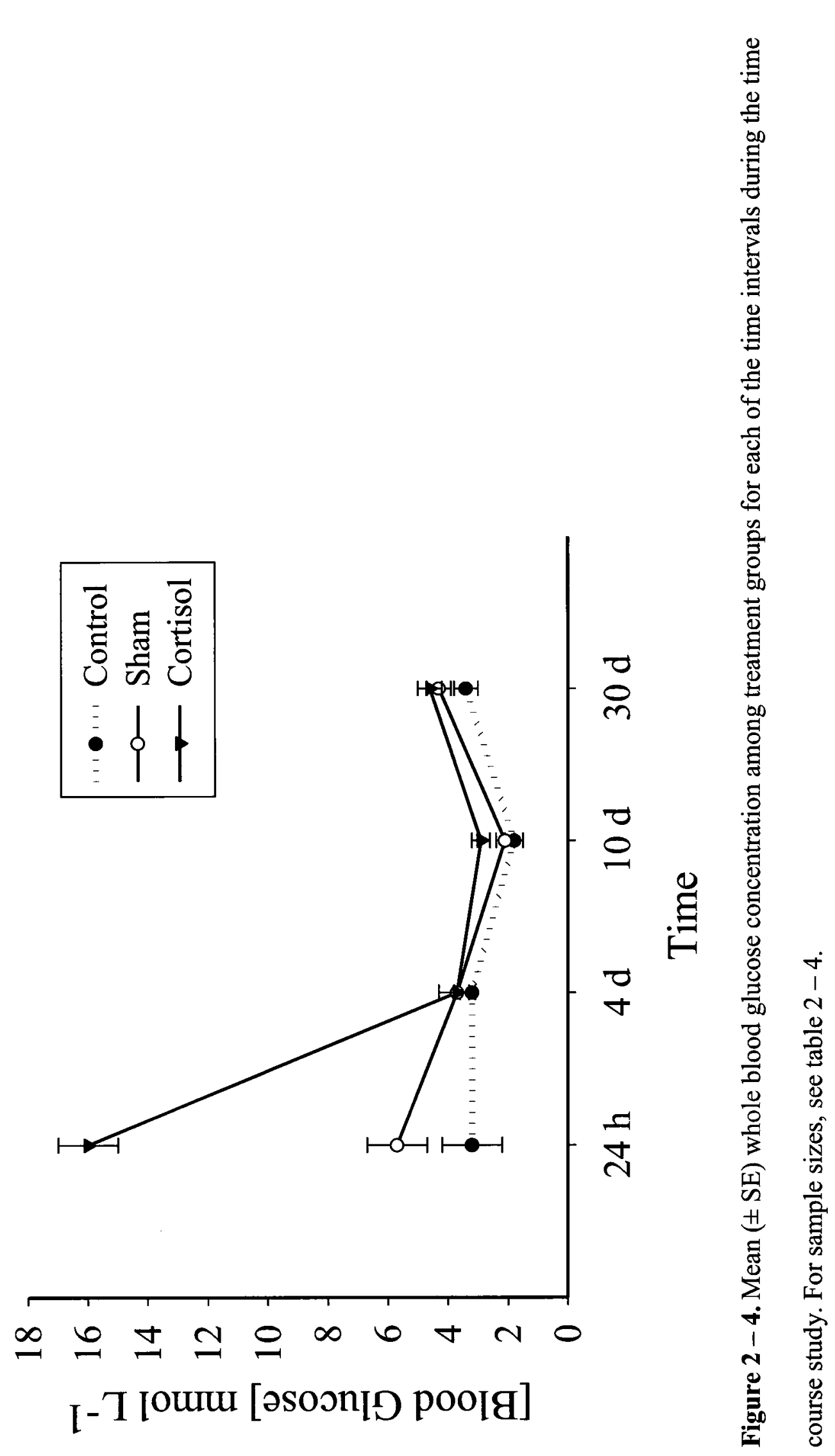




\section{Chapter 3: Understanding the Consequences of Stress and Cortisol Elevation on the Behaviour and Fitness of Spawning Pink Salmon (Oncorhynchus gorbuscha).}

Abstract

Challenging conditions during upriver migrations for semelparous Pacific salmon (Oncorhynchus spp.) can result in elevated cortisol levels which correspond with decreases in reproductive hormones, potentially impairing gonadal development. Based on life-history theory one would predict that the stress response in semelparous salmon would be muted during this period to maximize fitness. However, cortisol levels are elevated on spawning grounds in populations that successfully reproduce. Thus the relationships between cortisol and reproduction are unclear for semelparous salmon on their spawning grounds. Using adult female pink salmon (O. gorbuscha) with varying degrees of ovulation (i.e., ripe and unripe) as a model, we determined how varying degrees of stress affected behaviour and fitness on the spawning grounds. The acute stressors were exhaustive exercise and air exposure. Cortisol and metyrapone (corticosteroid synthesis inhibitor) implants were also used to evaluate how cortisol influences reproductive hormones, behaviour, and success in behavioural arenas and for free-swimming fish in a spawning channel. Neither the acute stressors nor the metyrapone implant had any significant negative impacts on reproductive success and behaviour. However, elevating cortisol negatively influenced reproductive success because cortisol-treated fish released fewer eggs and died sooner than fish in other treatment groups. None of the treatments resulted in alteration of physiological condition, other than the cortisol status, or reproductive hormone status. In addition, the state of ovulation influenced outcomes predictably, with ripe fish more likely to spawn. Findings 
are consistent with life history theory and the idea that when exposed to stressful situations upon arrival at spawning grounds, semelparous animals should allocate resources to reproduction rather than entering an emergency life-history phase.

\section{Introduction}

In general, there is much evidence supporting the notion that stress, through a negative feedback loop, can impair reproductive outcome of a wide range of taxa including birds (Silverin, 1986; Wingfield, 1988), reptiles (DeNardo \& Sinervo, 1994a \& b), mammals (Negro-Vilar, 1993; Boonstra et al. 1998) and fish (Pickering et al. 1987; Schreck et al.2001). Although the acute stress response and associated elevation of glucocorticoids is believed to be adaptive, chronic elevations in glucocorticoids in particular can result in a variety of negative tertiary effects including impairments in immune function and fitness as resources are directed towards an emergency life-history phase (Barton \& Iwama, 1991; Wingfield et al. 1998; Barton, 2002; Wingfield, 2003) as animals attempt to regain allostasis (Wingfield, 2003; Schreck, 2010). However, much of the existing work related to the effects of stress on reproduction is focused on long-term impacts on animals at non-reproductive periods rather than effects of exposure to stress immediately before or during reproduction. For example, numerous toxicological studies have demonstrated direct long-term reproductive impairments (e.g., suppression of reproductive hormones) and the reallocation of resources to maintenance and survival (e.g., reviewed in Van Der Kraak et al. 1998; see also Jardine et al. 1996; Janz et al. 1997; Bowron et al. 2009). In addition, those studies focused on the relationship between stress and reproduction are often limited to repeat-breeders (iteroparous species). 
In contrast to repeat-breeders are those animals that invest in reproduction once in a lifetime (semelparous species). For semelparous Pacific salmonids (Oncorhynchus $s p p$.), virtually nothing is known about whether exposing fish to stress at spawning grounds influences behaviour and reproductive success. The acute stress response remains active and cortisol concentrations can become elevated beyond background during the spawning migration, especially in situations when fish encounter hydraulic challenges and increased water temperatures. For example, Hinch et al. (2006) found that increased cortisol levels during a challenging component of the spawning migration can depress reproductive hormone levels, potentially impairing gonad development and thus reproductive success. However, it seems that the presence of cortisol is not solely related to challenging situations. For example, cortisol levels are elevated in on the spawning grounds (McBride et al. 1986; Hinch et al. 2006), increasing from their arrival (female pink salmon: $\sim$ mean $75 \mathrm{ng} \mathrm{ml}^{-1}$ ) to when the fish have reproduced (female pink salmon: $\sim$ mean $252.8 \mathrm{ng} \mathrm{ml}^{-1}$ ) (McBride et al. 1986).

Based on life-history theory, one might postulate that the stress response of semelparous salmon would be muted during this period to maximize fitness (Wingfield \& Sapolsky, 2003), while mitigating the negative effects of cortisol on reproduction. Indeed, a stressed state should be incompatible with reproduction. However, Carruth et al. (2002) proposed that this increase of cortisol during migration is adaptive and necessary for salmon to be able to return to their natal streams and therefore increases fitness. The interactions of corticosteroid function in fish reproduction is mostly unknown, but there is some suggestion that it may play a role in the maturation of oocytes in females (Milla, 2009). Additionally, Pacific salmon on spawning grounds are 
also entering their senescent phase where many physiological processes, such as hormone regulation, are altered as a result (Morbey et al. 2005; Hruska et al. 2007, Hruska et al. 2010). We are currently unaware of any attempts to manipulate cortisol levels in wild semelparous fish immediately prior to spawning to elucidate the role of cortisol on the spawning grounds.

The focus of this study was to determine how acute and chronic glucocorticoid challenges influence the physiology, behaviour and fitness of female pink salmon (Oncorhynchus gorbuscha) on spawning grounds. We do understand the progression of sex hormone values on Pacific salmon spawning grounds (Dye et al. 1986), but what is unclear is how cortisol interacts with reproductive hormone values at this time. Specifically, we predicted that a chronic cortisol elevation, achieved by an implant, would negatively affect reproductive behaviour, physiology and success. We also predicted, with accordance to life history theory, that the stress response would be muted when semelparous salmon were exposed to acute stressors during their only chance to spawn. In addition, it was hypothesized that cortisol plays an important role during reproduction and blocking cortisol synthesis to prevent cortisol elevation and/or lower cortisol values would elicit alterations in reproductive behaviour, physiology and/or success. Female pink salmon were acutely stressed through exposure to exhaustive exercise or air exposure. Fish in other treatment groups were given an intraperitoneal injection of cortisol to elicit a chronic elevation of cortisol. Additionally, salmon were exposed to an intraperitoneal implant of metyrapone, which blocks the last step of glucocorticoid synthesis, thus lowering cortisol levels (Doyon et al. 2006). We conducted a validation study to determine how treatments influenced blood physiology parameters 
after 24 hours. We performed two field experiments focusing on behaviour and fitness to determine the effects of different challenges on fish immediately prior to spawning in arenas and in a spawning channel where fish were unrestrained.

\section{Materials and Methods}

All fish were handled in accordance with the guidelines of the Canadian Council on Animal Care (Carleton University, B09-12). Before the field study took place, a pilot experiment was conducted in the laboratory to determine the effectiveness of metryapone (2-Methyl-1, 2-di-3-pyridyl-1-propanone; Sigma 85625, Sigma-Aldrich) delivered in a cocoa butter implant in blocking cortisol synthesis. Metyrapone has been used previously in fish to block cortisol synthesis in the short-term (e.g., Hopkins et al. 1995; Milligan, 2003; Rodela et al. 2009), but has rarely been used with a cocoa butter carrier (Doyon et al. 2006). Rainbow trout (Oncorhynchus mykiss) weighing approximately $150 \mathrm{~g}$ were anesthetised with benzocaine $\left(0.05 \mathrm{mg} \mathrm{m}^{-1}\right.$ water; $\mathrm{p}$-aminobenzoic acid ethyl ester; Sigma E1501, Sigma-Aldrich) and injected intraperitoneally with a cocoa butter and metyrapone implant (200 $\mathrm{mg} \mathrm{kg}^{-1}$ fish; $1 \mathrm{ml}$ cocoa butter $\mathrm{kg}^{-1}$ fish). The fish were stressed for $1 \mathrm{~min}$ with air exposure to elicit a cortisol response at $24 \mathrm{~h}$ and $5 \mathrm{~d}$ after implant administration, and blood sampled $30 \mathrm{~min}$ later to determine if cortisol synthesis had been blocked.

The following experiments were conducted at the Weaver Creek Spawning Channel in British Columbia, Canada (see Quinn, 1999 for detailed information). Sampling was timed for the arrival of Pink Salmon migrating up the Fraser River to their spawning grounds throughout October 2009. Movement of fish into the channel is 
regulated through the use of a raceway and manually operated gates. Female salmon were obtained individually via dip net from the raceway upon arrival at the spawning channel and were immediately placed in a trough supplied with water from the raceway (flowthrough). A blood sample was collected (via caudal puncture $-2 \mathrm{ml}$ blood sample using $3 \mathrm{ml}$ vacutainer and 1.5", $18 \mathrm{~g}$ needle, lithium heparin; Becton Dickson, NJ) and fish were tagged through the dorsal musculature using individually recognizable Peterson disc tags. All blood samples taken from the raceway were analyzed to determine if fish were in good condition. Each fish was checked for "ripeness" by gently pressing their abdominal cavity near their vent to determine if eggs were easily expelled (sexual maturity as indicated by presence or absence of free flowing eggs in the abdominal cavity which occurs after ovulation) and categorized as either "unripe" (unovulated) or "ripe" (ovulated). After tagging, fish were randomly subjected to one of six treatment groups; two types of acute stressors or two hormone manipulations as follows: a 3 min continuous chase where fish were chased by hand in a circular tank supplied with flow through water (chase); a 3 min chase followed by 1 min of air exposure (chase +1 ); an intraperitoneal injection of cortisol (hydrocortisone 21-hemisuccinate; Sigma H4881, Sigma-Aldrich) and cocoa butter (110 $\mathrm{mg} \mathrm{kg}^{-1}$ fish; $50 \mathrm{ml}$ melted cocoa butter kg $\mathrm{kg}^{-1}$ fish) (cortisol); and an intraperitoneal injection of metyrapone (sigma) and cocoa butter (200 $\mathrm{mg} \mathrm{kg}^{-1}$ fish; $1 \mathrm{ml}$ cocoa butter $\mathrm{kg}^{-1}$ fish) (metyrapone). In addition, control fish which were only blood sampled and tagged, and sham controls (as an injection control), which were given an injection ( $50 \mathrm{ml}$ per $\mathrm{kg}$ of fish) of melted cocoa butter intraperitoneally (sham) were included in the experimental design. 
Raceway Blood Physiology and Cortisol and Metyrapone Validation

All blood samples collected from fish immediately after removal from the raceway were compared between ripe and unripe fish to evaluate the physiological and hormone status of fish prior to experimentation. Additionally, to provide context for the consequences of the hormone treatments after $24 \mathrm{~h}$, we obtained a subset of fish that were removed from the raceway and placed into individual opaque experimental chambers supplied with a constant flow of channel water. After $24 \mathrm{~h}$, these fish were removed from the chambers individually and blood samples were collected as described above. Whole blood was centrifuged for $5 \mathrm{~min}$ at $10,000 \mathrm{~g}$ and the plasma was frozen in liquid nitrogen immediately, then transferred to an ultra-cold $\left(-80^{\circ} \mathrm{C}\right)$ freezer until further analysis.

Experiment 1: Channel Longevity and Reproductive Success

On October $6^{\text {th }}$ and $7^{\text {th }} 2009,120$ unripe pink salmon ( $N=20$ per treatment group) were individually collected from the raceway and processed as described above, except blood samples were not collected. After being tagged, each fish was randomly assigned to one of our six treatment groups and then released into the spawning channel. Following their release into the channel, constant monitoring of the channel commenced to ensure that moribund or dead fish would be collected from the channel on the same day that death occurred. When a dying or dead fish was discovered, it was retrieved and immediately dissected. Longevity was documented as the time the fish spent in the channel following initial treatment (Hruska et al. 2010). Fork length, total mass and gonad weights were 
recorded. Fungal cover and general condition parameters were also documented. Often, the fish had spawned out all of their eggs, but when eggs were present they were usually loose within the body cavity. Remaining eggs were weighed in five groups of 10 eggs, and then the remaining eggs were weighed collectively. Since individual egg mass has been found to be uniform within an individual (D. Patterson, personal communication), this method provided an accurate estimate of the number of eggs retained by each fish without having to count every egg. Prior to this experiment, we weighed and counted eggs in whole ovaries in a subset of unripe pink salmon obtained from the raceway. The mass to fork length relationship and fork length to gonad mass was linear for unripe female pink salmon, thus it was easy to predict what each individual fish's gonads weighed before spawning. In addition, our egg weights informed us as to the amount of eggs each fish should have before ovulation and spawning. This egg value was used to determine the percentage of eggs released while fish were in the channel.

\section{Experiment 2: Net-Pen Behaviour Observations}

This experiment was broken into two phases. The first included fish that entered the raceway unripe, whereas the second only including fish that were ripe prior to experimentation. Fish were obtained from the raceway as described above, blood sampled and were transferred to a holding tank and transferred from the raceway to a netpen within the channel, constructed out of Vexar (Masternet, Mississauga, Ontario) that was $2 \mathrm{~m}$ wide and $15 \mathrm{~m}$ long. Twenty male pink salmon that released sperm when squeezed gently near their vent (signifying reproductive maturity) were placed into the 
net-pen $12 \mathrm{~h}$ before experimentation. We placed fewer males than females in the net pen to increase competition between females to determine if our treatments influenced time spent with ripe males. Fish ( $\mathrm{N}=5$ per treatment) were treated as described above and immediately transferred to the net-pen. Fish remained in the net-pen for $4 \mathrm{~d}$ and each fish was observed individually for 10 min each day so detailed behavioural observations could be made. The order of observation was randomly chosen each day. Female pink salmon reproductive behaviours are well known, and are similar to behaviours displayed by other semelparous Pacific salmon (Heard, 1991; Mehranvar et al. 2004). To be successful, female fish display specific reproductive behaviours that are used to prepare their nesting area; they also fend off intruders from their territory through aggressive action, and spend time with males to ensure fertilization occurs. To this end, we recorded what day fish established a territory, how much time they spent holding that territory (represented as a percent, averaged over days on territory), what percentage of their time females spent with males (averaged across days on established territory), the number of nest construction digging behaviours occurred (averaged across days spent on a territory), how many times a fish made an aggressive display towards a conspecific and how many times that fish was on the receiving end of an aggressive act (both summed and divided by total observation minutes and subtracted from each other to yield an overall aggression score). After $4 \mathrm{~d}$, fish were rounded up, netted and culled in a process lasting no longer than $10 \mathrm{~min}$ overall. Each fish was sacrificed using cerebral percussion and then immediately blood sampled. After blood sampling, each fish was dissected following methods from the channel experiment, to determine egg retention. This 
experiment was repeated in quadruplicate throughout the course of October 2009; twice with unripe fish in early October and twice with ripe fish in late October.

Sample Analysis

Plasma glucose and cortisol were measured following methods outlined by Farrell et al. 2001. Briefly, plasma glucose values were determined using a YSI 2300 STAT Plus glucose analyzer (YSI Inc., yellow Springs, Ohio). Cortisol was measured by the Environmental Watch Laboratory (Department of Fisheries and Oceans, Canada) using a commercial ELISA kit (Neogen Co., Lexington Ky.). Cortisol values were measured to test the validity of our hormone treatments and were also used as a measure of stress and HPI axis activity during maturation/senescence in all of our experimental fish. Glucose was measured as an indicator of an immediate response to stress. Plasma testosterone and 17 beta-estradiol were measured by radioimmunoassay (McMaster et al. 1992).

Testosterone and 17 beta-estradiol are both major reproductive hormones that respond predictably to maturation and ovulation (both decrease after ovulation).

Statistical Analysis

Results from the metyrapone pilot study were analyzed using a two-way analysis of variance (ANOVA) to determine if cortisol values varied by treatment and treatment day. Results from the cortisol and metyrapone validation study before and after $24 \mathrm{~h}$ were compared using one-way ANOVA models with repeated measures. For experiment 1 , 
longevity among treatment groups was compared using a log-rank survival analysis. The percentage of eggs released by each fish was averaged among groups and compared using a one-way ANOVA. For experiment 2, all hormone and blood physiology values and behavioural metrics were compared before and after $4 \mathrm{~d}$ using one-way ANOVA models with repeated measures. Time until territory establishment was determined using log-rank survival analyses. The percentage of eggs released by each fish was averaged for each treatment group and compared using a one-way ANOVA. Tukey's post-hoc tests were employed following significant one-way ANOVAs to determine differences among groups. The assumptions of equality of variances and normal distribution were tested for all analyses and relevant transformations applied where assumptions could not be met. For those data not able to be transformed, non-parametric analyses were performed. All analyses were performed using JMP, version 8.0.2 (SAS Institute Inc., Cary, NC). The level of significance for all tests $(\alpha)$ was assessed at 0.05 . All data are presented as mean \pm standard error unless otherwise noted.

\section{Results}

Pilot Experiment

Analyses (see below for cortisol assay details) revealed that metyrapone in a cocoa butter carrier blocked cortisol synthesis after $24 \mathrm{~h}$, but by $5 \mathrm{~d}$ the effect was attenuated (Figure 3-1). 
Raceway Blood Physiology and Hormone Validations

Glucose and cortisol values were comparable for both unripe and ripe fish (Table 3-1). Estradiol was significantly higher for unripe fish $\left(4.5 \pm 0.3 \mathrm{ng} \mathrm{ml}^{-1}\right)$, than for ripe fish $(0.28 \pm 0.3)(F=70.4, d f=1, p<0.001)$. Similarly, testosterone was significantly higher for unripe fish $(150 \pm 13)$, than for ripe fish $(63 \pm 12)(F=24.8, d f=1, p<0.001)$.

For unripe fish in sensory deprivation chambers, injection of cortisol elevated plasma cortisol levels by 10 -fold after $24 \mathrm{~h}\left(208 \pm 42\right.$ pre-treatment to $\left.2034 \pm 136 \mathrm{ng} \mathrm{ml}^{-1}\right)$. Metyrapone-treatment had no effect on plasma cortisol levels (304 \pm 42 pre-treatment to $313 \pm 136 \mathrm{ng} \mathrm{ml}^{-1}$ post-treatment) (more data forthcoming for unripe control fish) (Table 3-2). Neither cortisol injection nor metyrapone treatment significantly altered reproductive hormone titres.

The responses of the ripe fish were qualitatively similar and cortisol-injection increased plasma cortisol to about half of the level seen in unripe fish ( $310 \pm 70$ to $1084 \pm$ $144 \mathrm{ng} \mathrm{ml}^{-1}$ ). None of the treatments caused any detectable changes in reproductive hormone titres (Table 3-2). In view of these results, we assumed that, after $24 \mathrm{~h}$ in the channel longevity experiment, injection of cortisol elevated plasma cortisol without affecting reproductive hormone profiles.

\section{Channel Longevity and Reproductive Success}

Cortisol treatment influenced mortality as fish spent less time in the channel than all other treatment groups (Log-rank survival analysis to $50 \%$ mortality; $\lambda^{2}=13.1, \mathrm{df}=5, \mathrm{p}=0.023$ ) 
(Figure 3-2). It also significantly reduced percent eggs release: $47 \%$ for cortisol-treated fish $69 \%$ for sham-treated fish at $69 \%$ and $>85 \%$ for all other groups $(F=13.4, \mathrm{df}=5$, $\mathrm{p}<0.001$ ) (Figure 3-3).

\section{Net-Pen Behaviour Observations}

Unripe fish: No differences were observed regarding ovulation by treatment group by $4 \mathrm{~d}$ (Figure 3-4A). For those fish that had matured and so were able to spawn, the percentage of eggs released among treatments differed significantly (Figure 3-4B). Control and chase-treated fish released more than $80 \%$ of their eggs, chase +1 and cortisol-treated fish released between 50 and $80 \%$, and metyrapone and sham-treated fish released fewest eggs $\left(<10 \%\right.$ ) (Wilcoxon Rank Sum; $\lambda^{2}=11.2, \mathrm{df}=5, \mathrm{p}=0.047$ ). Reproductive hormone profiles for unripe fish did not differ among groups (Table 3-3). Cortisol values remained elevated $4 \mathrm{~d}$ after cortisol-treatment $\left(712 \pm 73 \mathrm{ng} \mathrm{ml}^{-1}\right)$ relative to controls $(262 \pm 77 \mathrm{ng}$ $\mathrm{ml}^{-1}$ ). Glucose values were also elevated when fish were sampled 4 days after treatment in all treatment groups. Estradiol and testosterone decreased as expected over the $4 \mathrm{~d}$ period (Table 3-3). There were no differences in how long it took fish in different treatment groups to establish territories (log-rank survival analysis; $\lambda^{2}=2.37, \mathrm{df}=5$, $\mathrm{p}=0.841$ ). Based on behavioural observations recorded from fish that were on an established territory, cortisol-treated fish spent $10 \%$ less of their time holding on their territory when compared with controls $(\mathrm{F}=12.3, \mathrm{df}=5, \mathrm{p}=0.031)$. Additionally, cortisoltreated fish were much less aggressive and experienced more aggressive acts by others when compared to fish in all other treatment groups $(F=12.7, \mathrm{df}=5, \mathrm{p}=0.054)($ Table 3-4). 
Ripe fish: Percent of eggs released by treatment group included low values for cortisol, around $50 \%$, and $>70 \%$ for all other groups, although the differences were not significant (Figure 3-5). Hormone profiles are outlined in Table 3-5. Testosterone levels decreased predictably and estradiol levels remained consistently low. Glucose values increased over the $4 \mathrm{~d}$ period. For this experiment, cortisol levels were elevated for cortisol-treated fish after 4 days. However, cortisol levels were elevated when compared to fish at the initiation of the experiment for all groups. Control, sham and cortisol-treated fish all had cortisol values greater than $1000 \mathrm{ng} \mathrm{ml}^{-1}$ and the other treatment groups had values less than 1000 but greater than $500 \mathrm{ng} \mathrm{ml}^{-1}$. No behavioural differences were observed among the treatments groups for ripe fish (Table 3-6).

\section{Discussion}

We predicted, in accordance with life history theory, that when semelparous salmon are exposed to acute stressors during their only chance to spawn, they will not respond to the stressor in such a way as to impair reproduction. Pink salmon responded according to life-history theory (Sapolsky et al. 2000; Wingfield \& Sapolsky, 2003) and did not alter reproductive behaviour, physiology or success after exposure to acute stress (i.e., did not enter an emergency life-history phase; Wingfield et al. 1998; Wingfield, 2003). We also predicted that a chronic cortisol elevation, achieved by an implant, would negatively affect reproductive behaviour, physiology and success. The results of the cortisol injections, which increased cortisol by 2 - to 10 -fold, clearly illustrated the importance of suppressing this acute response. Elevating cortisol levels for up to 4 days decreased 
longevity and reproductive success in ripe and unripe fish, as well as altering reproductive behaviours. The metyrapone treatment did not alter reproductive hormones, behaviour or success. This finding verifies, using a field approach, that cortisol has an important role in the process of final maturation and senescence. To our knowledge, the above experimental hormone manipulations are among the first to be conducted on wild semelparous fish during their reproductive period.

Physiological condition of fish at spawning ground arrival - ripe vs. unripe

The net-pen experiments were separated by unripe and ripe fish. Both groups had cortisol levels above $\left(>250 \mathrm{ng} \mathrm{ml}^{-1}\right)$ typical baseline levels for pink salmon $\left(\sim 65 \mathrm{ng} \mathrm{ml}^{-1}\right.$ at a mainstream lower Fraser River sampling location, D. Patterson, personal communication), but similar to levels detected after an acute stressor and on spawning grounds in this species and other Pacific salmon (McBride et al. 1986; Barton, 2002; Carruth et al. 2002; Hinch et al. 2006; Hruska et al. 2010). Cortisol levels also increased as fish became ripe, whereas as plasma testosterone and 17 beta-estradiol decreased. These changes were expected based of previous observations that reproductive hormone values fall steadily after reaching their peak before arrival at spawning grounds (Dye $e t$ al. 1986). 
Cortisol manipulation and reproductive hormones

In a variety of fish species it has been documented that elevation of glucocorticoids results in decreased reproductive hormone concentrations (see review by Barton \& Iwama, 1991). In addition, a stressful reproductive environment negatively impacts reproductive fitness in various ways (e.g., fish exposed to bleached kraft pulp mill effluent; Jardine et al. 1996; Janz et al. 1997; Bowron et al. 2009). In the case of Pacific salmon exposed to a hydraulic challenge at Hell's Gate fishway, hormone titres decrease dramatically (11-Ketotestosterone drops from $\sim 20 \mathrm{ng} \mathrm{ml}^{-1}$ to under $5 \mathrm{ng} \mathrm{ml}^{-1}$; estradiol drops from $6 \mathrm{ng} \mathrm{ml}^{-1}$ to $3 \mathrm{ng} \mathrm{ml}^{-1}$; testosterone drop from $\sim 50 \mathrm{ng} \mathrm{ml}^{-1}$ to under $25 \mathrm{ng} \mathrm{ml}^{-1}$ ) while cortisol levels are increased $\left(\sim 700 \mathrm{ng} \mathrm{ml}^{-1}\right)$. Further upstream, where the river is less challenging reaches, normal cortisol is restored $\left(\sim 100 \mathrm{ng} \mathrm{ml}^{-1}\right)$ and reproductive hormone levels return to their elevated level (Hinch et al. 2006). Prior to the present study, the potential interaction between cortisol and reproductive hormones in salmon on their spawning grounds had not been investigated. Data generated here differ dramatically from the pattern observed at Hell's gate and with stress in general in fishes. The raceway blood profiles and the hormone validation verified that neither the metyrapone nor the cortisol treatment altered reproductive hormone titres in any way in either unripe or ripe fish. Cortisol titres in cortisol-treated fish were increased to levels observed in moribund, senescing salmon (Stein-Behrens \& Sapolsky, 1992; Hruska et al. 2010; Barry et al. 2010).

Collectively, these data are consistent with life-history theory where it has been proposed that the stress response of semelparous animals would be muted during the final 
phases of reproductive preparedness such that they can focus on maximizing fitness (Wingfield \& Sapolsky, 2003). In the case of Pacific salmon, it is unclear exactly when such a transition takes place during the migration because in mainstem riverine habitats cortisol does indeed result in suppression of reproductive hormone titres yet upon arrival at spawning grounds, it does not. Because we did not observe any differences between ripe and unripe fish with respect to influence of cortisol elevation on hormone titres, the change in response to stressors appears to happen prior to ovulation. This change may be associated with the decline from stable levels of reproductive hormones as the fish move into an ovulated state, at which time there is a critical need to increase $17 \mathrm{a}$-hydroxy-20 beta-dihydroprogesterone (17a, 20beta-P) to complete reproduction (Dye et al. 1986). $17 \mathrm{a}, 20 \mathrm{beta}-\mathrm{P}$ is a maturation-inducing-hormone involved in the ovulation process, where corticosteroids mediate maturation and ovulation (Goetz, 1983; Mishra \& Joy, 2006).

\section{Channel longevity and reproductive success}

Despite the finding that our cortisol treatment did not change reproductive hormone titres, cortisol-treated fish still displayed decreased longevity and reproductive success during the channel experiment. Cortisol-treated fish were the only treatment group to exhibit significant egg retention that seemed to negatively influence overall reproductive outcome in the channel experiment. Therefore, chronic cortisol elevation on spawning grounds negatively influences reproductive function and success. Even though metyrapone and sham-treated fish failed to release as many eggs during the unripe net- 
pen experiment when compared to other treatment groups, they still successfully released the majority of their eggs in the long-run and had comparable longevity to control groups. This finding is important since fisheries managers are concerned with the largely unexplained phenomenon of "pre-spawn mortality" - fish that die on spawning grounds either without spawning or with significant egg retention (Quinn et al. 2007). The eggs of such fishes are often still viable (Tierney et al. 2009) so it appears that other factors are inhibiting reproductive behaviour and/or advancing senescence. In a study of sockeye salmon at the Weaver Creek spawning channel, Hruska et al. (2010) related mortality to changes in physiological condition and activity levels, providing a baseline of variables that change as Pacific salmon (specifically sockeye salmon ) senesce. To that end, this study attempted to identify whether stressful conditions can cause pre-spawn mortality on spawning grounds. It seems plausible that since our cortisol treatment increased cortisol values to those seen in senescing fish, that the mortality we saw was a function of this senescent-like physiological state.

Net-pen study

No physiological or hormonal changes were noted for the acute stressors or metyraponetreated fish in the net-pen experiments relative to controls four days post-treatment for either unripe or ripe fish. For unripe fish, cortisol-treated fish exhibited differing behaviour when compared to all other treatment groups. Specifically, cortisol-treated fish spent an average $10 \%$ less time on their territory then all other groups. In addition, cortisol-treated fish were significantly less aggressive and received more aggressive 
attacks from conspecifics when compared with all other treatment groups. A decrease in aggressiveness is detrimental to reproductive success since females benefit from guarding their territories from other females looking for suitable habitat and aggressive behaviour is often tied into reproductive success (Heard, 1991; Quinn \& Foote, 1994). These results are supported by previous studies that show that cortisol treatment increases the probability that a fish will become subordinate (DiBattista et al. 2005; Gilmour et al. 2005). No behavioural differences were detected for the experiments involving ripe fish. This finding is interesting in that eggs released for cortisol-treated fish (in the ripe experiments) followed the same trend as the channel study; they had lower \% eggs released than any other treatment group. It seems that even in the face of chronically elevated cortisol levels, cortisol-treated fish will still maintain key reproductive behaviours, further supporting life history theory and the idea that fish with limited reproductive opportunity will still spawn in the face of extreme stress situations.

\section{Metyrapone treatment}

Metyrapone blocks cortisol synthesis by inhibiting 11-beta hydroxylase, preventing synthesis of cortisol from 11-deoxycortisol (Mommsen et al. 1999). No significant changes in cortisol titres, reproductive behaviour, success or hormone levels occurred as a result of our metyrapone injections. Perhaps the concentrations we used were insufficient or the treatment was exhausted from the system before $24 \mathrm{~h}$. Conversely, there is suggestion that plasma cortisol does not turn over rapidly for semelparous salmon on spawning grounds (Donaldson \& Fagerlund, 1972) so it is possible that a constituent 
level of cortisol was maintained, but increases with stress were prevented. For future studies, responsiveness could be observed following injection to determine if metyrapone-treated fish respond to acute stressors.

There was suggestion that our injection of metyrapone caused some egg retention and delay in senescent physiology as observed in the net-pen study (i.e., trend toward lower cortisol values compared with controls in ripe fish). If cortisol does spike immediately prior to ovulation (Milla et al. 2009), this process could have been delayed through the action of metyrapone. Additionally, since cortisol spikes again during senescence (Hruska, 2010), this process also could have been delayed through the administration of metyrapone. However, we did not characterize the hormone fluxes across all time periods so it is difficult to interpret the results. It would be ideal to administer the injection with a longer-lasting cocoa butter release vehicle to extend the blocking action, allowing us to determine what exactly would occur during metyrapone treatment just prior to ovulation or immediately following egg release and before morbidity.

\section{Elevated cortisol levels on spawning grounds}

Iteroparous species will forego reproduction in the face of external stressors to ensure their condition is maintained for more favourable circumstances (Wingfield \& Sapolsky, 2003). One of the most notable findings of this experiment was that acute stressors on spawning grounds did not alter spawning ground longevity, reproductive success or behaviour, corresponding with life-history theory in that semelparous animals in general 
should resist stress in favour of allotting energy to current reproductive opportunities (Wingfield \& Sapolsky, 2003). Research on birds has shown that older birds and those with fewer reproductive opportunities will attenuate their stress response during reproduction when compared to younger birds, or those with more opportunity to spawn (Angelier et al. 2007; Silverin, 1997). Behavioural and physiological profiles of Pacific salmon are well documented on their spawning grounds but the purpose of cortisol elevation in semelparous fish in their natural spawning habitat is not. From a mechanistic standpoint, how semelparous salmon successfully breed despite elevated circulating cortisol levels is unknown (Wingfield \& Sapolsky, 2003). Our data verify that there is a limit to this capacity, since our cortisol treatment did impair reproduction. Regardless, there are a number of reasons why cortisol appears to be elevated in Pacific salmon while they are on spawning grounds including; ovulation (females), the stress associated with behavioural interactions, and impending senescence. Here we briefly examine each of these potential explanations.

1. Ovulation - Cortisol has been shown to negatively affect vitellogenesis, but it may also enhance pituitary gonadotropins at the onset of oogenesis, stimulating puberty (Milla et al. 2009). In addition, estradiol can activate the HPI axis (estradiol peaks just before ovulation) (Van Overbeeke \& McBride, 1971). If our metyrapone treatment effectively blocked cortisol synthesis, it may explain the trend seen in metyrapone-treated fish during the unripe net-pen experiment, where they released the fewest eggs compared with other treatment groups, suggesting a delay in final maturation. 
2. Stressful Behaviours on Spawning Grounds: It was observed that female pink salmon actively on territories were constantly in motion in efforts to construct and maintain nests, guard against other female intruders, and conduct and withstand aggressive attacks. Interestingly, it has been demonstrated, in other Pacific salmon, that the glycolic pathway is down-regulated during migration but it up-regulated on spawning grounds, suggesting that glycolysis, up-regulated on spawning grounds, is necessary for fuelling taxing reproductive behaviours (Miller et al. 2009; Hruska et al. 2010).

3. Impending Senescence: It has been shown that fish on spawning grounds exhibit interrenal hypertrophy which can help explain elevated levels of cortisol (Robertson \& Wexler, 1959, 1960, 1962). High levels of cortisol as fish approach senescence mediate programmed death by causing immune suppression and tissue degeneration (Dickhoff, 1989; Stein-Behrens and Sapolsky, 1992; Maule et al. 1996). However, high levels of gonadal hormones may be an initial stimulus for cortisol hypersecretion. Evidence, includes experimental gonadectomies that were shown to reverse glucocorticosteroid hypersecretion, while androgen injections in gonadectomised males increased cortisol secretion (Fagerlund \& Donaldson, 1970; Donaldson \& Fagerlund, 1972). Cortisol levels are high on spawning grounds and are even higher following a second spike occurring just before programmed death, verified by our data (Carruth et al. 2000; Hruska et al. 2010).

Given the scope of the present study, we cannot speculate as to what the exact purpose of cortisol elevation is on spawning grounds. We can conclude, however, that elevated cortisol levels are a necessary component facilitating normal reproductive behaviour and outcome. In addition, it seems that the second spike in cortisol is an 
indicator of impending senescence. If high levels are evident before spawning is complete, key reproductive behaviours and fitness are negatively affected, as evidenced by the outcome of our chronic cortisol elevation.

\section{Overall Conclusions}

Because the migratory and spawning processes are so challenging, we strive to understand the links between physiology, behaviours and ecology of migration as a means to aid in management. Salmon migrations have historically shown a large degree of consistency, but any environmental changes or anthropogenic perturbations are considered a potential threat to reproduction, and thus survival of a given population. Our results suggest that acute stressors do not influence behaviour or reproductive success which corresponds with life history theory (Wingfield and Sapolsky, 2003). However, there is a limit to elevated cortisol levels since our cortisol treatment negatively affected reproductive success and longevity. Our cortisol implants prematurely raised cortisol levels to those that are consistent with senescing salmon and maladaptive effects of this elevation were observed. Although we did not determine exactly why cortisol levels are high on spawning grounds, but we can conclude that it is a necessary function of reproduction. Additionally, metyrapone treatment may cause temporary egg retention and delay senescence, but further investigation is needed. Collectively, our results fill a void in current research explaining how varying degrees of stressors can influence reproductive behaviour and spawning success of Pacific salmon. In addition, it is among 
the first field studies conducted to investigate the ecological consequences of stress during reproduction for a semelparous species. 


\section{Tables}

Table 3 - 1. Starting blood physiology and hormone values of all $O$. gorbuscha removed from the Weaver creek raceway in October, 2009, presented as mean $( \pm \mathrm{SE}) . N=52$ for ripe fish and $N=60$ for ripe fish. All data were analyzed using the Wilcoxon Rank-Sum Test, except for cortisol $\left({ }^{*}\right)$ which was analyzed using log-transformed data in a one-way ANOVA.

\begin{tabular}{|c|c|c|c|c|}
\hline \multirow[b]{2}{*}{ VARIABLE } & \multicolumn{2}{|c|}{ TREATMENT } & \multicolumn{2}{|c|}{ STATISTICS } \\
\hline & $\begin{array}{c}\text { Unripe } \\
(\text { mean } \pm \mathrm{SE})\end{array}$ & $\begin{array}{c}\text { Ripe } \\
(\text { mean } \pm \mathrm{SE})\end{array}$ & Statistic & P-Value \\
\hline Glucose $\left(\mathrm{mmol} \mathrm{L}^{-1}\right)$ & $5 \pm 0.2$ & $6 \pm 0.2$ & 13.0 & $<0.001$ \\
\hline Cortisol $\left(\mathrm{ng} \mathrm{ml}^{-1}\right) *$ & $338 \pm 21$ & $297 \pm 21$ & 0.310 & 0.579 \\
\hline Estradiol (ng ml $\left.{ }^{-1}\right)$ & $4.5 \pm 0.3$ & $0.28 \pm 0.3$ & 70.4 & $<0.001$ \\
\hline Testosterone $\left(\mathrm{ng} \mathrm{ml}^{-1}\right)$ & $150 \pm 13$ & $63 \pm 12$ & 24.8 & $<0.001$ \\
\hline
\end{tabular}




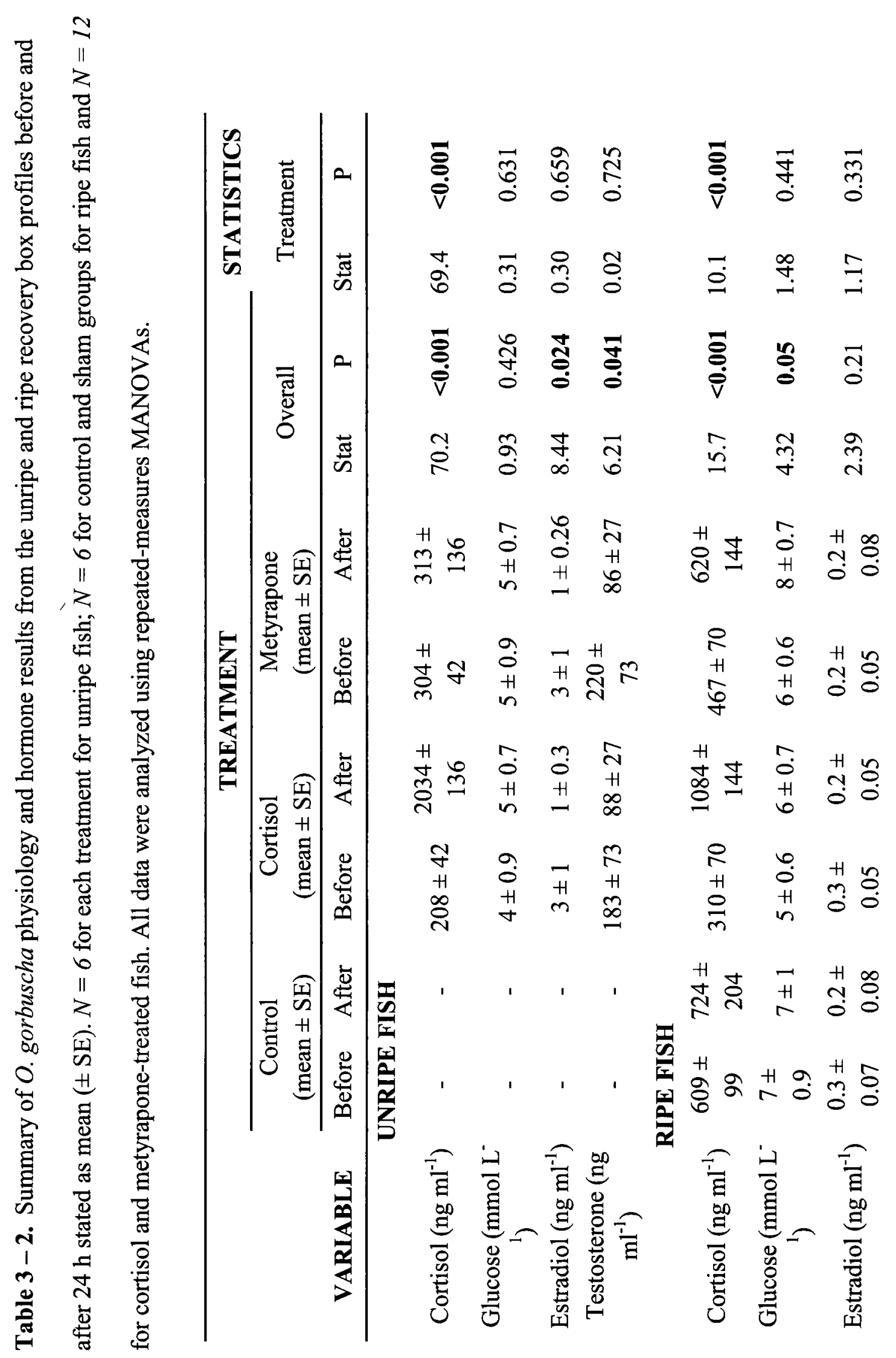




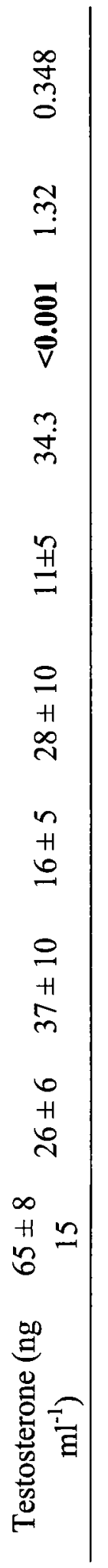




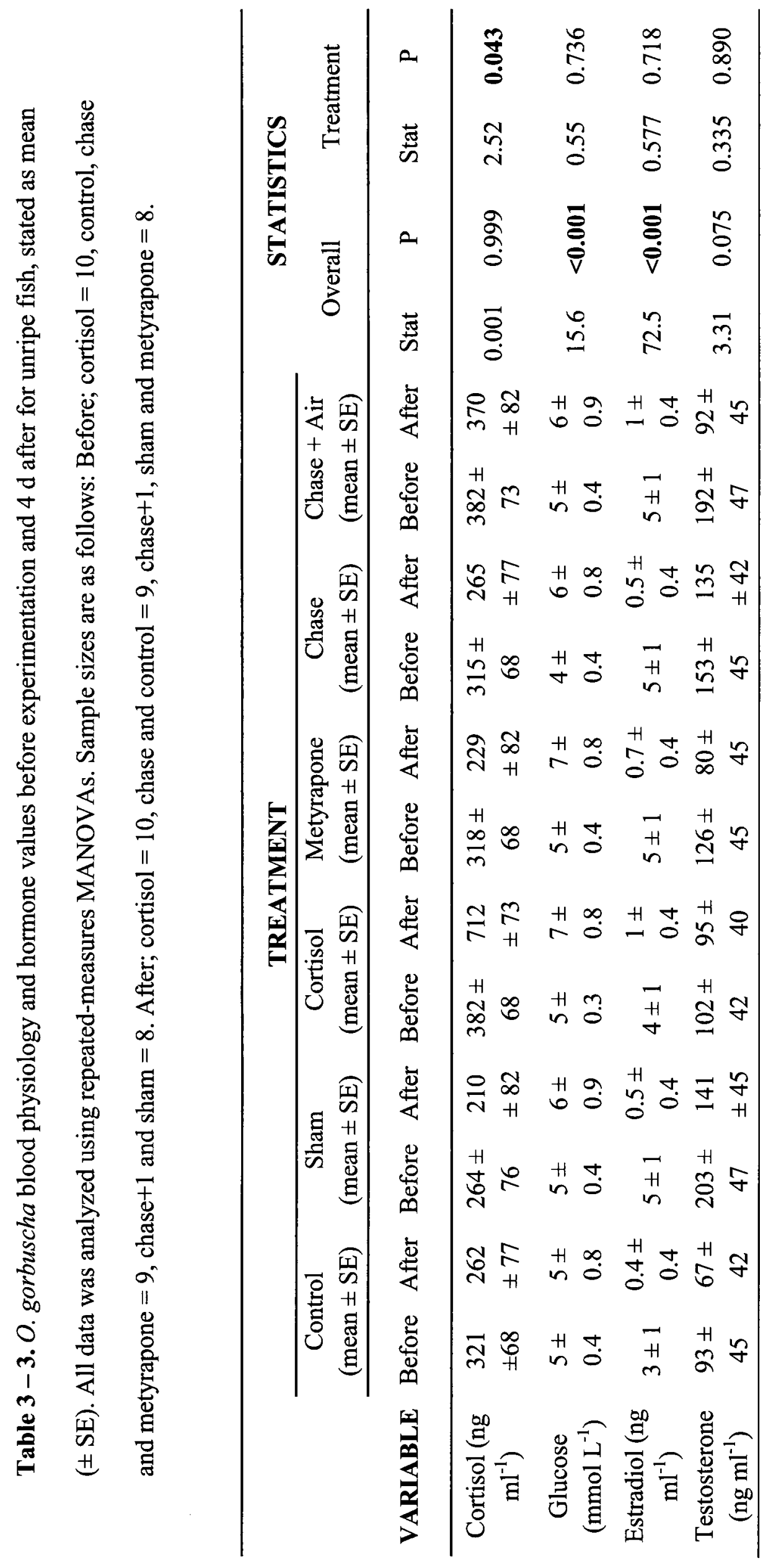




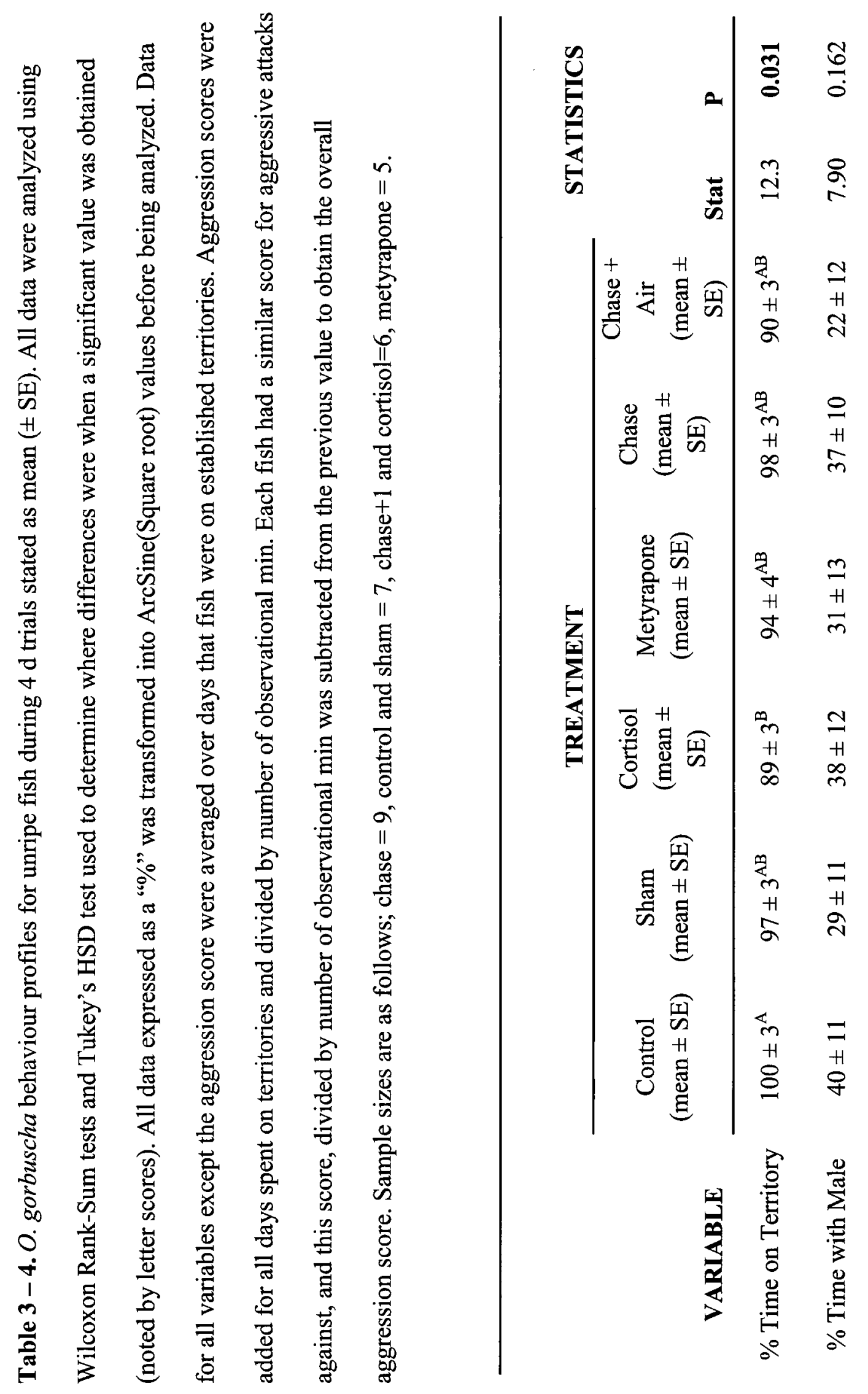




$$
\begin{aligned}
& \stackrel{n}{7} \stackrel{n}{0} \\
& \text { 모 ำ }
\end{aligned}
$$

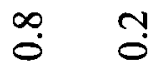

$$
\begin{aligned}
& \text { ஸे } \\
& \begin{array}{cc}
r & \multicolumn{2}{c}{} \\
0 & 0 \\
+ & +1 \\
- & 0
\end{array}
\end{aligned}
$$

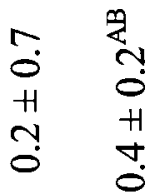

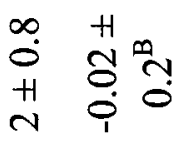

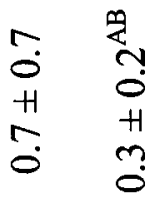

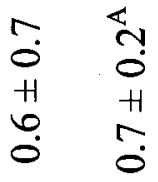

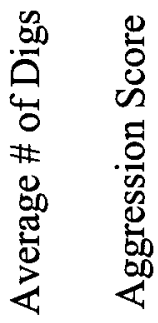




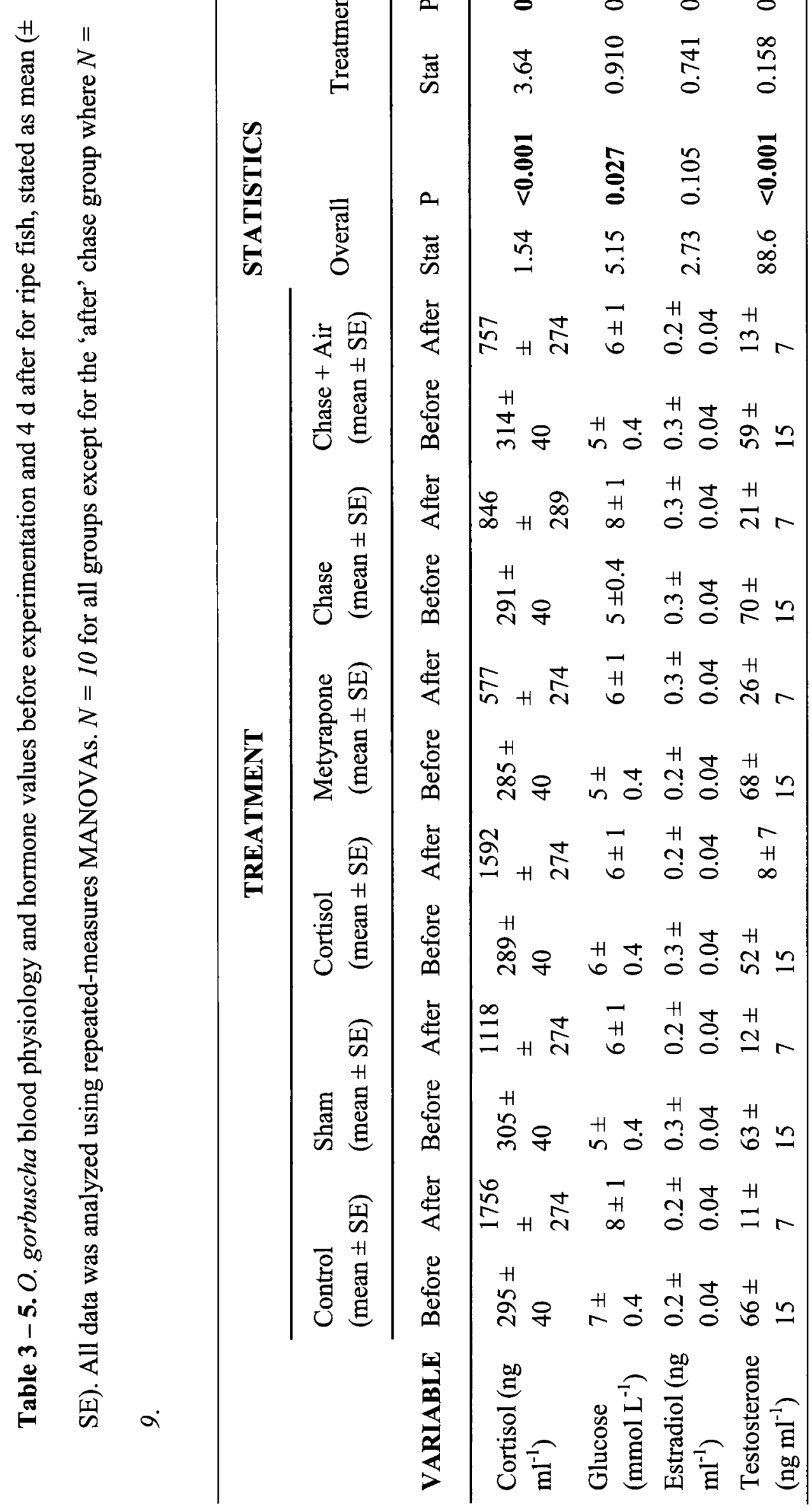




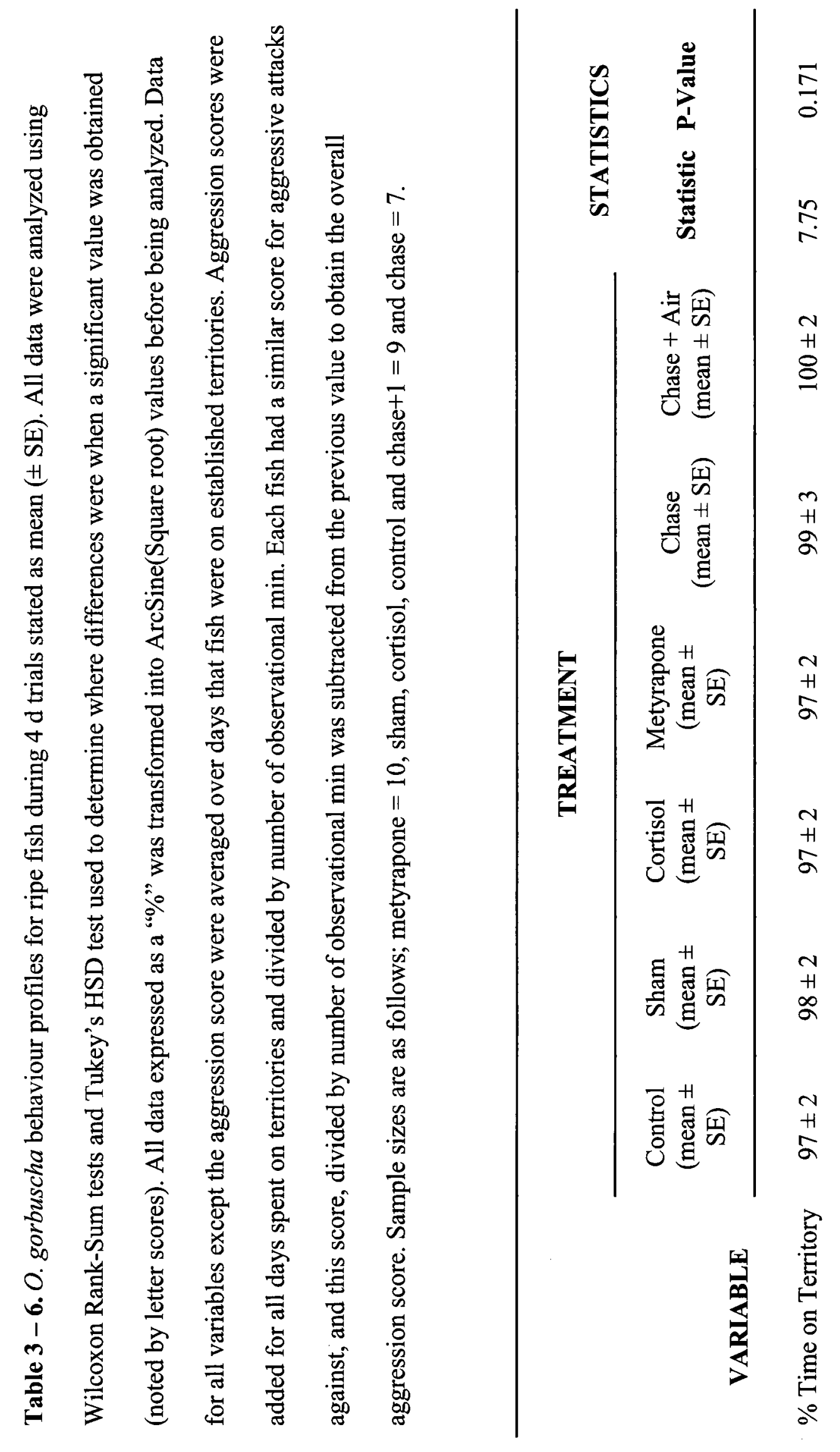




$$
\begin{aligned}
& \text { ñn }
\end{aligned}
$$

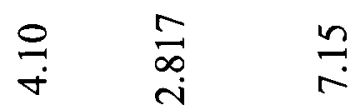

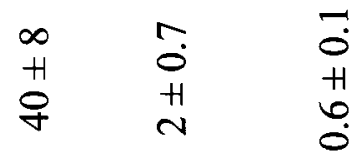

$$
\begin{aligned}
& \begin{array}{lll}
a & \infty & \overrightarrow{0} \\
H & 0 & H \\
0 & H & -1
\end{array}
\end{aligned}
$$

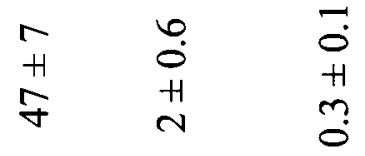

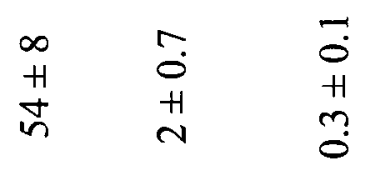

$$
\begin{aligned}
& \begin{array}{lll}
\infty & \tilde{0} & \overrightarrow{0} \\
H & 0 & H \\
m & H & \tilde{0}
\end{array}
\end{aligned}
$$

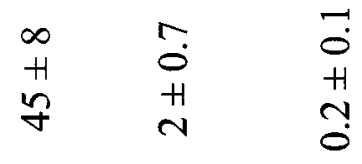

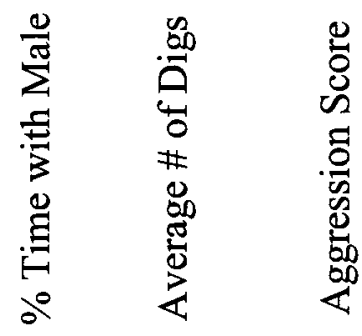


Figures

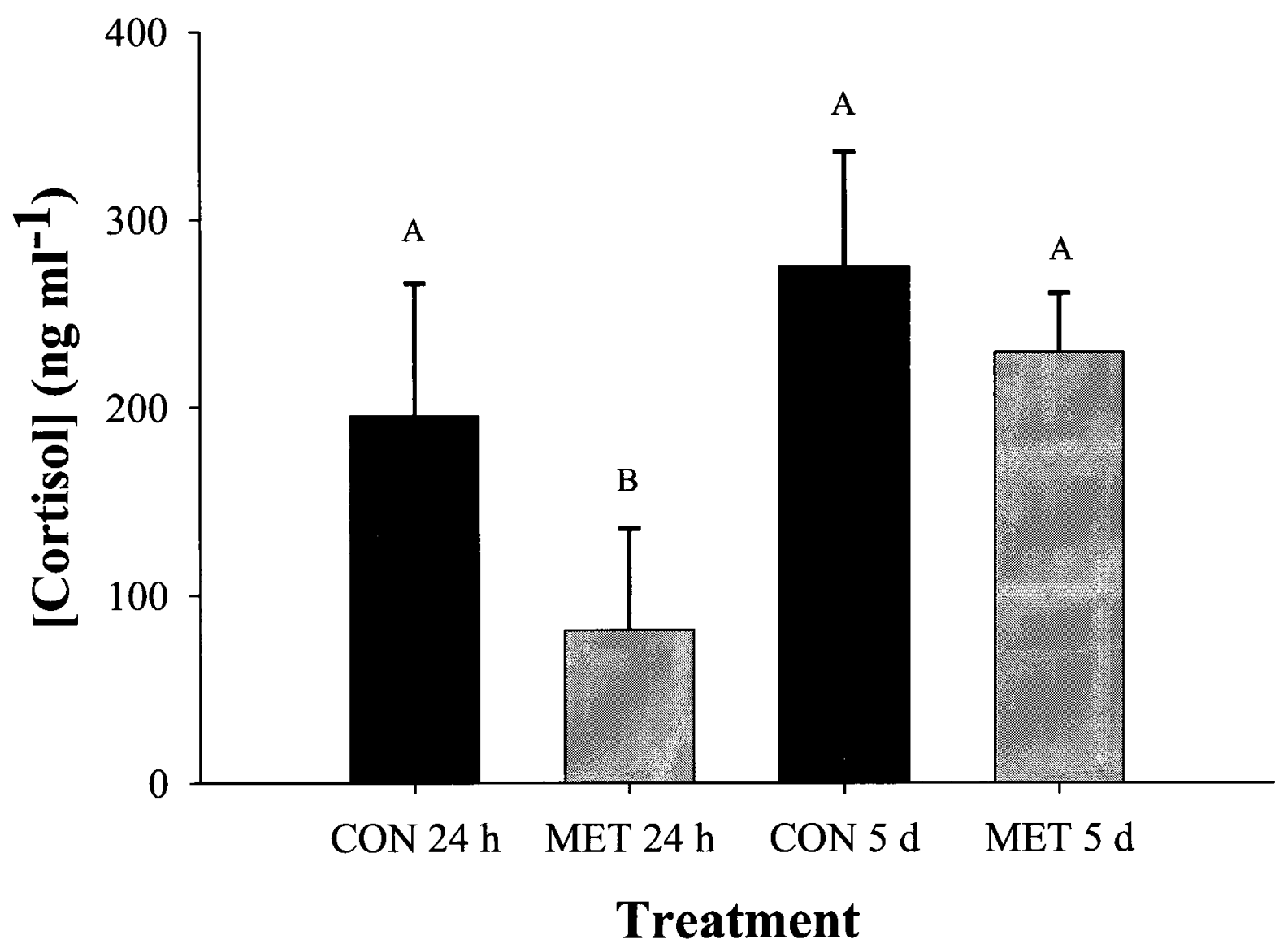

Figure 3-1. Mean ( $\pm \mathrm{SE})$ cortisol values for control $(\mathrm{CON})$ and metyrapone-treated $O$. mykiss. (MET) $24 \mathrm{~h}$ after treatment and $5 \mathrm{~d}$ after treatment. Sample sizes are as follows: $24 \mathrm{~h}$; control = 2 , metyrapone $=5.5 \mathrm{~d}$; control $=4$, metyrapone $=4$. The effects tests for the two-way ANOVA are as follows (using $\log$ transformed cortisol data): treatment, $\mathrm{df}=1, \mathrm{~F}$ ratio $=3.07, \mathrm{p}=0.103$; day, $\mathrm{df}=1, \mathrm{~F}$ ratio $=7.82, \mathrm{p}=0.0151$; interaction, $\mathrm{df}=3, \mathrm{~F}=4.70, \mathrm{p}=0.0240$. Metyraponetreated fish at $24 \mathrm{~h}$ had the lowest cortisol levels, when compared to controls and both groups at $5 \mathrm{~d}$. 


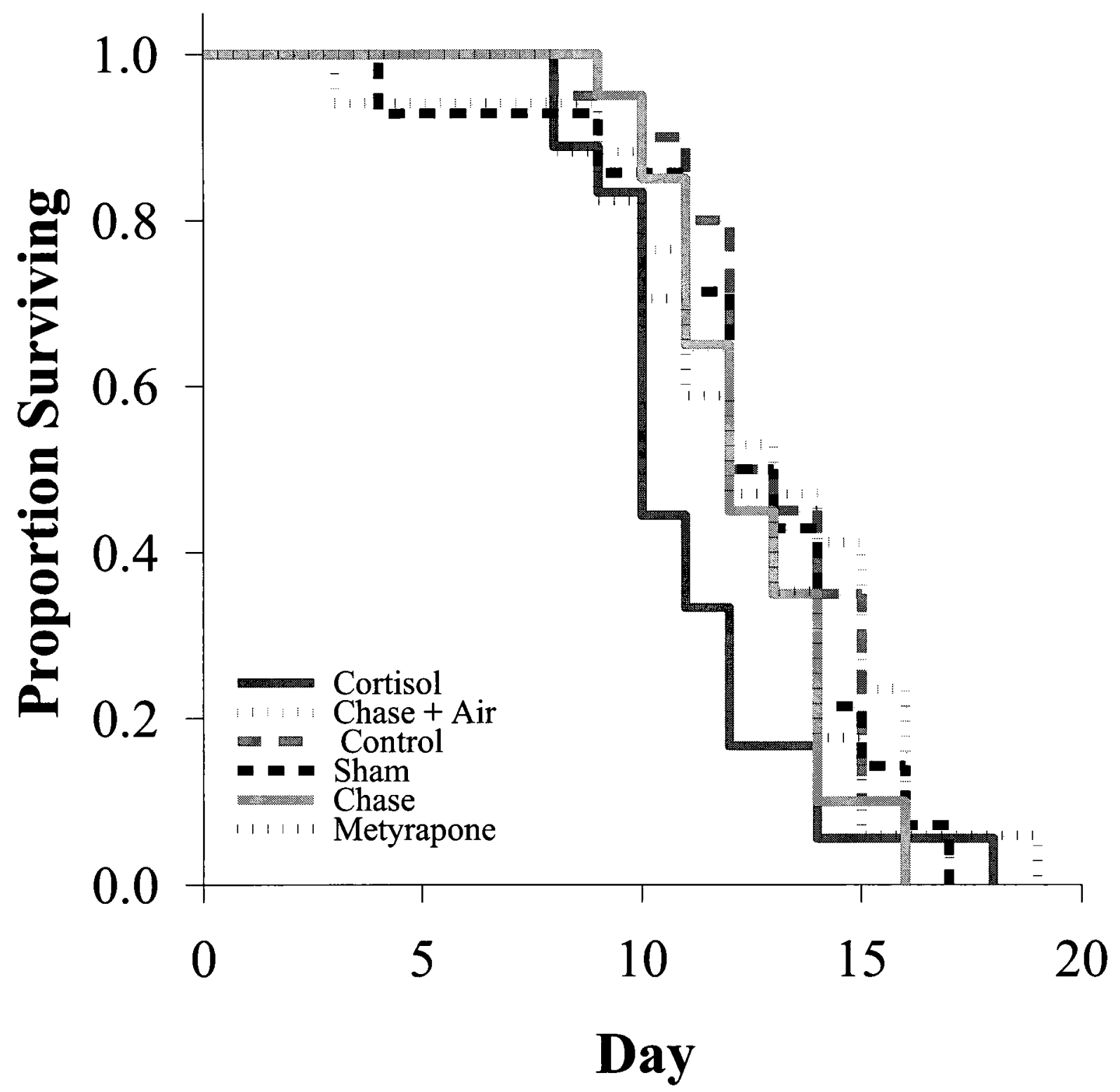

Figure 3-2. Log-rank survival analysis to $50 \%$ mortality in each treatment group, comparing longevity among $O$. gorbuscha in the Weaver Creek spawning channel. Sample sizes are as follows; chase and control $=20$, cortisol $=18$, chase +1 and metyrapone $=17$ and sham $=14$. 


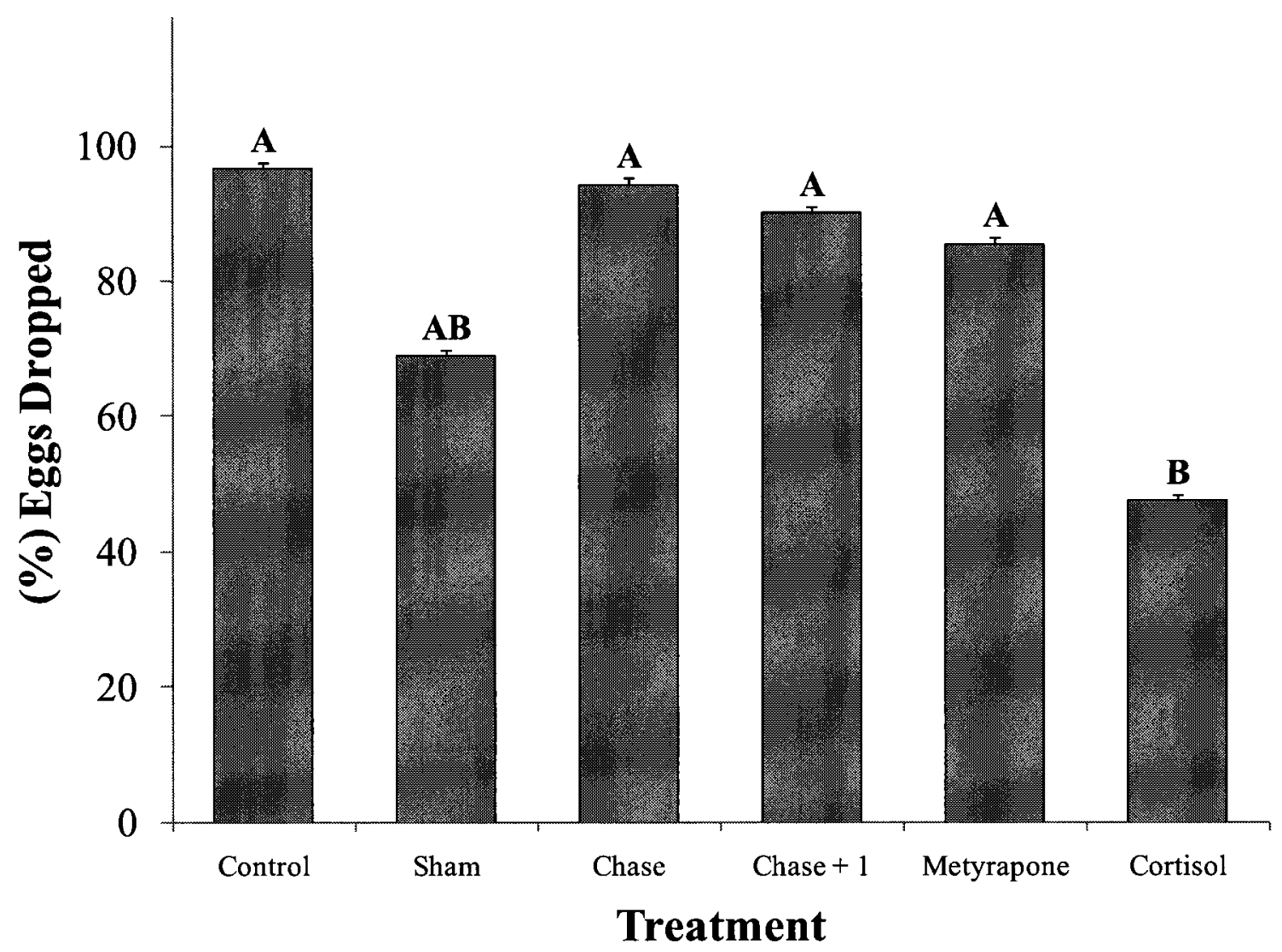

Figure 3 - 3. A comparison of percent (\%) eggs dropped by $O$. gorbuscha in the Weaver Creek spawning channel during experiment 1 . All data were transformed into ArcSine(Square root) values before being analyzed. Sample sizes are as follows; chase and control $=20$, cortisol $=18$, chase +1 and metyrapone $=17$ and sham $=14$. Dissimilar letters denote significant differences among treatment groups (Tukey-Kramer HSD test, $\mathrm{p}<0.05)$ 


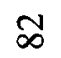

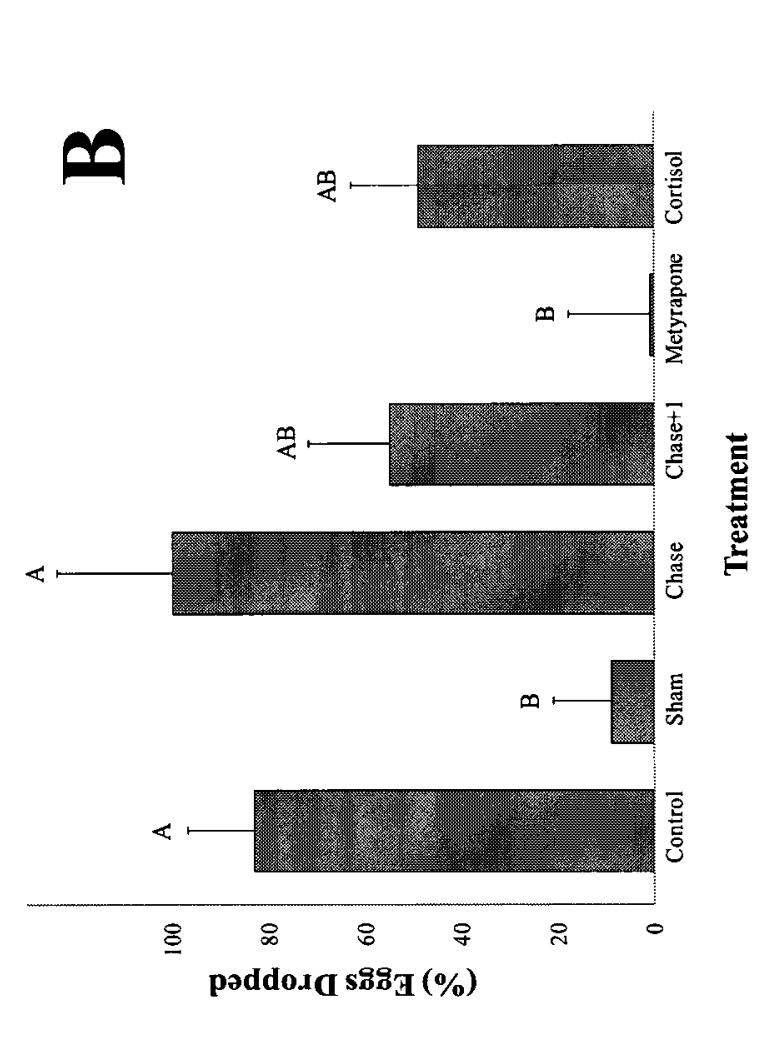

$\infty \infty$
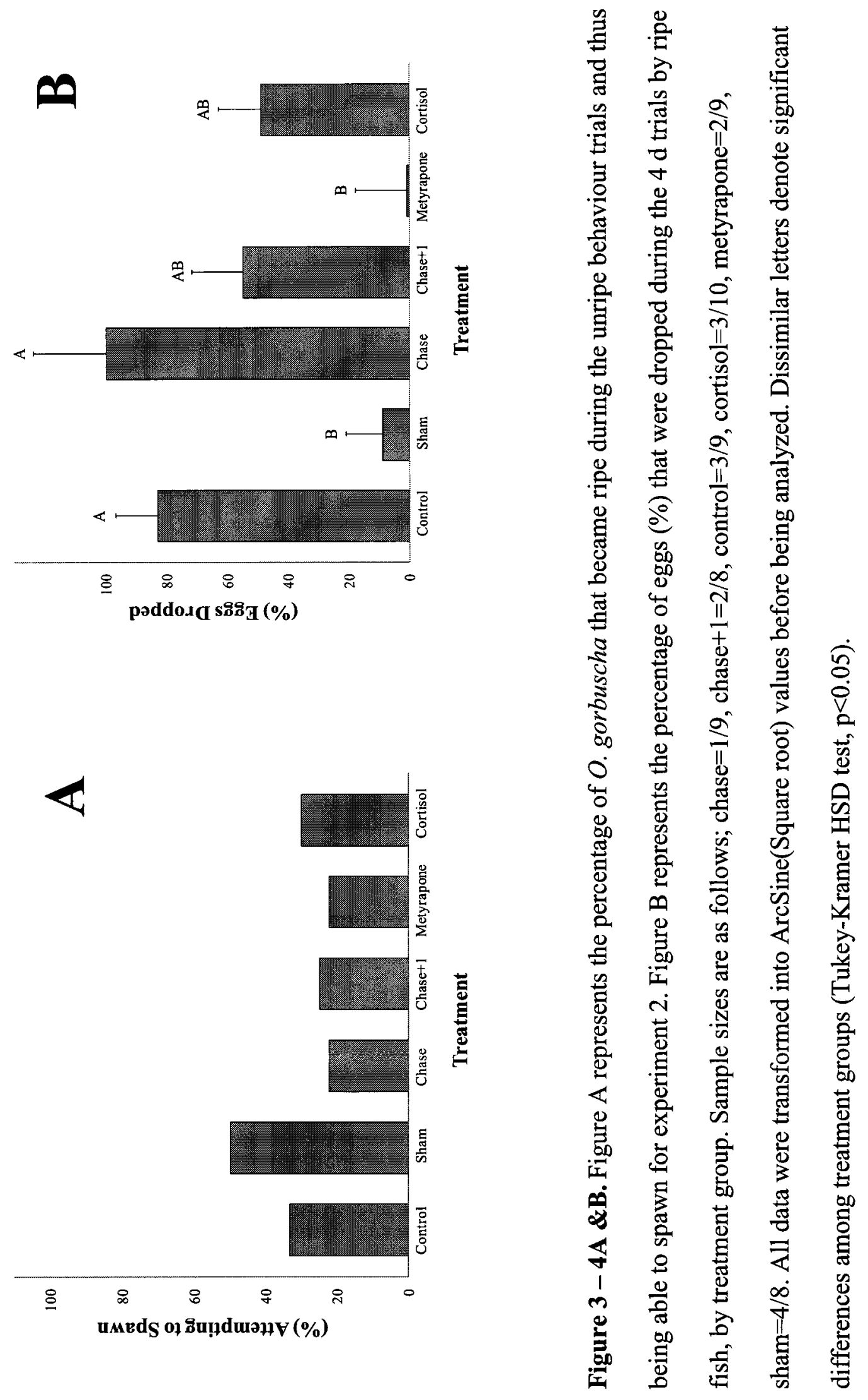


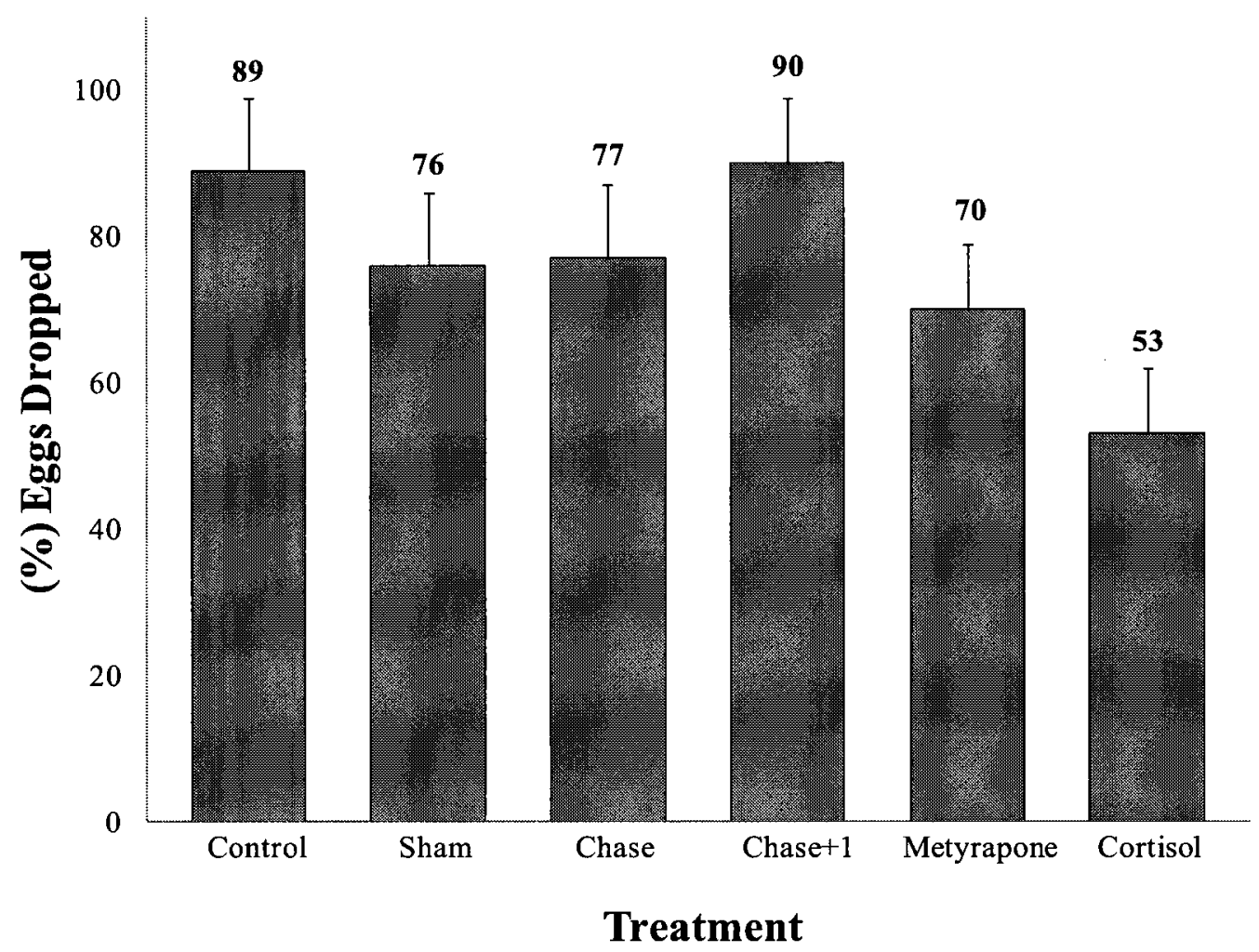

Figure 3-5. A comparison of the amount of eggs (\%) that were dropped by $O$. gorbuscha during the ripe net-pen behaviour trials during experiment 2. $N=10$ for all groups. Number values (in \%) are stated on top of each column. All data were transformed into ArcSine(Square root) values before being analyzed. 


\section{Chapter 4: General Discussion}

This thesis is a compilation of two distinct studies that together can help elucidate how stress influences physiology, behaviour and survivability in wild fish populations, contributing to our understanding of the ecology of stress in wild animals. This was investigated through the results of inducing experimental chronic cortisol elevations (or cortisol suppression) on overall fish condition, behaviour and physiology in the shortand long-term. There are many interrelated responses to a chronic cortisol elevation and all can have negative effects; specifically, chronic stress is known to cause complications when secondary and tertiary responses become maladaptive (Barton, 2002). Overall, these negative effects can impact individual fitness and populations through reduced reproductive capacity (as seen in Chapter 3 ) and the inability to tolerate additional stressors (as seen in Chapter 2) (Barton, 2002).

\section{Findings and Implications}

In Chapter 2, it was determined that fish experiencing a chronic cortisol elevation can tolerate additional stressors during the short-term response period. However, once the long-term secondary effects of that chronic elevation manifest themselves, they interfere with a fish's ability to overcome additional stressors. These effects are detected even when resting physiological variables have returned to "normal" baseline values, suggesting evidence of a carryover effect. Even though the dose used was supraphysiological at $24 \mathrm{~h}$, results show that chronic cortisol elevations in fish negatively 
affect their ability to respond to secondary stressors due to the deleterious effects on condition and physiology.

In Chapter 3, it was verified that an acute stressor applied to a semelparous fish on their spawning grounds will not influence reproductive hormones, reproductive behaviour or success in the short- or long-term. This finding is logical since according to life history theory, a semelparous species with only reproductive opportunity is less likely to respond to external stressors, investing all energy into maintaining normal spawning behaviours (Wingfield \& Sapolsky, 2003). However, there is a limit to this capacity since chronic cortisol elevations did negatively influence longevity, behaviours and reproductive success. It was also suggested that an injection of metyrapone briefly delayed senescence and egg release, although I did not detect a reduction in cortisol values corresponding to this treatment. Cortisol appears to be a necessary component of the final maturation of pink salmon on their spawning grounds.

The implications for the third chapter are a little more difficult to identify given the myriad of physiological and energetic processes occurring during the spawning period for semelparous species. As fish are nearing senescence, they have very few reserves to endure negative chronic stimuli and many interesting physiological changes are occurring making it difficult to determine how much "stress" is too much. It was observed, however, that cortisol injections raised cortisol levels to those seen by senescing fish, negatively affecting normal reproductive functions. Chronic cortisol elevations (levels higher than those seen at arrival) on salmon spawning grounds are 
maladaptive, but fish are able to endure acute stressors in order to ensure fitness is secured.

The findings for both data chapters do suggest that chronic cortisol elevations can influence individual fitness and whole populations by negatively affecting both survival and reproductive success. The approach used for both studies was novel because few have been conducted using experimental hormone manipulations in field settings (i.e., Chapters 2 and 3). Although variation is an inherent issue when using wild fish, an experimental field approach allows us to understand how our treatments influence behaviour and survival in a natural setting. This increases the application of results to real conservation issues (see Cooke and O'Connor, 2010).

\section{Summary and Future Research Directions}

The concepts investigated in this thesis fill a void of research aimed at elucidating the role of cortisol on survival, fitness and reproduction in wild fish populations, broadening our scope of our understanding of the ecology of stress in wild animals For instance, the majority of carryover research has been focused on migrating birds (e.g., Webster et al. 2002; Norris, 2005; Norris \& Taylor, 2006); and the majority of studies understanding how stress affects reproduction is focused on iteroparous species (Angelier et al. 2007; Schreck et al. 2001; Silverin, 1997). Of special importance is the finding that fish experiencing a chronic cortisol elevation may be at a disadvantage when they are exposed to other stressful events later in life, even after recovering from the initial chronic cortisol elevation. Additionally, much is to be learned about the physiology of senescence and 
what role cortisol plays on spawning grounds of a semelparous species. It was previously unclear whether the stress response was muted on spawning grounds, which would follow life history predictions (Wingfield \& Sapolsky, 2003). The findings from Chapter 3 indicate that in semelparous species, reproductive behaviour, physiology or success are not affected in the face of an acute stressor.

As with most studies, the findings from my experiments raise additional questions that could further elucidate the sub-lethal consequences of a chronic cortisol elevation, and could clarify the role of cortisol in the final maturation of semelparous salmon species.

\section{Bluegill (Lepomis macrochirus)}

1. The findings from Chapter 2 suggest that fish experiencing a chronic cortisol elevation can survive additional stressors in the short-term (even with supraphysiological levels), but not in the long-term. Would the effects of an ecologically relevant stressor with the associated attenuation of the stress response yield similar (but likely more cryptic) results? Along these lines, it would be interesting to conduct similar experiments using ecologically relevant stressors in a wild setting using observational or tagging techniques.

2. Lab studies, conducted to answer similar questions, could control for the disease, water quality, and environmental instability issues I had with the lake-water flow through system. The fact that bluegill endured frequent temperature fluctuations 
and constant pathogen exposure could have hindered results, and can explain some of the overall mortality that was observed.

3. It would be interesting to experimentally infect fish responding to and those that have recovered from a chronic cortisol elevation with a pathogen to see if they are differentially infected from fish that have not been treated experimentally with cortisol. It would be ideal to perform such a study in a controlled laboratory environment.

\section{Pink salmon (Oncorhynchus gorbuscha)}

1. Acute stress events did not affect reproductive behaviour or outcome for either ripe or unripe fish. Studies have shown that fish do respond to stress during their migration and it negatively affects reproductive hormone titres. It would be interesting to investigate when fish stop responding to stress physiologically. It appears to occur before fish arrive on spawning grounds and it does not seem to be a function of ovulation.

2. What level of stress will cause a spawning (or sexually mature) semelparous salmon to forgo reproduction to attempt to respond to the stressor (or just die)? Salmon will not likely forgo reproduction to respond to a stressor, but I do believe that the energetic constraints of stress will leave them physiologically and energetically incapable of reproduction. What is this threshold? 
3. Longer/increased dosage of metyrapone vs. control fish, with repeated blood sampling to determine if there is in fact a delay in egg drop/reproduction and senescence when cortisol synthesis is blocked.

4. More concrete studies determining the role of cortisol in final maturation (e.g., mechanistic). Is it a product of impending senescence or is it necessary for reproduction and the process of maturation? Why are there two spikes? Is the first (on spawning ground arrival) just the beginning of inter-renal hypertrophy useful and necessary for what will occur on spawning grounds which is followed by a complete breakdown right before senescence?

\section{Overall Conclusions}

1. Chronic cortisol elevation will incur maladaptive secondary effects that will likely cause whole-animal changes in performance and will affect survivorship. Fish may seem normal physiologically, but they can experience carryover effects from the chronic cortisol elevation that are not evident until exposure to stressors later in life.

2. It has been shown that iteroparous fish species enduring a severe stressor will forego reproduction to ensure there are proper resources to respond to the stressor remain intact. However, the results from Chapter 3 suggest that semelparous fish will attempt to spawn in the face of an acute stressor to ensure that they pass along reproductive material before they succumb to senescence. 
3. Even though cortisol levels are high in fish on spawning grounds there is a limit to this capacity. Fish facing a chronic cortisol elevation will still attempt to spawn, but as a whole they will be negatively affected by the elevation causing a reduction in reproductive success, longevity and key reproductive behaviours.

4. Cortisol seems to be an important steroid in the final maturation processes of semelparous salmon. It is still unclear how the suppression of cortisol synthesis influences changes in senescence/longevity, behaviour and reproductive success but there is a suggestion that it may delay the final maturation processes.

5. The integrative approach to determining the effects of chronic cortisol elevations on fish physiology, behaviour and overall condition will help clarify how individual responses will influence populations as a whole. Such information is particularly important given the range of disturbances faced by wild animals as a result of continued human alteration of aquatic ecosystems. 


\section{References}

Adams, S.M., A.M. Brown, and R.W. Goede. 1993. A quantitative health assessment index for rapid evaluation of fish condition in the field. Transactions of the American Fisheries Society 122: 63-73.

Anderson, E.P., M.C. Freeman, and C.M. Pringle. 2006. Ecological consequences of hydropower development in Central America: impacts of small dam and water diversion on neotropical stream fish assemblages. River Research and Applications 22: $397-411$.

Angelier, F., H. Weimerskirch, S. Dano, and O. Chastel. Age, experience and reproductive performance in a long-lived bird: a hormonal perspective. Behavioural Ecology and Sociobiology 61: 611-621.

Arlinghaus, R., S.J. Cooke, J. Luman, D. Policansky, A. Schwab, C. Suski, S.G. Sutton, and E.B. Thorstad. 2007. Understanding the complexity of catch-and-release in recreational fishing: An integrative synthesis of global knowledge from historical, ethical, social, and biological perspectives. Reviews in Fisheries Science 12: 75167.

Barry, T.P., A. Marwah, and S. Nunez. 2010. Inhibition of cortisol metabolism by $17 \alpha$, 206-P: mechanism mediating semelparity in salmon? General and Comparative Endocrinology 165: 53-59. 
Barton, B.A. 2002. Stress in fish: a diversity of responses with particular references to changes in circulating corticosteroids. Integrative and Comparative Biology 42: $517-525$.

Barton, B.A. and G.K. Iwama. 1991. Physiological changes in fish from stress in aquaculture with emphasis on the response end effects of corticosteroids. Annual Review in Fish Diseases 1: 2-26.

Barton, B.A. 1988. Endocrine and metabolic responses of fish to stress. Proceedings of the International Association of Aquatic Animal Medicine 19: 41-55.

Barton, B.A., C.B. Schreck, and L.D. Barton. 1987. Effects of chronic cortisol administration and daily acute stress on growth, physiological conditions, and stress responses in juvenile rainbow trout. Diseases of Aquatic Organisms 2: 173-185.

Barton, B.A., C.B. Schreck, and L.A. Sigismondi. 1986. Multiple acute disturbances evoke cumulative physiological stress responses in juvenile Chinook salmon. Transactions of the American Fisheries Society 115: 245-251.

Basu, N., C.J. Kennedy, P.V. Hodson, and G.K. Iwama. 2002. Altered stress responses in rainbow trout following a dietary administration of cortisol and B-napthoflavone. Fish Physiology and Biochemistry 25: 131-140.

Basu, N., T. Nakano, E.G. Grau, and G.K Iwama. 2001. The effects of cortisol on heat shock protein 70 levels in two fish species. General and Comparative Endocrinology 124: 97-105. 
Boonstra, R., D. Hik, G.R. Singleton, and A. Tinnikov. 1998. The impact of predatorinduced stress on the snowshoe hare cycle. Ecological Monographs 79: 371-394.

Bowron, L.K., K.R. Munkittrick, M.E. McMaster, G. Tetrault, and L.M. Hewitt. 2009. Responses of white sucker (Catostomus commersoni) to 20 years of process and water treatment changes at a bleached kraft pulp mill, and to mill shutdown. Aquatic Toxicology 95: 117-132.

Brett, J.R. 1995. Energetics. In Physiological Ecology of Pacific Salmon (C. Groot, L. Margolis, and W.C. Clark Eds). pp. 1-68. UBC Press, Vancouver.

Busacker, G.P., I.R. Adelman, and E.M. Goolish. 1990. Growth. In Methods for Fish Biology (C.B. Schreck and P.B Moyle eds) pp. 363-387. American Fisheries Society, U.S.A.

Carruth, L.L., R.E. Jones, and D.O. Norris. 2002. Cortisol and pacific salmon: a new look at the role of stress hormones in olfaction home-stream migration. Integrative and Comparative Biology 42: 574-581.

Carruth, L.L., R.M. Dores, T.A. Maldonado, D.O. Norris, T. Ruth and R.E. Jones. 2000. Elevation of plasma cortisol during the spawning migration of landlocked kokanee salmon (Oncorhynchus nerka kennerlyi). Comparative Biochemistry and Physiology Part C 127: 123-131.

Chan, D.K.O. and N.Y.S. Woo. 1978. Effect of cortisol on the metabolism of the eel, Anguilla japonica. General and Comparative Endocrinology 35: 205-215. 
Cooke, S.J. and C.M. O'Connor. 2010. Making conservation physiology relevant to policy makers and conservation practitioners. Conservation Letters 3: 159-166.

Cooke, S.J., C.D. Suski, S.E. Danylchuk, A.J. Danylchuk, M.R. Donaldson, C. Pullen, G. Bulté, A.O’Toole, K.J. Murchie, J.B. Koppelman, A.D. Shucltz, E. Brooks, and T.L. Goldberg. 2008. Effects of different capture techniques on the physiological condition of bonefish Albula vulpes evaluated using field diagnostic tools. Journal of Fish Biology 73: 1351-1375.

Cooke, S.J., S.G. Hinch, G.T. Crossin, D.A. Patterson, K.K. English, M.C. Healey, J.M. Shrimpton, G. Van Der Kraak, and A.P. Farrell. 2006. Mechanistic basis of individual mortality in Pacific salmon during spawning migrations. Ecology 87: $1575-1586$.

Cooke, S.J. and C.D. Suski. 2005. Do we need species-specific guidelines for catch-andrelease recreational angling to effectively conserve diverse fishery resources? Biodiversity and Conservation 14: 1195-1209.

Cooke, S.J., S.G. Hinch, A.P. Farrell, M.F. Lapointe, S.R.M. Jones, J.S. Macdonald, D.A. Patterson, M.C. Healey, and G. Van Der Kraak. 2004. Abnormal migration timing and high en route mortality of sockeye salmon in the Fraser River, British Columbia. Fisheries 29: 22-33.

Davis, M.W. 2002. Key principles for understanding fish bycatch discard mortality. Canadian Journal of Fisheries and Aquatic Science 59: 1834-1843. 
de Oliveria Fernandes, M. and G.L. Volpato. 1993. Heterogeneous growth in the Nile tilapia: social stress and carbohydrate metabolism. Physiology and Behaviour 54: 319-323.

DeNardo, D.F. and B. Sinervo. 1994a. Effects of Corticosterone and activity and home range size of free-ranging male lizards. Hormones and Behaviour 28: 53-65.

DeNardo, D.F. and B. Sinervo. 1994b. Effects of steroid hormone interaction on activity and home range size of male lizards. Hormones and Behaviour 28: 273-287.

Dey, C.J., C.M. O’Connor, K.M. Gilmour, G. Van Der Kraak, and S.J. Cooke. In Press. Behavioral and physiological responses of a wild teleost fish to cortisol and androgen manipulation during parental care. Hormones and Behaviour. 00: 000000.

DiBattista, J.D., H.M. Levesque, T.W. Moon, and K.M. Gilmour. 2006. Growth depression in socially subordinate rainbow trout Oncorhynchus mykiss: more than a fasting effect. Physiology and Biochemical Zoology 79: 675-687.

Dibattista, J.D., H. Anisman, M. Whitehead, and K.M. Gilmour. 2005. The effects of cortisol administration on social status and brain monoaminergic activity in rainbow trout Oncorhynchus mykiss. Journal of Experimental Biology 208: 27072718.

Dickhoff, W.W. 1989. Salmonids and annual fishes: death after sex. In Development, Maturation and Senescence of Neuroendocrine Systems: A Comparative Approach. 
(M.P. Schreibman and C.G. Scanes eds). pp. 253-266 Academic Press, New York, NY.

Dietz, T., E.A. Rosa, and R. York. 2007. Driving the human ecological footprint. Frontiers in Ecology and the Environment 5: 13-18.

Donaldson, E.M. and U.H.M Fagerlund. 1972. Corticosteroid dynamics in Pacific salmon. General and Comparative Endocrinology 3: 254-265.

Doyon, C., J. Leclair, V.L. Trudeau, and T.W. Moon. 2006. Corticotropin-releasing factor and neuropeptide Y mRNA levels are modified by glucocorticoids in rainbow trout, Oncorhynchus mykiss. General and Comparative Endocrinology 146: $126-135$.

Dutil, J.D. and Y. Lambert. 2000. Natural mortality from poor condition in Atlantic cod (Gadus morhua). Canadian Journal of Fisheries and Aquatic Science 57: 826-836.

Dye, H.M., J.P. Sumpter, U.H.M. Fagerlund, and E.M. Donaldson. 1986. Changes in reproductive parameters during the spawning migration of pink salmon, Oncorhynchus gorbuscha (Walbaum). Journal of Fish Biology. 29: 167-176.

Fagerlund, U.H.M. and E.M. Donaldson. 1970. Dynamics of cortisone secretion in sockeye salmon (Oncorhynchus nerka) during sexual maturation and after gonadectomy. Journal of the Fisheries Research Board of Canada 27: 2323-2331. 
Fagerlund, U.H.M. and J.R. McBride. 1969. Suppression by dexamethasone of interrenal activity in adult sockeye salmon (Oncorhynchus nerka). General and Comparative Endocrinology 12: 651-657.

Farrell, A.P., P.E. Gallaugher, and R. Routledge. 2001. Rapid Recovery of exhausted adult coho salmon after commercial capture by troll fishing. Canadian Journal of Fisheries and Aquatic Sciences. 58: 2319-2324.

Fraser, D.F. and J.F. Gilliam. 1992. Nonlethal impacts of predator invasion: Facultative suppression of growth and reproduction. Ecology 73: 959-970.

Gamperl, A.K., M.M. Vijayan, and R.G. Boutilier. 1994. Experimental control of stress hormone levels in fishes: techniques and applications. Reviews in Fish Biology and Fisheries 4: 215-255.

Gilhousen, P. 1990. Prespawning mortality of sockeye salmon in the Fraser River system and possible causal factors. International Pacific Salmon Fisheries Commission Publications 26: 1-58.

Gilmour, K.M., J.D. DiBattista, and J.B. Thomas. 2005. Physiological causes and consequences of social status in salmonids fish. Integrative and Comparative Biology 45: 263-273.

Goetz, F.W. 1983. Hormonal control of oocyte final maturation and ovulation in fishes. In Fish physiology: Reproduction, behaviour and fertility control (Eds W.S. Hoar and D.J. Randall). Volume 9 Part 2, Academic Press, NY, NY. Pgs 117-170. 
Gregory, T.R. and C.M. Wood. 1999. The effects of chronic plasma cortisol elevation on the feeding, behaviour, growth, competitive ability, and swimming performance of juvenile rainbow trout. Physiological and Biochemical Zoology 72: 286-295.

Harvell, C.D., C.E. Mitchell, J.R. Ward, S. Altizer, A.P. Dobson, R.S. Ostfeld, and M.D. Samuel. 2002. Climate warming and disease risks for terrestrial and marine biota. Science 296: 2158-2162.

Heard, W.R. 1991. Life history of pink salmon (Oncohynchus gorbuscha). In Pacific salmon life histories. Edited by C. Groot and L. Margolis. UBC Press, Vancouver. pp.120-230.

Hendry, A.P., Y.E. Morbey, O.K. Berg, and J.K. Wenburg. 2004. Adaptive variation in senescence: reproductive lifespan in a wild salmon population. Proceedings of the Royal Society of London. 271: 259-266.

Hinch, S.G., S.J. Cooke, M.C. Healey, and A.P. Farrell. 2006. Behavioural physiology of fish migrations: salmon as a model approach. In Behaviour and physiology of fish. Edited by A.P. Farrell and, C.J. Brauner. Fish physiology Vol 24.

Hontela, A., C. Daniel, and J.B. Rasmussen. 1997. Structrual and functional impairment of the hypothalamo-pituitary-interrenal axis in fish exposed to bleached kraft mill effluenct in the St. Maurice River, Quebec. Ecotoxicology 6: 1-12. 
Hopkins, T.E., C.M. Wood, and P.J. Walsh. 1995. Interactions of cortisol and nitrogen metabolism in the ureogenic toadfish Opsanus beta. The Journal of Experimental Biology 198: 2229-2235.

Hruska, K.A., S.G. Hinch, M.C. Healey, D.A. Patterson, S. Larsson, and A.P. Farrell. 2010. Influences of sex and activity level on physiological changes in individual adult sockeye salmon during rapid senescence. Physiological and Biochemical Zoology. 83: 663-676.

Hruska, K.A., S.G. Hinch, M.C. Healey, and A.P. Farrell. 2007. Electromyogram telemetry, non-destructive physiological biopsy, and genetic markers: Linking recent techniques with behavioural observations for the study of reproductive susses in sockeye salmon mating systems. American Fisheries Society Symposium 54: 17-29.

Janz, D.M., M.E. McMaster, K.R. Munkittrick, and G. Van Der Kraak. 1997. Elevated ovarian follicular apoptosis and heat shock protein-70 expression in white sucker exposed to bleached kraft pulp mill effluent. Toxicology and Applied Pharmacology 147: 391-398.

Jardine, J.J., G.J. Van Der Kraak, and K.R. Munkittrick. 1996. Capture and confinement stress in white sucker exposed to kraft pulp mill effluent. Ecotoxicology and Environmental Safety 33: 287-298.

Lepak, J.M. and C.E. Kraft. 2008. Alewife mortality, condition, and immune response to prolonged cold temperatures. Journal of Great Lakes Research 34: 134-142. 
Litwack, G. 1955. Photometric determination of lysozyme activity. Proceedings of the Society of Experimental Biological Medicine. 89: 401-403.

Mallat, J. 1985. Fish gill structural changes induced by toxicants and other irritants: a statistical review. Canadian Journal of Fisheries and Aquatic Sciences 42: 630648.

Maule, A.G., R. Schrock, C. Slater, M.S. Fitzpatrick, and C.B. Schreck. 1996. Immune and endocrine responses of adult Chinook salmon during freshwater immigration and sexual maturation. Fish and Shellfish Immunology 6: 221-233.

Maule, A.G. and C.B. Schreck. 1991. Stress and cortisol treatment changed affinity and number of glucocorticoids receptors in leukocytes and gill of coho salmon. General and Comparative Endocrinology 84: 83-93.

Maule, A.G., C.B. Schreck, C.S. Bradford, and B.A. Barton. 1988. Physiological effects of collecting and transporting emigrating juvenile Chinook salmon past dams on the Columbia River. Transactions of the American Fisheries Society 117: 245-261.

McBride, J.R., U.H.M. Fagerlund, H.M. Dye, and J. Bagshaw. 1986. Changes in structure of tissues and in plasma cortisol during the spawning migration of pick salmon, Oncorhynchus gorbuscha (Walbaum). Journal of Fish Biology 29: 153-166.

McBride, J.R. and A.P van Overbeeke. 1969. Hypertrophy of the interrenal tissue in sexually maturinf sockeye salmon (Oncorhynchus nerka) and the effect of gonadectomy. Journal of the Fisheries Research Board of Canada 26: 2975-2985. 
McEwen, B.S. and J.C. Wingfield. 2003. The concept of allostasis in biology and biomedicine. Hormones and Behaviour 43: 2-15.

McMaster, M., K. Munkittrick and G. Van Der Kraak. 1992. Protocol for measuring circulating levels of gonadal sex steroids in fish. Canadian Technical Report of Fisheries and Aquatic Sciences. 1836.

Mehranvar, L, M. Healey, A. Farrell and S. Hinch. 2004. Social versus genetic measures of reproductive success in sockeye salmon, Oncorhynchus nerka. Evolutionary Ecology Research 6: 1167-1181.

Milla, S., N. Wang, S.N.M. Mandiki, and P. Kestemont. 2009. Corticosteroids: Friends or foes of teleost fish reproduction? Comparative Biochemistry and Physiology 153: 242-251.

Miller, K.M., and A.D. Schulz, N. Ginther, S. Li, D.A. Patterson, A.P. Farrell, and S.G. Hinch. 2009. Salmon spawning migration: metabolic shifts and environmental triggers. Comparative Biochemistry and Physiology - Part D: Genomics and Proteomics 4: 75-89.

Milligan, C.L. 2003. A regulatory role for cortisol in muscle glycogen metabolism in rainbow trout Oncorhynchus mykiss Walbaum. The Journal of Experimental Biology 206: 3167-3173.

Mishra, A. And K.P. Joy. 2006. Effects of gonadotropin in vivoand 2-hydroxyoestradiol17 beta in vitro on follicular steroid hormone profile associated with oocyte 
maturation in the catfish Heteropneustes fossilis. Journal of Endocrinology 189: $341-252$.

Mommsen, T.P., M.M. Vijayan, and T.W. Moon. 1999. Cortisol in teleosts: dynamics, mechanisms of action, and metabolic regulation. Reviews in Fish Biology and Fisheries 9: 211-268.

Morbey, Y.E., C.E. Brassil, and A.P. Hendry. 2005. Rapid senescence in Pacific salmon. The American Naturalist 166: 556-568.

Morgan, J.D. and G.K. Iwama. 1996. Cortisol-induced changes in oxygen consumption and ionic regulation in coastal cutthroat trout (Oncorhynchus clarki clarki) parr. Fish Physiology and Biochemistry 15: 385-394.

Müller, C., B. Almasi, A. Roulin, C.W. Breuner, S. Jenni-Eiermann, and L. Jenni. 2009. Effects of Corticosterone pellets on baseline and stress-induced Corticosterone and corticosteroid-binding-globulin. General and Comparative Endocrinology 160: 5966.

Muona, M. and A. Soivio. 1992. Changes in plasma lysozyme and blood leucocyte levels of hatchery-reared Atlantic salmon (Salmo salar L.) and sea trout (Salmo trutta L.) during parr-smolt transformation. Aquaculture 106: 75-87.

Murchie, K.P.E., C.E. Pullen, T.D. Redpath, H.R. Stephens, and S.J. Cooke. 2008. Fish response to modified flow regimes in regulated rivers: research methods, effects and opportunities. River Research and Applications 24: 197-217. 
Negro-Vilar, A. 1993. Stress and other environmental factors affecting fertility in men and women: overview. Environmental Health Perspectives 101: 59-64.

Norris, D.R. and P.P Marra. 2007. Seasonal interactions, habitat quality, and population dynamics in migratory birds. The Condor 109: 535-547.

Norris, D.R. 2005. Carry-over effects and habitat quality in migratory populations. Oikos 109: $178-186$.

Norris, D.R., P.P. Marra, T.K. Kyser, T.W. Sherry, and L.M. Ratcliffe. 2004. Tropical winter habitat limits reproductive success on the temperate breeding grounds in a migratory bird. Proceedings of the Royal Society B: Biological Sciences 271: 171179.

O’Connor, C.M., K.M. Gilmour, R. Arlinghaus, S. Matsumura, C.D. Suski, D.P. Philipp and S.J. Cooke. In Review. Short-term cortisol elevation in the wild affects individual and population growth rate in largemouth bass (Micropterus salmoides). Canadian Journal of Fisheries and Aquatic Sciences. 00: 000-000.

O'Connor, C.M., K.M. Gilmour, R. Arlinghaus, D.P. Philipp, C.T. Hasler, and S.J. Cooke. In Press. Physiological and Biochemical Zoology 00: 000-000.

O'Connor, C., K.M. Gilmour, R. Arlinghaus, G. Van Der Kraak, and S.J. Cooke. 2009. Stress and parental care in a wild teleost fish: Insights from exogenous supraphysiological cortisol implants. Physiological and Biochemical Zoology 82: 709-719. 
O'Reilly, K.M. and J.C. Wingfield. 2003. Seasonal, age, and sex differences in weight, fat reserves, and plasma Corticosterone in western sandpipers. The Condor 105: 1326.

Parenskiy, V.A. and A.V. Podlesnykh. 1995. Sperm quality in sockeye males in connection with their morpho-physiological characteristics. Russian Journal of Marine Biology 15: 345-357.

Pfeiffer W. 1962. The fright reaction of fish. Biological Reviews 37: 495-511.

Pickering, A.D. and T.G. Pottinger. 1995. Biochemical effects of stress. In Environmental and Ecological Biochemistry (P.W. Hochachka and T.P Mommsen eds) pp. 349-379. Elsevier, Amsterdam.

Pickering, A.D. 1990. Stress and the suppression of somatic growth in teleost fish. In Progress in Comparative Endocrinology (A. Epple, C.G. Scanes and M.H. Steton eds) pp. 473-479. Wiley-Liss, New York.

Pickering, A.D. and T.G. Pottinger. 1989. Stress responses and disease resistance in salmonids fish: effects of chronic elevation of plasma cortisol. Fish Physiology and Biochemistry 7: 253-258.

Pickering, A.D., T.G. Pottinger, J. Carragher, and J.P. Sumpter. 1987. The effects of acute and chronic stress on the levels of reproductive hormones in the plasma of the mature brown trout, Salmo trutta L. General and Comparative Endocrinology 68: 249-259. 
Pickering, A.D., T.G. Pottinger, and P.J. Christie. 1982. Recovery of the brown trout Salmo trutta L. from acute handling stress: a time course study. Journal of Fish Biology 20: 229-244.

Quinn, T.P., D.M. Eggers, J.H. Clark, and H.B. Rich. 2007. Density, climate, and the processes of prespaning mortality and egg retention in Pacific salmon (Oncorhynchus spp.). Canadian Journal of Fisheries and Aquatic Sciences 64: 574582.

Quinn, T.P. 1999. Variation in Pacific salmon reproductive behaviour associated with species, sex and levels of competition. Behaviour 136: 179-204.

Quinn, T.P. and C.J. Foote. 1994. The effects of body size and sexual dimorphism on the reproductive behaviour of sockeye salmon, Oncorhynchus nerka. Animal Behaviour 48: 751-761.

Reid, S.G., N.J. Bernier, and S.F. Perry. 1998. The adrenergic stress response in fish: control of catecholamine storage and release. Comparative Biochemistry and Physiology Part C: Pharmacology, Toxicology and Endocrinology 120: 1-27.

Rice, J.A. 1990. Bioenergetics modelling approaches to evaluation of stress in fish. American Fisheries Society Symposia 8: 80-92.

Robertson, O.H. and B.C. Wexler. 1962. Histological changes in the pituitary gland of the Pacific salmon (genus Oncorhynchus) accompanying sexual maturation and spawning. Journal of Morphology 110: 171-185. 
Robertson, O.H. and B.C. Wexler. 1960. Histological changes in the organs and tissues of migratory and spawning Pacific salmon (genus Oncorhynchus). Endocrinology 66: 222-239.

Robertson, O.H. and B.C. Wexler. 1959. Hyperplasia of the adrenal cortical tissue in Pacific salmon (genus Oncorhynchus) and rainbow trout (Salmo gairnerii) accompanying sexual maturation and spawning. Endocrinology 65: 225-238.

Robertson, O.H. and B.C. Wexler. 1957. Pituitary degeneration and adrenal tissue hyperplasia in spawning Pacific salmon. Science 125: 1295-1296.

Rodela, T.M., M.D. McDonald, P.J. Walsh, and K.M Gilmour. 2009. The regulatory role of glucocorticoid and mineralocorticoid receptors in pulsatile urea excretion of the gulf toadfish, Opsanus beta. The Journal of Experimental Biology 212: 1849-1858.

Romero, L.M., M.J. Dickens, and N.E. Cyr. 2009. The reactive scope model - A new model integrating homeostasis, allostasis and stress. Hormones and Behaviour 55: 375-389.

Sapolsky, R.M., L.M. Romero, and A.U. Munck. 2000. How do glucocorticosteroids influence stress responses? Integrating permissive, suppressive, stimulatory and preparative actions. Endocrine Reviews 21: 55-89.

Schreck, C.B. 2010. Stress and fish reproduction: the roles of allostasis and hormesis. General and Comparative Endocrinology 165: 549-556. 
Schreck, C.B., W. Contreras-Sanchez, M.S. Fitzpatrick. 2001. Effects of stress on fish reproduction, gamete quality, and progeny. Aquaculture 197: 3-24.

Silverin, B. 1986. Corticosterone-binding proteins and behavioural effects of high plasma levels of Corticosterone during the breeding period. General and Comparative Endocrinology 64: 67-74.

Silverin, B. The stress response and autumn dispersal behaviour in willow tits. 1997. Animal Behaviour 10: 451-459.

Soldatov, A.A. 1996. The effect of hypoxia on red blood cells of flounder: a morphologic and autoradiographic study. Journal of Fish Biology 48: 321-328.

Sorensen, M.C., J.M Hipfner, T.K. Kyser, and D.R. Norris. 2008. Carry-over effects in a Pacific seabird: stable isotope evidence that pre-breeding diet quality influences reproductive success. Journal of Animal Ecology 78: 460-467.

Stauffer, J.C., R.M. Goldstein, and R.M. Newman. 2000. Relationship of wooded riparian zone and runoff potential to fish community composition in agricultural streams. Canadian Journal of Fisheries and Aquatic Science 57: 207-316.

Stein-Behrens, B.A. and R.M. Sapolsky. 1992. Stress, glucocorticoids, and aging. Aging Clinical and Experimental Research 4: 197-210.

Tierney, K.B., D.A. Patterson, and C.J. Kennedy. 2009. The influence of maternal condition on offspring performance in sockeye salmon Oncorhynchus nerka. Journal of Fish Biology 75: 1244-1257. 
Todgham, A.E., P.M Schulte, and G.K. Iwama. 2005. Cross-tolerance in the tidepool sculpin: the role of heat shock proteins. Physiological and Biochemical Zoology 78 : 133-144.

Van Der Kraak, G., K.R. Munkittrick, M.E. McMaster and, D.L. MacLatchy. 1998. A comparison of bleached kraft mill effluent 17 beta-estradiol, and beta-sitisterol effects on reproductive function in fish. In Principles and Processes for Evaluation Endocrine Disruption in Wildlife (R.J. Kendall, D.L. Dickerson, J.P. Giesy, and W.P. Suk eds) pp. 249-265, SETAC Press, Florida.

Van Overbeeke, A.P. and J.R. McBride. 1971. Histological effects of 11ketotestosterone, 17-methyltestosterone, estradiol, estradiol cypionate, and cortisol on the interrenal tissue, thyroid gland, and pituitary gland of gonadectomised sockeye salmon (Oncorhynchus nerka). Journal of the Fisheries Research Board of Canada 28: $477-484$.

Vijayan, M.M., G. Feist, D.M.E. Otto, C.B. Schreck, and T.W. Moon. 1997. 3,3', 4,4'tetrachlorobiphenyl affects cortisol dynamics and hepatic function in rainbow trout. Aquatic Toxicology 37: 87-98.

Vijayan, M.M., J.S. Ballantyne, and J.F. Leatherland. 1991. Cortisol-induced changes in aspects of the intermediary metabolism of Salvelinus fontinalis. General and Comparative Endocrinology 82: 476-486.

Wagner, G.N., S.G. Hinch, L.J. Kuchel, A. Lotto, S.R.M. Jones, D.A. Patterson, J.S. Macdonald, G. Van Der Kraak, M. Shrimpton, K.K. English, S. Larsson, S.J. 
Cooke, M.C. Healey, and A.P. Farrell. 2005. Metabolic rates and swimming performance of adult Fraser River sockeye salmon (Oncorhynchus nerka) after a controlled infection with Parvicapsula minibicornis. Canadian Journal of Fisheries and Aquatic Sciences 62: 2124-2133.

Wang, W.B., A.H. Li, T.Z. Cai, and J.G. Wang. 2005. Effects of intraperitoneal injection of cortisol on non-specific immune functions of Ctenopharyngodon idella. Journal of Fish Biology 67:779-793.

Wang, L., J. Lyons, P. Kanehl, R. Bannerman, and E. Emmons. 2000. Watershed urbanization and changes in fish communities in southeastern Wisconsin streams. Journal of the American Water Resources Association 36: 1173-1189.

Webster, M.S., P.P. Marra, S.M. Haig, S. Bensch, and R.T. Holmes. 2002. Links between worlds: unravelling migratory connectivity. Trends in Ecology and Evolution 17: 76-83.

Wendelaar Bonga, S.E. 1997. The stress response in fish. Physiological Reviews 77: 591625 .

Wilson, J.M., M.M. Vijayan, C.J. Kennedy, G.K. Iwama, and T.W. Moon. 1998. Bnaphthoflavone abolishes the interrenal sensitivity to ACTH stimulation in rainbow trout. Journal of Endocrinology 157: 63-70.

Wingfield, J.C. 2005. The concept of allostasis: coping with a capricious environment. Journal of Mammalogy 86: 248-254. 
Wingfield, J.C. 2003. Control of behavioural strategies for capricious environments. Animal Behaviour 66: 807-816.

Wingfield, J.C. and R.M. Sapolsky. 2003. Reproduction and resistance to stress: when and how. Journal of Neuroendocrinology 15: 711-724.

Wingfield, J.C., D.L. Maney, C.W. Breuner, J.D. Jacobs, S. Lynn, M. Ramenofsky, and R.D. Richardson. 1998. Ecological bases of hormone-behaviour interaction: the emergency life history stage. American Zoologist 38: 191-206.

Wingfield, J.C. 1988. Changes in reproductive function of free-living birds in direct response to environmental perturbations. In Processing of environmental information in vertebrates (M.H. Stetson $E d$ ) pp. 121-148. Springer-Verlag, Berlin. 